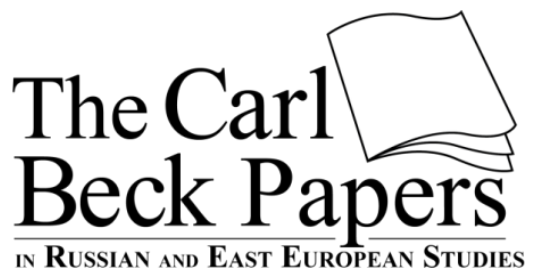

Number 2502
David J. Meadows

The Effects of ReligiousCultural Worldviews on the Lack of PoliticalEconomic Liberalization in Belarus over Twenty Years since rise of Lukashenko

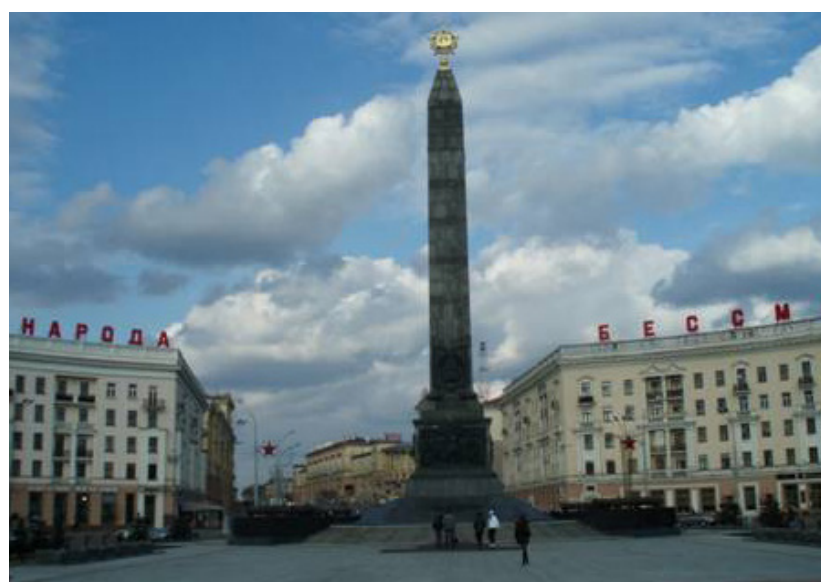




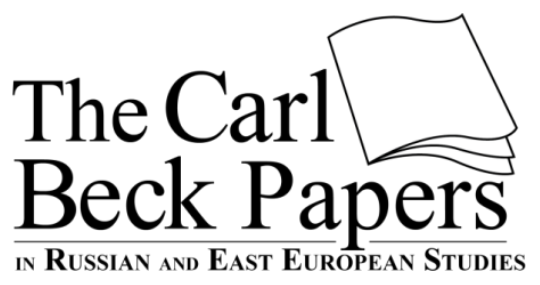

Number 2502

ISSN: 2163-839X (online)

David J. Meadows, PhD, Centre For Foreign Policy Studies, Dalhousie The Effects of Religious-Cultural Worldviews on the
Lack of Political-Economic Liberalization in Belarus
over Twenty Years since rise of Lukashenko

\section{(cc) $\mathrm{BY}-\mathrm{NC}-\mathrm{ND}$}

This work is licensed under a Creative Commons Attribution-Noncommercial-No Derivative Works 3.0 United States License.
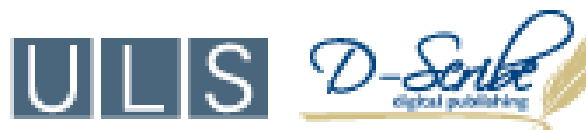

This site is published by the University Library System of the University of Pittsburgh as part of its D-Scribe Digital Publishing Program, and is cosponsored by the University of Pittsburgh Press. 
David J. Meadows holds a PhD in Political Science from Dalhousie University (Halifax, NS, Canada), specializing in International Relations and Comparative Politics, with expertise in the politics of Eastern Europe, Russia and Eurasia.

Photograph: courtesy of David J. Meadows.

No. 2502, May 2017

2017 by The Center for Russian and East European Studies, a program of the University Center for International Studies, University of Pittsburgh

ISSN 2163-839X (online)

\section{The Carl Beck Papers}

Publisher: University Library System, University of Pittsburgh

Editors: William Chase, Bob Donnorummo

Managing Editor: Zsuzsánna Magdó

Editor Emeritus: Ronald H. Linden

For 34 years, The Carl Beck Papers in Russian and East European Studies, named after the first director of the University Center for International Studies, published hundreds of monographlength articles presenting innovative research by scholars focused on East Europe, the USSR and the Soviet successor states. At the end of 2015, the Carl Beck Papers ceased accepting new submissions. However, the entire digital collection of The Carl Beck Papers is now available free of charge, thus providing scholars from around the world with access to a large repository of high-quality, peer reviewed research on a broad range of topics related to the region. The fully searchable archive is available at: carlbeckpapers.pitt.edu/ojs/index.php/cbp/issue/archive. 
This paper focuses on the effects of political-culture in shaping the lack of political-economic liberalization in Belarus since 1991. Specifically, this paper will elucidate the intricate interplay between historically rooted cultural worldviews, ways of life and historical memories, to explain how the historical roots of Orthodox Christianity had a central influence on the patterns of political-economic development chosen by Belarus, even long after these religious-cultural values had been secularized and taken for granted. In doing so, this paper will help understand why Belarus chose to pursue such an illiberal and authoritarian orientation, and help explain the longevity of President Lukashenko. 


\title{
The Effects of Religious-Cultural Worldviews on the Lack of Political-Economic Liberalization in Belarus over Twenty Years since rise of Lukashenko
}

\begin{abstract}
This paper focuses on the effects of political-culture in shaping the lack of political-economic liberalization in Belarus since 1991. Specifically, this paper will elucidate the intricate interplay between historically rooted cultural worldviews, ways of life and historical memories, to explain how the historical roots of Orthodox Christianity had a central influence on the patterns of political-economic development chosen by Belarus, even long after these religious-cultural values had been secularized and taken for granted. In doing so, this paper will help understand why Belarus chose to pursue such an illiberal and authoritarian orientation, and help explain the longevity of President Lukashenko.
\end{abstract}

\section{Introduction}

Following the breakup of the Soviet Union, many predicted that the post-Soviet states would transition into liberal-capitalist economies. ${ }^{1}$ Over twenty years later, however, the "triumph" of liberalism has proved illusory, and these forecasts have been confounded by the fact that only a minority of the post-Communist states have transformed into liberal-capitalist economies. This wide divergence from the triumph of liberalism thesis has been particularly apparent in Belarus, where there has been an almost complete lack of reform since 1991.

In terms of policy, Belarus has followed a consistent pattern of political-economic behavior, which could be described as being anti-liberal, anti-reform, and pro-Russian in orientation, where the state controls almost all the economy. In terms of monetary policy, the central bank has been repeatedly subject to intense political interference, where authorities placed less emphasis on anti-inflationary monetarist policies. A liberalized commercial banking sector is also non-existent, as banks are largely owned and controlled by the state. Structural reforms have also been absent, seen with the continued state control over agricultural land and real-estate, and the lack of privatization of small, medium and large enterprises. Additionally, markets and competition are not prioritized, and the state continues to play a strong role, via extensive regulations, price controls, subsidization of industry, high taxes, and arbitrary decisions that flout the rule of law. Finally, at the international level, Belarus has taken an anti-liberal approach, and continues to uphold significant barriers to trade and foreign investment. As a result, there has been little transformation from a state controlled economy in Belarus, and political-economic practices under President Alexander Lukashenko have remained stuck in Soviet-era statist methods, which are illiberal, authoritarian, arbitrary, and lack respect for the rule of law.

The objective of this paper is to understand the factors for why Belarus chose to pursue such an illiberal, statist, and authoritarian political-economic orientation. In doing so, this paper will utilize political-cultural theoretical frameworks to explain why Belarus diverged so far from the predictions in the triumph of liberalism thesis. Specifically, it is argued that the illiberal political-economic practices found in Belarus are attributable to the historically rooted political-cultural worldviews that are found in Belarus, which favour collectivism, communal property, statist solutions, paternalism, and authoritarian leadership. To understand the causal characteristics played by political-cultural worldviews it is important to trace their historical origins. Specifically, it is argued that the critical historical juncture that was definitive in the evolution of Belarusian political-culture was Belarus's original conversion into Orthodox Christianity, the foundations of which were crucial in informing and setting Belarus's political-cultural worldviews and ways of life down a unique evolutionary path.

This paper is organized into four parts. Part one will describe the theoretical foundations informing the conceptualization of political-culture used in the main hypotheses. This part also provides a description of the 
four qualitative methods that form the core methodologies of this paper. Part two traces the historical roots of Belarus's political-culture to the contemporary period. Part three compares contemporary political-culture and public opinion after 1991 to highlight how such worldviews have influenced policy in the present era. Finally, part four shows the inadequacies that exist with National Identity theories in explaining Belarus's post-Soviet political-economic behavior. This will be followed by a brief section offering conclusions.

\section{Political-Culture: Worldviews, Ways of Life and Historical Memories}

The political-cultural theoretical arguments presented here are rooted in the rich body of cultural theory found within Social Constructivism. These conceptions of political-culture follow and build on the work pioneered by Max Weber, who saw culture as a key determinant of political, social and economic action, and crucial in explaining political authority and legitimacy. ${ }^{2}$ Such views of culture also follow other pioneering studies that focused on cultural habits and the taken for granted ideas of everyday life affecting social behavior, including Berger and Luckmann's "social stock of knowledge" and "symbolic universe," Geertz's "web of meaning," Bourdieu's "habitus," Wittgenstein's "form of life," Putnam's "civic community," and Hopf's "logic of habit." 3 In doing so, this paper emphasizes the importance of historic contextual legacies in shaping political-cultural worldviews, ways of life, and historical memories, and distinguishing them from other cultural contexts. Such a view agrees with the statement that "culture is a worldview offering a shared account of action and its meaning and provid[es] people with social and political identities; [and] is manifested in a way of life transmitted...overtime, and embodied in a community's institutions, values, and behavioral regularities." 4 This takes a 'strong' view of culture, seeing cultures as distinctive, autonomous, slow to change, and stable to that of institutional and material conditions. ${ }^{5}$

Such cultural theories take a divergent outlook from rationalists, and view it as not enough to categorize what is rational or irrational when explaining political behavior. In this view, "what is rational depends on the social setting within which the act is embedded," and "acts that are rational from the perspective of one way of life may be the height of irrationality from the perspective of a competing way of life." 6 This contrasts with rationalist assumptions that view ideas as reducible to individual actor's rational utilitarian calculations.

It is also the position here that political-cultural worldviews do not predominate as a result of material power structures. Thus, it is much more than a Gramscian or Coxian version of simply a predominant hegemonic discourse or prevailing class structure sustaining an elite group's ideological hegemony over alternative ideologies. ${ }^{7}$ While not arguing that culture is homogeneous, nor denying that alternative cultural outlooks exist, it is the position here that such cultural worldviews that are most predominant can be seen as much more organically and historically rooted within the context where these are found, and are shared amongst both elites and society, and not simply predicated on materialist power structures.

Theoretical arguments following such premises view political-culture as important in shaping what sociological institutionalists refer to as the intangible institutions of society. This involves the influence of political-cultural worldviews, which includes the "practices, symbols, norms, grammars, models, and identities through which people interpret their world." "In addition, political-culture also involves ways of life, which includes the "taken-for-granted scripts, rules and classifications... which institutions are made." In this view, worldviews, and ways of life are largely taken for granted within the societal context these are situated. Politicalculture can thus be seen as highly influential in legitimating and ruling out certain types of behavior. As Bourdieu notes, other ideas and behavior remain "unthinkable." 10 Furthermore, there is a normative aspect influencing political action, as members of a particular culture will "do certain things not because they work, but because they are right - right...in terms of the ultimate definitions of reality" of what is normal, legitimate, and natural. ${ }^{11}$ Thus, political-culture can be seen as the taken for granted worldviews that shape the intangible institutions of society, and act to limit certain behaviors, shape preferences, narrow policy options, and enforce continuity. 
Many works, including Hopf's seminal study of identity and culture, placed particular emphasis on habits, which includes significant focus on "the routine, repetitive, habitual, customary, and everyday,",12 to understand the factors that give people meaning in the world and affect their behavior and decisions. However, in this focus on habits and practice (herein referred to as ways of life), ${ }^{13}$ less emphasis is placed on the normative (worldviews) aspects of culture. While ways of life are crucially important in any understanding of culture, it is also important to examine the two other intricately related components of political-culture, including worldviews and historical memories. A major contribution of this paper builds on such cultural frameworks, by showing that the three core components of political-culture (worldviews, way of life, and historical memories) all work intricately together to project political-culture as a key determinant of political action.

In this formulation (see Figure 1), the first core component of political-culture includes worldviews (norms, rules, values and beliefs), which influence ideas about proper modes of living, social organization and ways of life (habits, practices, traditions and customs), and inform the normative views regarding how politicaleconomic relations 'should' and 'ought' to be managed. Therefore, worldviews influence what is seen as the 'right,' 'best,' 'natural' and 'normal' policy practices and behaviors. In a general sense, worldviews result in certain policy prescriptions being viewed as 'right' and 'best' in terms of being the most effective means to organize the political-economic affairs of society, and thus most 'rational' to promote economic growth and development. Additionally, such worldviews regarding appropriate policy behavior are taken for granted and legitimized in that these are seen as 'normal' and 'natural,' which contributes to alternative ideas being either normatively ruled-out or becoming 'un-thinkable.'

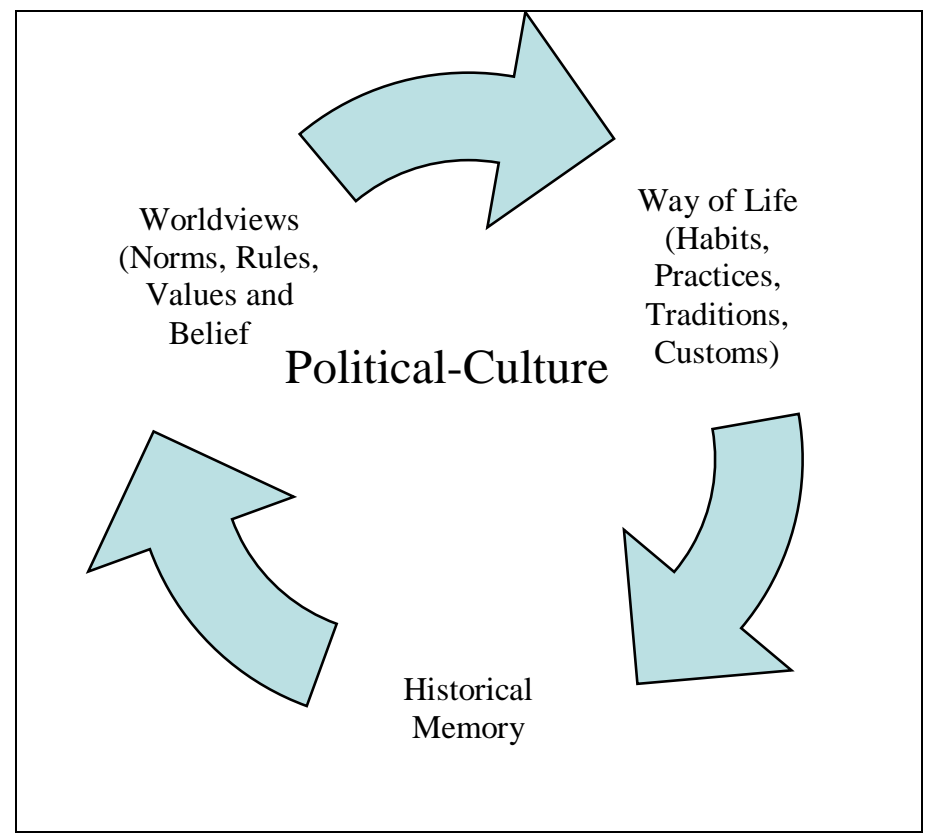

\section{Figure 1: Three Core Components of Political- Culture}

The second interrelated core component of political-culture includes ways of life, which are the predominant habits, practices, traditions and customs in regards to the conduct of political-economic relations (e.g. how property relations are historically managed). As Figure 1 illustrates, ways of life are not only influenced by worldviews, but also work to shape worldviews, via historical memories, in the sense that long-term historical ways of life can harden into worldviews. This builds on Berger and Luckmann's idea of habitualization, where "any action that is repeated frequently becomes cast into a pattern," a taken for granted worldview of the proper patterned action that is viewed to work best. ${ }^{14}$

The hardening of ways of life into worldviews via the third political-cultural component of historical memory, reinforces and sustains the continuity of those ways of life. Here, the hardening of worldviews occurs via the persistence and continuity of historical ways of life, where historical memories of the longevity of such patterns of behavior serves to harden into worldviews legitimating such behavior, which become viewed as the 'best,' 'right,' 'normal' and 'natural' modes to organize political-economic relations. ${ }^{15}$ Indeed, if such policy behaviors appear to continue to work, this will serve to keep on reinforcing the predominance of worldviews that regard such policies as the most effective and correct way to organize society. 
While all three components make political-culture slow to change, historical memory is important because it helps to reinforce the longevity of existing worldviews and ways of life. ${ }^{16}$ Furthermore, historical memory also signifies the historical and evolutionary aspect that political-culture is constantly in motion, and has the ability to potentially change and evolve over the long-term, as a result of new memories developing following future events. Nevertheless, the expectation is that political-culture is slow to change, which results from critical historical junctures, where specific influences result in path dependence and self-reinforcing tendencies. Therefore, the arguments here emphasize the historical roots of political-culture, where old ingrained worldviews and ways of life, in regards to the organization of political-economic relations, are slow to change and persistent over time. As a result of the self-reinforcing tendencies of political-culture, the predominant worldviews informing the preferences and habits regarding appropriate forms of political-economic organization, are also largely taken for granted by most of society, and thus viewed as 'normal' and 'natural.' In this conception, worldviews are seen as "beliefs that are held as articles of faith and thus resistant to change." 17 In Belarus, such taken for granted worldviews include the political-cultural emphasis placed upon collective social-welfare.

The conception here, takes the view that political-cultural worldviews and ways of life are intricately interwoven, shaped and defined by the religious context within which they are historically situated, even long after these religious values and norms have been secularized and taken for granted. As Braudel notes, "religion is the strongest feature of civilizations [cultures], at the heart of both present and their past... [and] all civilizations [cultures] are pervaded or submerged by religion." 18

A key aspect making religion a prime influence over culture involves the conceptions of natural law that are derived from and rooted in religious beliefs. Such conceptions of natural law as espoused in political-cultural worldviews, help to define what is perceived as the 'best,' 'right,' 'natural' and 'normal' modes of political behavior and organization. ${ }^{19}$ Specifically, it will be demonstrated that Orthodox Christianity in Belarus offered specific conceptions of natural law, which promoted collective, communal, statist and authoritarian notions of natural rights, which were crucial in defining what was deemed as 'right', 'best,' 'natural,' and 'normal,' in the political-cultural worldviews of Belarusians, even long after much of these religious values had been secularized and taken for granted, and that these worldviews played a central role in influencing patterns of political-economic development historically in Belarus to the contemporary period. ${ }^{20}$ In addition to affecting domestic policy, it will also be demonstrated that the historic religious-cultural context found in Belarus also had important implications for international relations, in that with Belarus being situated predominantly in the cultural sphere of Orthodox Christianity, Belarus was more naturally prone in its worldviews to gravitate towards closer relations with Russia, and away from Western Europe.

\section{Methods}

This study used several qualitative research methods in combination, to trace the historical roots of Belarus's political-culture, and highlight how such worldviews, ways of life and historical memories have influenced public attitudes and policy in the post-Soviet era. The first method included comparative historical analysis, which was essential to understand how Belarus's political-culture was conditioned by its unique historical legacies. Here, it was necessary to find evidence identifying commonalities and dominant themes, and specifically the cultural attributes that "predominate" across numerous historiographic accounts. ${ }^{21}$ The timeline under focus stretched back over a millennium, beginning with Belarusians original conversion to Orthodox Christianity. Here, one needed to uncover the strength and consistency of political-cultural worldviews and ways of life at key stages throughout history. Such a process helped "uncover what was repressed" before 1991, and thus "g[ave] clues [of] what may be predominant" after $1991 .{ }^{22}$ This facilitated understanding into how such worldviews were transmitted during the contemporary period. 
The inspiration for such methods came from two sources. First, there was a necessity to examine longterm historical processes, or what Braudel called the longue durée. ${ }^{23}$ However, in Braudel's longue durée, there was not a tight connection between the vast information given in regards to each cultural civilization. Thus, there was a necessity to provide tight connections to facilitate the tracing of the predominant political-culture in various eras. Here, the second influence came from Hopf's extensive historical detail in tracing Soviet/Russian identities in 1955 and $1999 .{ }^{24}$ However, the problem with Hopf was that there was little sense given for where the cultural identities of 1955 came from. This study builds on these two different styles of studying culture, and makes an important contribution by providing an exhaustive means of historical sampling to adequately trace the historic roots of Belarus's political-culture, by showing continuity in how the predominant worldviews, ways of life and historical memories were present in shaping political-economic behavior in various eras, and subsequently transmitted to the contemporary period to help shape current attitudes and policy preferences after 1991.

A second method examined public opinion surveys conducted since 1991. Extensive polling data was available from the Centre for the Study of Public Policy's New Democracies Barometers, World Values Surveys, and the Independent Institute of Socio-Economic and Political Studies (IISEPS). Such steps were important because polls offer the ability to understand whether these numbers substantiate and adhered to the predominant political-cultural worldviews identified in the comparative historical analysis. Moreover, polls were important to understand preferences when it comes to values towards political-economic issues, democracy, societal norms, governance, reform, historical memory, trust, identity issues, nationalism, and preferred relations with Russia and the West.

A third method for measuring contemporary political-culture examined government policy documents, announcements, speeches, news media reports, quotes from public officials, and secondary political commentary about Belarus since 1991. Analysis was done based on the political-cultural characteristics identified as central during the comparative historical methods, and polling analysis. This was important in gaining contextual understanding into the visions and motivations behind political-economic behavior in Belarus since 1991.

Finally, the methods used open-ended, semi-structured interviews of government officials, and nongovernmental figures, to discuss the challenges of post-Soviet transformation and gain understanding into the visions, motivations, and ideas behind policy. The advantage of using open-ended interviews, "is that subjects [were] able to talk about their identity [political-culture] in their own words, rather than being forced to select from alternatives that they might not feel describe them accurately." 25 The rationale here is that elites do not operate in a vacuum when formulating policy, and are informed and influenced by the political-cultural worldviews, ways of life, and historical memories that are historically predominant in their society. ${ }^{26}$

\section{Historical Roots of Belarusian Political-Culture}

From the outset since 1991, Belarus followed a consistent and clear pattern of political-economic behavior, which could be described as being anti-liberal, anti-reform, and pro-Russian in orientation, where the state controls almost all the economy. This resulted from preferences amongst both elites and society, which did not share a faith in the market, and instead favoured the maintenance of collectivistic and statist control over most realms of political-economic activity. Such preferences were rooted in political-cultural worldviews that are found historically in Belarus, which favour collective/communal interests, lack private property traditions, exhibit higher political passivity, prefer a strong economic role for the state, and have paternalistic tendencies favouring a strong leader.

To understand the roots of such worldviews, it is necessary to trace the origins of Belarus's politicalculture, which place Belarus firmly in the realm of Russian Orthodox Christianity. The religious foundations of Orthodox Christianity were crucial definitive influences informing the content of Belarus's historic political- 
culture. Religiously, the Orthodox Church was hierarchical, and promoted values of collectivism, communalism, passivity, paternalism, absolutism, strong state rule, and authoritarian leadership. Here, Orthodoxy brought what could be called a 'communal spirit' to the Belarusian political-cultural way of life. This 'communal spirit' was "antipathetic to the growth of the individual ethos," and private property because it fostered "the notion that private enrichment was disadvantageous to the community, and...discredible and even sinful." 27 Orthodox teachings were further prohibitive towards private property, not only because "Western ideas of property were alien," but also because these religious doctrines promoted a worldview of natural rights, which held that "the soil was God's, and all who toiled and laboured at it might enjoy use of it." ${ }^{28}$ As a result, worldviews favouring the individual accumulation of property were absent and unthinkable to the Orthodox infused collectivistic and communally oriented political-culture of Belarusians.

Overall, individual private property was not something historically taken for granted, but was instead culturally alien in the worldviews of the vast majority of rural Belarusian peasants. The historical pattern shows the trend in Belarus was towards a predominant tradition of communal/collective control of land, seen with the village commune, as opposed to traditions of individual private farmsteads. ${ }^{29}$ As time progressed, this reinforced not only a strong sense of collectivistic values, habits and historical memories, but also the strong importance of the extended collective family in the village commune, which played a central role in the everyday lives of Belarusian peasants.

The historic worldviews and ways of life influenced by Orthodox Christianity also reinforced patriarchal conceptions of natural law where one must be obedient to the family, the commune, and higher authorities like the Church and Tsar. In regards to socialization, the family was important in spreading these values to future generations, since the extended family operated as a collectivized unit whose collective will was enforced by an authoritarian head. This can be found in descriptions of how "the family was unified under the absolute authority of the head...A totalitarian society in miniature, [that] demand[ed] not only obedience of all members to the head of the group but the devotion of each to the purposes of the whole." ${ }^{30}$ As time passed, such habits resulted in historical memories that reinforced worldviews that viewed collectivistic and passive behavior as the best and right way for society to develop and prosper.

These worldviews favouring collectivistic, communal, paternalistic and authoritarian tendencies came to life in the village commune, which had the primary responsibility of collectively managing, partitioning, and redistributing the land for common usage. In the village commune, Vakar notes that "the striking fact of peasant life was its primary communism. The basic social unit was the village. To each of these an individual inextricably belonged, and could not act or be thought of in his daily existence apart from them...In fact, the mir had absolved individual responsibility." 31 Thus, there was no semblance of rule of law in the political-culture of the village commune, which was headed by a communal elder charged with enacting the village's collective will in an authoritarian manner. In such an environment, any conceptions of legality based on liberal rule of law, were culturally alien. ${ }^{32}$

Absolutist and authoritarian traditions promoted by Orthodoxy were carried upward from the family and village commune, all the way to the autocratic leadership of the Tsars, which further served to restrict liberal notions of individual rights and rule of law. Overall, Orthodox doctrines promoted patriarchal worldviews that viewed the Tsar as a father to the people, whose power was ordained by the grace of God. From such doctrines came worldviews that promoted passivity and favouritism towards absolutist authoritarian rule, often characterized by rule by decrees that flouted rule of law. When combined with the complementary religious teachings promoting the collectivized management of land, such worldviews of the Tsar as being God's representative helped to legitimize the pattern of having strong statist solutions, especially in regards to the state acting as the supreme guardian of the land. As Pipes points out, because land was viewed as "created by God for everyone's use," when "the crown took advantage of this attitude to claim title to all soil...the peasantry found [such actions] quite acceptable and logical since the church taught it to regard the Tsar as God's vicar." 33 
The Effects of Religious-Cultural Worldviews on the Lack of Political-Economic Liberalization in Belarus over Twenty Years since rise of Lukashenko

Working from such legitimating doctrines, Russian Tsars would begin to implement a burgeoning system of an authoritarian state, with controls over the individual that would become even more pervasive under Soviet totalitarianism. This can be seen as an example of political-culture driving politics, as opposed to autocratic institutions causing behaviors. As Vakar observed, "the Russian [Orthodox] habits of obedience have been the cause, not the result, of political autocracy." 34 Such patterns and adherence to values promoting the collective over the individual, and a penchant for favouring authoritarian, paternalist and statist leadership, would be a common feature of Belarusian political-culture during the Tsarist period, through the Soviet era, to the present.

While Belarus did have historical links with the Grand Duchy of Lithuania and Poland, there is generally a lack of positive historical memories towards the Grand Duchy. First, the majority of the political elite of the Grand Duchy were not culturally Belarusian, but those of either Polish-Lithuanian descent, or individuals that had been sufficiently Polonized. ${ }^{35}$ It is evident that Belarusian peasants were also forcefully subjected to attempts at cultural assimilation and religious conversion from the dominant Polish leadership of the Grand Duchy. Although substantial numbers of Belarusians did come under the Uniate Church, ${ }^{36}$ these influences did not have the 'Westernizing' effect that several historians claim. For instance, the Uniate Church in the lands of Belarus, was not so much Belarusian, as it was a Polish institution that was dominated culturally and linguistically by Poles. Moreover, unlike many of the ruling class, the vast majority of Belarusian peasantry did not go willingly into such conversions. ${ }^{37}$

There is evidence that in spite of overt coercion, the majority of Belarusians during this period remained true to their Orthodox faith, and were often openly resistant, resentful, and hostile to attempts of religious conversion and cultural Polonization. For example, it has been pointed out that "the denizens of the countryside and the vast majority of the townsfolk remained Orthodox,... [where] attachment to the faith of their forebears was seen by a majority of Belarusians as a matter of national survival." 38 Similarly, Dovnar-Zapolsky noted that "the pressure of Polonism and Catholicism compelled all Orthodox White Russians [Belarusians] to rally against it... and the peasantry...stubbornly upheld their right to an independent religious and national existence." 39 There was also an explosion of armed peasant resistance during the seventeenth century, which was motivated by Belarusians desire to defend "'the Orthodox faith and native speech," which was significant not only because "faith and the speech determined nationality," but also since "the movement can be described as one of "national emancipation." 40 Such evidence of the retention of the Orthodox faith and local cultural traditions provides evidence of a robust Belarusian culture and national identity at play.

In such a political environment, Belarusians resisting the persistent attempts of Polonization, looked to their religious-cultural brethren in Russian for protection. ${ }^{41}$ Thus, while Belarus did have historical links also to the Grand Duchy of Lithuania and Poland, it was Belarus's strong eastern cultural connections tying Belarusians to Orthodox Christianity, which had long-lasting effects influencing the pattern of Belarusian political-culture.

Under the Grand Duchy of Lithuania and Poland, the majority of Belarusians remained landless peasants, living in serfdom and subservient to Polish landlords, or continuing to live in the important cultural body of the village commune. ${ }^{42}$ Not all of Belarus operated under the village commune, as serfdom was strong in western Belarus. In these areas, there was private ownership both before and after the reforms of the 1860 s. ${ }^{43}$ However, this should not be taken as evidence of the weakness of collective arrangements, or as an example of Belarusians having experience with private landownership, because Belarusian peasants owned virtually no private land. Where there was private land, this was controlled by a small number of ethnic-Polish nobles, which retained their privileges for many years after the lands of Belarus came under Russian control after 1795. Furthermore, serfdom for Belarusian peasants living under Polish landlords was harsh, and increasingly during the late-nineteenth century, Belarusian peasants began to view the Polish landlords as their oppressors. ${ }^{44}$ Here, one can infer a clash of cultures between the ethnic-Polish landlords and the landless Belarusians, whose traditionally collectivistic worldviews would have viewed such patterns as being unjust. 
Since ethnic-Poles continued to own most of the private land that was available in western Belarus after the 1861 reforms, average Belarusians did not have any experience of private land ownership. Additionally, in areas remaining under the village commune, collectivist traditions of land organization were strengthened after the 1861 reforms. There was thus a great deal of political-cultural continuity in the worldviews and ways of life of Belarusians. While there was experience of Belarusian families having hereditary tenure on plots of communal land, such tenure should not be confused with private property ownership. Indeed, Belarusian peasants in all areas tended to live more communally in rural villages, where collective obligations remained an important part of everyday life. ${ }^{45}$ As a result, a view of private property being sacred, was absent and unthinkable to the collectivistic/communally oriented worldviews of Belarusians.

Throughout history there was a persistent pattern of Belarusian acquiescence to authoritarian rule. Thus, there were more positive reactions from Belarusians towards the Russian Revolution, as there was greater support for the Bolsheviks amongst Belarusians. Indeed, evidence suggests that Belarusian peasants were receptive and supportive of Communist ideas during the Bolshevik Revolution. ${ }^{46}$ As Berdyaev argues, "Bolshevism...fitted in with the absence among the [Belarusian] people of the Roman view of property and bourgeois virtues, [and] fitted with [the] collectivism that had its roots in religion,... [thus] proclaim[ing] the necessity of the integral totalitarian outlook..., which corresponded with the habits, experience, and requirements of people in faith and the... principles of life." ${ }^{47}$ In other words, key aspects of Communism jived with the traditional collectivism and paternalism characteristic of the peasants historic political-culture.

The Bolsheviks also outpaced more nationalist political groups, such as the Belarusian Socialist Hramada. What made things difficult for the more nationalist oriented groups, which wanted to remain outside the Bolshevik fold, was that their political visions did not differ significantly from the worldviews towards political-economic management espoused by pro-Bolshevik forces. Indeed, the Belarusian nationalist groups, can be viewed to have been competing with the Bolsheviks, as there was a general lack of liberal values amongst both groups and most tended to be socialist and revolutionary in orientation. This can be seen with one of the Belarusian Socialist Hramada's key goals of nationalizing and collectivizing all private land. These policy goals were often modeled on that of similarly oriented socialist-revolutionary parties in Russia. ${ }^{48}$ Thus, the more nationalist Belarusian political groups were hampered in gaining mass appeal, since many of their policy goals promoted a socialist orientation, which were similarly promoted by the more Russian oriented Belarusian Bolsheviks.

Even in the realm of national autonomy, the ideas and goals of Belarusian Bolsheviks should not be viewed as entirely divergent from that of more Belarusian national political forces, especially when it came to the Bolsheviks goals to form the Belarusian Soviet Socialist Republic (BSSR), which can be viewed as promoting national autonomy and state-building for Belarus, albeit within a federated Soviet Union. Indeed, the Belarusian Socialist Hramada favoured similar goals of local autonomy for Belarus within a new Russian federation, which infers that such political groups were not averse towards close ties with Russia. Thus, Belarusian nationalism received support from the Belarusian Bolsheviks, in addition to the more nationalist groups. ${ }^{49}$ As a result, the fact that Belarusian Bolsheviks were working for such socialist goals in cooperation with Russian Bolsheviks, should not be viewed as a case of Belarus lacking a distinct national identity.

In regards to the Belarusian national opposition to the Bolsheviks, which formed the Belarusian Democratic Republic (BDR), from 1918 to 1920, many of this nascent state's goals could be described as quite revolutionary and socialist in orientation, particularly when it came to nationalizing all property. Indeed, evidence suggests that many of the members of the BDR government actually had strong socialist and revolutionary leanings. However, the BDR also suffered in gaining mass popular appeal due to the fact that its socialistrevolutionary message was in direct competition with the Belarusian Bolsheviks, and since the BDR was increasingly seen to have dubious links with the Central Powers. ${ }^{50}$

Belarus gained its first modern tangible experience with statehood under the BSSR, where state-building and political-economic development built on and reinforced the preexisting collectivist, communal and 
The Effects of Religious-Cultural Worldviews on the Lack of Political-Economic Liberalization in Belarus over Twenty Years since rise of Lukashenko

paternalistic political-culture already historically prevalent amongst Belarusians. During this period, a distinct Belarusian national identity was readily present, which was seen with extensive Belarusianization promoted by Belarusian Soviet authorities. For most Belarusians, which remained overwhelmingly rural, the state-building policies implemented under the BSSR would have been seen in a positive light. Under policies of Belarusianization, ethnic-Belarusians, which made up over $80 \%$ of the population, would become the dominant majority in the Belarusian Communist Party (BCP), and in all major administrative, political-economic, and cultural positions in the BSSR. Many Belarusians from rural backgrounds would for the first time also have real opportunities of educational, and social advancement. Moreover, Belarusianization resulted in great advancements being made in the fields of culture and education, and Belarusian language newspapers were promoted and flourished, largely to the detriment of anything Russian. ${ }^{51}$

Even though Soviet agriculture was far more brutal in its centralizing effect, various continuities existed in the ways of life under the collective farm with that previously experienced under the village commune, where traditions of private property were nonexistent. Moreover, even before the advent of full-scale collectivization, Belarusian peasants had re-communalized many of the private lands that had been initially confiscated from the Polish gentry. Indeed, the traditional body of the rural village began to thrive again in the immediate period after the formation of the Soviet Union. To illustrate, in 1925 and 1926, communes held 55.2\% and $63.5 \%$ of the land respectively, while private landholdings amounted to $22.6 \%$ and $20.7 \%$ respectively. ${ }^{52}$ Thus, progress towards collectivization, on a more voluntary level was impressive, even before the full-scale efforts instituted by Stalin in the 1930s.

Since a large portion of rural Belarus remained under a primitive communist form of land organization found in the village commune, it was not hard to convert these into a broader system of state-owned collective farms, as property was already communalized and people were living collectivity. Indeed, the process of agricultural collectivization moved quite rapidly and experienced little resistance, where state collective farms numbered $38.3 \%$ in $1930,55.1 \%$ by mid-1934, so that by 1937 , collectivization was virtually completed. ${ }^{53}$ Overall, many ideas from Marxism made great headway amongst the predominantly peasant population, because key aspects of Communism jived with the traditional Orthodox inspired collectivist political-cultural worldviews shared by rural peasants. As Vakar suggests "peasants... practiced Communist principles long before Marx made ideals out of them," which meant that "collectivization....was not a revolutionary idea but a very old one...[and] undoubtedly appealed to many poorer peasants... [because] it hustled the[m] back into their age-old communes." 54 Thus, collectivization reinforced a cultural way of life that was historically known and taken for granted by Belarusian peasants.

While there might have been disappointment with some effects of Soviet collectivization, this had little to do with any real aversion to collectivism, and more to do with local resentment that power over everyday decisions regarding things like crop planting, and land redistribution, was taken away from the local village, and had been shifted upwards to central authorities that did not always respect the needs or knowledge of locals. There was also increased mandatory deliveries of produce and labour that collective farm workers had to deliver to the state. Nevertheless, the Bolsheviks succeeded to a greater extent in collectivizing agriculture, with fewer resistance than areas such as Ukraine and the Baltic States, and in gaining support for such policies, which was even the case after 1939 in the newly annexed territories of western Belarus. ${ }^{55}$ The fact that such collective traditions persisted served to reinforce the historically preexisting collectivist and communal political-culture of Belarusians, and also meant there was a continued absence of any historical memories of property ownership.

When examining the interwar period under the BSSR, one cannot ignore the crimes committed under Stalin..$^{56}$ At first glance, one would assume this would have resulted in negative historical memories for all things Soviet. However, even with the many terrors committed under Stalinization, there still exists positive historical memories of this first period of BSSR state-building. Indeed, "Belarusians do not see the Stalin era as a time when 
their culture was suppressed and their national development thwarted." 57 Thus, while large numbers of elites fell victim, either being executed or sent to near certain death in the Soviet Gulags, there exists many contradictions of positive memories during this time, which seem to trump many of these negative aspects.

Even under the centralizing control of Stalin, the Belarusianization of education, culture, and even BSSR leadership positions remained the norm. Thus, while a great many ethnic-Belarusian were purged, these positions were nonetheless filled by many willing ethnic-Belarusians. Often, ethnic-minorities (Russian, Poles and Jews) were purged from administrative positions, and replaced by local Belarusians, thus ironically furthering Belarusianization. As Guthier points out, "such trappings of cultural nationalism as Belorussian language in the schools, administration, and literature continued to receive official support," which was witnessed with the majority of newspapers and books being published in Belarusian in 1939. ${ }^{58}$ Similarly, Vakar points out that "the national framework of the Republic had been wisely left intact,...[under] the younger generation, ideologically conditioned in the Soviet mixer." ${ }^{59}$ Many of this new generation of ethnic-Belarusian recruits filling key BSSR leadership and administrative positions came from rural peasant backgrounds, and brought with them their traditional sense of collectivism, communalism, paternalism, and authoritarianism in their outlooks and worldviews, thus bringing an element of authentic Belarusification. As a result, Belarus's early incorporation into the USSR, served to reinforce the collectivist, communal, patriarchal, statist and authoritarian tendencies historically predominant in Belarusian political-culture.

In contrast to the BSSR, Belarusians shared negative historical memories of experiences suffered by Belarusians living in western Belarus, which was under Polish dominion during the interwar. In regards to religion, most Belarusians remained Russian-Orthodox in their beliefs and faced an increased policy of discrimination from Polish authorities during this time. In the areas next to the Soviet border, the Belarusian Orthodox faithful inhabiting this region were forced into Roman Catholicism. In many other areas, hundreds of Orthodox churches were closed, and others were converted into Roman Catholic places of worship. For those remaining open, these were forcefully subjected to using Polish religious texts, even though the congregations could not speak Polish. Additionally, religious educational instruction was mandated to be only conducted in Polish. Polish authorities further attempted to undercut the authority of Belarusian Orthodox religious figures by arresting or exiling prominent and low ranking members of the clergy. ${ }^{60}$

Under Polish rule, the Belarusian language was discriminated against in public affairs and government services, and restricted from being used in public areas such as courts, post offices, and railway stations. Additionally, Belarusian newspapers were banned and closed, and many of their editors were imprisoned. In regards to education, opportunities for learning the Belarusian language were increasingly restricted. Finally, large numbers of Belarusian political and cultural elites were imprisoned in concentration camps by Polish authorities at Bereza Kartuska. ${ }^{61}$

The policies of cultural imperialism displayed in the concerted attack on the culture of Belarusians living in interwar Poland have been condemned by most scholars on the subject, and described as "an intensive campaign of Polonization that consciously sought the eradication of all Belorussian cultural, religious and educational institutions." 62 Belarusians belonging to the Orthodox faith were also not allowed to own property, and most located in rural areas remained in serf-like conditions. To illustrate, around 50\% of all private farm land in western Belarus was owned by Polish landlords which numbered only $1 \%$ of all landowners, with $90 \%$ of forested land also being owned by Polish landlords. In contrast, most ethnic-Belarusians had access to only a couple of acres, with many being landless and subject to mandatory corvee labour to the state. ${ }^{63}$ Such experiences were crucial for reinforcing Belarusians historical worldviews which favoured collective and communal property relations, and generally took negative views towards private property. Moreover, such understandings of ethnic-Belarusians circumstances under Polish domination helps understand how these Belarusians would be receptive to future Soviet policies of land collectivization. 
The Effects of Religious-Cultural Worldviews on the Lack of Political-Economic Liberalization in Belarus over Twenty Years since rise of Lukashenko

In this environment, where a clash of cultures was present, the majority of ethnic-Belarusians living in Poland were increasingly becoming pro-Communist and pro-Soviet in their politics, which was seen with the biggest Belarusian parties being predominantly Socialist, Communist and pro-Soviet in orientation. Indeed, parties such as the Communist Party of West Belarus had strong links and were directly connected to the BCP. Additionally, many of the BDR's exiled leaders in eastern Poland would increasingly take on a pro-Communist, anti-Polish and a pro-BSSR stance, which owed a great deal to the fact that many had strong socialist backgrounds. In general, a major portion of the whole Belarusian national movement in interwar Poland was totally Communized in their political orientation. Such worldviews formed into an increasingly strong and noticeable national identity, which was seen with most ethnic-Belarusians also beginning to yearn for unification of all culturally Belarusian lands into the BSSR. ${ }^{64}$ In general, the predominant historical memories informing Belarusian worldviews about the interwar, view Polish rule as time oppression. ${ }^{65}$ This helps understand how Belarusians negative historical memories of this period might result in antagonistic outlooks towards the West and Poland, and explain the persistence of strong collectivistic, communal, and pro-Russian orientations in Belarusian worldviews.

Belarusians also have unique historical memories of World War Two. First, Belarusians took a more positive view of the Molotov-Ribbentrop Pact, because this ended Polish dominion over western Belarus, and resulted in the reunification of the historic cultural lands of Belarus into one political entity. As Vakar notes, "it meant the restoration of their own territorial integrity... a full-sized nation at last...[and] people naturally rejoiced at seeing their land and kin reunited, their dignity and freedom...restored." 66 Since the BSSR played a highly visible role in this liberation and reunification, this signals the importance that the BSSR would fill in the worldviews and historical memories informing Belarusian national identity.

While the German invasion in June 1941 was not so much viewed as a liberation, as in the Baltic States, it is apparent that these events were viewed by Belarusians with goodwill, positive indifference and passivity. However, any anti-Soviet sentiment was not even close to the seething hatred found in the Baltic States. Indeed, Belarusians did not take retribution against local Soviets remaining in Belarus, as these figures were often adopted into local communities. Moreover, as Vakar points out, any "'hatred [toward the Soviets] was always motivated by some personal offense and hardly ever by any realization of the evils and moral and physical devastations [of] Communism." "67 Thus, most Belarusian anger was located at the personal level, rather than as a hatred towards the collective/communal aspects of Soviet rule.

There was also a persistence of collective traditions and practices in rural areas, which was especially apparent in parts of Belarus that did not immediately fall under German authority after the Soviet retreat. In these areas where there was a vacuum of authority, the first German's that arrived described how the locals resorted to their historically collectivist traditions, adopting tried and tested solutions that were known to them, which meant dividing the land based on centuries old collectivist principles and control by the village commune. In administering justice, peasants and later Belarusian guerilla's utilized traditions of collectivized justice and communal order historically utilized by the village commune, which although lacking in rule of law, were the patterns of justice that generations of rural villagers were historically accustomed. As Vakar points out, "a medieval pattern of government, the mir, was spontaneously revived, [and] all kinds of communal 'liberation committees'... and [a] pattern of communal order began to shape up." ${ }^{68}$ This is important for showing the importance of collectivist worldviews at play in influencing behavior, because in the absence of Soviet power, rural Belarusians reverted to traditional practices, which were oriented towards collectivistic, communal and patriarchal patterns of behavior.

As German rule progressed, the initial passivity and indifference was replaced by outright hostility towards German authorities, which had unleashed a new wave of horrors. Overall, there was little collaboration with German authorities, relative to that in Latvia and Estonia, and Belarus would become the centre-point of 
anti-German guerilla warfare, where the local population formed the core of pro-Soviet guerilla forces. This proSoviet resistance was largely grass-roots and made up of local Belarusians. The Belarusian guerilla fighters, while being pro-Soviet, also operated with a great deal of operational autonomy in their activities and chain of command throughout most of their existence, thus remaining autonomous from the control of the Red Army and Soviet intelligence. Such a grass-roots nature can be found in accounts showing the Belarusian guerilla's enjoyed wide popularity and support amongst the people. ${ }^{69}$

Strong notions of patriotism came into play, because the guerillas believed they were fighting for their cultural Motherland against a hostile foreign invader. Additionally, there was a popular sentiment amongst Belarusian guerillas that played on the strongly religious Orthodox sentiments shared by Belarusians. Even today, one can find evidence of religious-cultural pride informing the predominant historical memories, in that there was a noticeable "degree of pride for its role as the bulwark of defense of the Slavic peoples and the Orthodox faith against attackers from the West." 70 As a result, Belarusians historical memories about WWII exude a great deal of patriotism, where the Soviet victory not only meant liberation from the German invaders, but also a shared victory for Belarusians and the BSSR with Russians. Indeed, victory in the Great Patriotic War would become a key historical event for the BSSR, the historical memories of which would harden and reinforce pro-Soviet worldviews, thus strengthening the important place of the BSSR in Belarusian identity. ${ }^{71}$

Many leaders of the guerilla forces would become prominent leaders of the BSSR throughout the post1945 period. Today, leaders such as Kyril T. Mazurov and especially Piotr M. Masherov, who ruled Belarus from 1965 to 1980, are viewed as positive figures in the historical memories of Belarusians, particularly in the view that such leaders were selfless, put Belarusian interests first, and were not tainted by corruption. Indeed, such leaders as Mazurov and Masherov were closely connected with rural Belarus, and shared leadership styles imbued with the collectivistic, communal and paternalistic traditions found amongst the majority of rural Belarusians from which the leaders of the BCP and BSSR originated. ${ }^{72}$

Evidence from historical descriptions suggest that a robust national identity was not absent in the leadership styles of these leaders, which while remaining staunchly Soviet, remained steadfast in promoting Belarusian national interests. Leaders such as Masherov would regularly use the Belarusian language when publicly addressing crowds, and would regularly promote the virtues of, and pride in Belarusian culture. One can infer the presence of national identity, in that these leaders exhibited and "adopted tenets of 'national communism." "73 Moreover, Urban points out that even "Belarusians in the West often regarded...Mazurov and Masherov as bearers, under Soviet circumstances, of Belarusian cultural nationalism." 74 Indeed, such evidence points to the presence of a strong national identity within the BSSR.

Overall, Belarusian leaders such as Mazerov and Masherov, which dominated BSSR politics throughout most of the post-1945 era, enjoyed great legitimacy and popularity. In the predominant historical memories shared by Belarusians today, many view such figures as important statesmen, and key in promoting Belarusian culture, national republican interests, and the development and state-building of Belarus. Such positive historical memories can be inferred from the results of polls that asked people to rate their ideal leader from a choice of contemporary and historical figures, where large numbers of respondents (45.2\% in 1996, 32.7\% in 2004, and $23.5 \%$ in 2008) picked Peter Masherov as their ideal choice. ${ }^{75}$

After 1945, Belarus experienced significant industrial development, becoming one of the leading 'industrial engines' of the Soviet economy. State-building and development under the BSSR are generally viewed positively in the worldviews and historical memories of Belarusians, largely because Soviet political-economic practices built on and reinforced the collectivist, communal, paternalistic and authoritarian political-culture already historically prevalent. Thus, even as Belarus experienced intensive modernization, industrialization and urbanization, many of these traditional political-cultural patterns continued in urban industrial settings. As Vakar notes, "Soviet enterprises continue[d] to be run essentially like overgrown households in which members ha[d] the obligation to work."76 Additionally, Vakar noted that in Soviet propaganda "the father figure in the collective 
The Effects of Religious-Cultural Worldviews on the Lack of Political-Economic Liberalization in Belarus over Twenty Years since rise of Lukashenko

or the factory [was] not merely a cultural survival; it [was] also idealized as a Soviet type." 77 Such continuation of traditional cultural leadership styles is logical considering that most working in the rapidly urbanizing and industrializing cities of Belarus after 1950, shared similar collectivist worldviews that were historically predominant in rural Belarus.

The fact that Soviet industrialization and modernization appeared to be working, only served to increase positive historical memories of this period, which helped reinforce the predominantly collectivist worldviews of Belarusians, and largely accounts for why Belarusians were Sovietized in the sense of having a pro-Soviet mentality and strong patriotism towards the BSSR. Indeed, the predominant historical memories shared by many Belarusians view the Soviet era of political-economic governance with nostalgia, and as a time of great advancement and progress. ${ }^{78}$

Moscow also trusted the local Belarusian leadership of the BCP and BSSR, and correctly perceived the stronger pro-Soviet/Russian sentiments of the Belarusian elite and public. As a result, there was less interference by Moscow into the local decision-making and administrative affairs of the BSSR, relative to that found in the Baltic States. Belarusians would also play a dominant role in administering the political-economic apparatus of the BSSR. Moscow's trust of Belarusians was also witnessed with the BSSR being designated as its own administrative district, which had much of its own national economic infrastructure put into place. As Zaprudnik and Urban point out, "within...the Soviet order, the BSSR had been since the mid-sixties, if not earlier, a selfgoverning republic." "T9 This contrasts with other Soviet republics that were divided regionally, or formed parts of larger regional units, such as the Baltic States and Ukraine. Indeed, this is helpful for illustrating how both Belarusian elites and society would have come to see the BSSR as authentically Belarusian and not as a culturally alien entity, since the governance and administrative structures were dominated by Belarusians.

Another sign of this trust was in foreign affairs, where Belarus was the only Soviet republic other than Ukraine to be given a seat in the UN General Assembly. Here, the accounts of Moscow's desire that Belarus be granted a UN seat, actually show significant amounts of Belarusian nationalism at play. As Zaprudnik points out, "Stalin's insistence on the UN seats...seems to have had more to do with placating...Belarusian nationalism," since the decision to grant UN membership for Belarus "certainly flattered the national ego of the Belarusians, who saw some of their national values and prestige rehabilitated." 80

Belarusians were also more willing to voice their support by joining the BCP. This was seen in high levels of membership in the BCP and other Communist bodies, where in 1945 membership in the BCP amounted to 19,787 , rising to 520,283 by 1978 , and close to 700,000 by 1989 , with Belarusians making up $77.2 \%$ of the party. ${ }^{81}$ Belarusians were thus an overwhelming majority when it came to the politics and administration of the BSSR, which stands in contrast to neighbouring Latvia, where ethnic-Latvians were a minority in the LSSR leadership. Evidence of such higher willingness of Belarusians to join the BCP can be found in polls asking respondents whether they or their family members had been members of the Communist party, which showed that Belarusians polled substantially higher in yes responses relative to ethnic-Latvians, and respondents from Central and Eastern Europe. ${ }^{82}$

Belarusian identity was thus 'Soviet' in the sense that the predominant worldviews and historical memories of Belarusians identified most prominently with statehood under the BSSR. Many commentators weighing in on the national identity debate often ignored or were reluctant to give acknowledgement to the positive affirmations that Belarusians held towards the BSSR, or simply played down these positive feelings. However, in doing so most National Identity explanations negate and ignore that the Belarusians positive worldviews toward the BSSR actually held factual weight, since the BSSR enjoyed some semblance of real and equal sovereignty under Soviet rule, which was seen in Belarus having its own relative control over its politicaleconomic decisions, and also symbolically in foreign affairs. Thus, for most Belarusians, the BSSR was not just a mere façade, but was viewed in their historical memories as being real progress, and with high amounts of 
national pride. Indeed, for most Belarusians this was the only tangible memory of real Belarusian statehood and national state-building, which served as a positive historical reference point in their political-cultural worldviews and historical memories. ${ }^{83}$ These positive historical memories, seen with high levels of pride and patriotism towards the BSSR, would play a prominent role reinforcing the collectively oriented political-cultural worldviews of Belarusians, which formed a key component of a robust Belarusian national identity. ${ }^{84}$

In general, there was a lack of anti-Soviet resistance in Belarus throughout the period from 1945 to 1991. Since progress under the BSSR was seen as positive, Belarusians saw little need to resist. Moreover, because the Soviet Union was not viewed as culturally alien, and Soviet political-economic practices adhered to Belarusians historically preexisting collectivistic worldviews, resistance to Soviet authorities was for many Belarusians simply unthinkable. This lack of anti-Soviet resistance, continued during glasnost and perestroika in the 1980s, where Belarusian dissidence was far less pronounced than in the Baltic States. It was not simply that Belarusians were overly Russified and lacked a coherent national identity. ${ }^{85}$ Instead, Belarusians viewed the Soviet system as working, and there was a predominant view held by many that reform was unnecessary. Because the BSSR was not viewed as broken, this meant that the language of reform promoted by glasnost and perestroika were simply out of the question and unthinkable in the worldviews of most Belarusians. Indeed, grass-roots support for largescale change was generally absent. Moreover, many of the economic problems now plaguing the Soviet economy only began to be felt by Belarusians by the late-1980s, and thus coincided with glasnost and perestroika and the subsequent breakup of the Soviet Union. The fact that such a downturn corresponded simultaneously with Gorbachev's reforms, and because Belarusians historical memories contrasted these hard times with the previous economic growth in the BSSR, this resulted in perestroika, glasnost, reform and liberalization more generally, becoming "dirty words for many Belarusians." ${ }^{86}$ One can find evidence of such views from polls, where the largest number of Belarusian respondents, $44.9 \%$ placed primary blame for the breakup of the USSR on Gorbachev and his reform initiatives during perestroika. ${ }^{87}$

During this time, there was also concerns about the environment, relating to the Chernobyl disaster. No doubt, issues such as Chernobyl were important in signifying that a national identity did exist in Belarus, since these events were able to stir up large amounts of sentiment favouring more local autonomy from Moscow. Moreover, the Belarusian Popular Front (BPF) and its leader's, Zyanon Paznyak's promotion of public knowledge of crimes committed by the Soviets authorities under Stalin, such as the massacre of Belarusians at Karapaty were also important in promoting anti-Moscow sentiments, and in signifying the presence of a pre-existing national identity. ${ }^{88}$

Although the BPF certainly had some popular following, it never enjoyed the widespread grass-roots support and mass popular appeal enjoyed by the Popular Fronts in the Baltic States. Thus, while promoting increased preferences favouring more autonomy for Minsk, the revelation of the crimes at Karapaty, and environmental disasters like Chernobyl were unable to discredit the overall policies of Soviet industrial development and modernization. Therefore, while more local control was viewed positively, preferences for a collectivized regime of political-economic organization were not discredited, due to the fact that Belarusians continued to view the general outcomes of Soviet industrial development as overwhelmingly positive. In other words, while some reform might have been viewed positively, Belarusians did not envision or desire reforms that would lead to the dismantling of the Soviet political-economic system. ${ }^{89}$

These unique historical legacies meant that even with the collapse of the USSR, collectivistic, commandstyle, and statist policy ideas were not discredited. This is because key aspects of Soviet Communism found in the BSSR were rooted in Belarus's historic political-culture, which included predominant worldviews favouring collectivism, communalism, and paternalism in the form of strong statist solutions and authoritarian leadership. Moreover, Belarusians shared significant nostalgia and patriotism for the BSSR. As a result, Belarusians were not prepared to seriously consider real reform after 1991, since Belarusians did not view the system under the BSSR as broken. 
The Effects of Religious-Cultural Worldviews on the Lack of Political-Economic Liberalization in Belarus over Twenty Years since rise of Lukashenko

\section{Contemporary Political-Culture and Public Opinion after 1991}

After the Soviet collapse, there was little preference for comprehensive market transformation, nor desire to radically de-Sovietize. Belarusians also felt no expediency to move towards Western Europe, and expressed desires to maintain close ties towards Russia, not because they lacked a national identity, but because of the predominant feeling that a close orientation with Russia was right and natural due to Belarus's close cultural heritage shared with Russia. Belarusians also believed that Soviet-era policies were a success. As a result, explicitly liberal ideas were largely absent from the political-cultural mix in Belarus. Instead, Belarusians collectivistic, communal, statist and paternalistic worldviews predominated and were reinforced by nostalgic historical memories of life under the BSSR. Indeed, Lukashenko was able to consolidate and legitimize his rule by playing on these worldviews and historical memories widely shared by both Belarusian elites and society.

Overall, little reform was implemented in the pre-Lukashenko period from 1991 to 1994. During this time there was actually an attempt by Belarusian policy-makers to maintain key structures of the collectively oriented command and control decision-making apparatus over political-economic affairs, where the administration of former Prime Minister Viacheslav Kebich did not take concrete steps to implement significant reform. As a result, the Kebich government did not let any private initiative evolve, nor implement much liberalized privatization. Indeed, the reform envisioned by the Kebich administration was not that radical in terms of limiting state control in the economy. In general, there was little political will to de-collectivize and de-Sovietize via the implementation of comprehensive liberalization because Belarusian elites and large segments of society did not view the old Soviet policies as broken.

Most Belarusian elites remained heavily Sovietized in their worldviews, habits, practices and behavior. This was especially the case for Kebich, who was Lukashenko's leading opponent in the 1994 presidential elections, and who was also very pro-Russian, pro-statist and anti-liberal, and had begun to exhibit some authoritarian tendencies. Indeed, it was Kebich, thinking that he would easily slide to victory, who drafted a new constitution that gave the president increased powers, which Lukashenko utilized to great effect upon gaining office. One can also find collectivist, authoritarian, statist, pro-Soviet and pro-Russian worldviews at play and that Kebich believed in the rightness of such policies, because "even after so many years, he still talks about the advantages of the Soviet model compared to the Western model." 90

Most of Belarusian society also shared strongly pro-Soviet, collectivistic and anti-reformist worldviews, where there was no widespread demand favouring liberal policy reforms in the period from 1991 to 1994. Moreover, if market reforms or capitalism were discussed, this tended not to go anywhere, since "there were very negative attitudes towards the market economy in the 1990s." liberal reforms let alone decentralization or privatization, which would have largely been unheard of and unthinkable for most Belarusians due the general absence of liberal worldviews.

Such attitudes had nothing to do with a lack of national identity, but resulted from the fact that Belarusian worldviews and historical memories did not see a great-deal wrong with the collectivist and statist system under the BSSR, which was still viewed as legitimate by most Belarusians. Indeed, collectivistic and statist solutions were maintained, "because the people and the government believed that this was the right way and stuck to old ways [habits]." "92 This is because amongst elites and society, "there were no really liberal and pro-market forces in the early 1990s...they all had a Soviet culture, they didn't understand how to do reform,... and were convinced the Soviet model was the best." ${ }^{93}$ Therefore, even when freedoms were opened up, and old repressive structures were temporarily removed, as occurred from 1991 to 1994, there was a certain limit to reforms and changes that could happen. This was due to the finiteness of ideas and habits that Belarusians could draw upon for policy 
inspiration, which depended largely on the predominant political-cultural worldviews, ways of life, and historical memories in Belarus that were highly collectivistic, pro-Soviet, and lacked any explicit liberal value orientation.

Since being elected in 1994, Lukashenko has followed a similar path of old traditions, where he has consolidated his authoritarian grip over most aspects of political-economic decision-making. While Lukashenko is certainly interested in maintaining his grip on power, such a desire is not simply based on power being an end in itself. Indeed, Belarus has had far fewer problems with oligarchs, largely as a result of the sheer dominance of Lukashenko. For instance, Zlotnikov noted that "Lukashenko...has impinged upon the interests of adherents to the 'oligarchic' model and even against the interests of the 'nomenklatura' entrepreneurs." 94 As a result, "criminality - economic and its other forms - has been kept in check, as a by-product of a zero-tolerance approach." 95 Such evidence is important for showing inadequacies of Rationalist arguments regarding the "rentseeking' motives of officials, since Lukashenko's decisions were not in the interest of self-aggrandizing bureaucrats.

Instead, Lukashenko and his close inner-circle view the necessity to maintain power, not for rationalistic economic gain, but as a means to maintain the neo-Soviet, collectivist and statist political-economic system. This is because such practices are in accordance with Lukashenko's worldviews of what constitutes the 'best,' and 'right' policy practices to promote overall development, growth and wellbeing. As one interviewee noted, "he [Lukashenko] strongly believes in the right nature of his policies and that he thinks, it's the best way for the country to develop." 96

The political-cultural worldviews held by Lukashenko can be described as being highly collectivistic, illiberal, pro-Soviet/Russian and historically rooted in the authoritarian leadership habits found in rural Belarus. One interviewee pointed out that "Lukashenko's mentality was like that of a Soviet person," while another added that "he is an idealist and believes that the Soviet system was a good system." "97 Another pointed out, "the ideology of Lukashenko is very much based on some kind of neo-Soviet nationalism, using Soviet symbols and Soviet nostalgia." 98 One can infer that such sentiments are rooted in pre-Soviet historical cultural influences, in that Lukashenko "prizes the values of justice and equal distribution," and views capitalist "motive[s] for an entrepreneur...the desire for profit... [and] 'the spirit of gain' [to be] incompatible with the values of the SlavicOrthodox peoples." 99 Indeed, one can see such worldviews and ideologies displayed in the policy rhetoric exhibited by Lukashenko. For example, Lukashenko was quoted as saying that he views the "ability to work not just for the sake of profiteering, but for the good of the society, the collective, and other people." ${ }^{100}$ What is key to note for Lukashenko, is that collectivistic, communal and statist solutions are not only preferred over market mechanisms, but also viewed normatively as being 'right' and 'best.'

Some might argue that because Belarus is a dictatorship, this limits the ability for the worldviews of society to influence decision-making. However, the current regime's legitimacy and longevity are not merely based on force, oppression and beating down opponents, because many of the preferences and values displayed by Lukashenko are in tune with the predominant political-cultural worldviews of the broader society. To illustrate, one commentator noted that "the Lukashenko regime, has "placed...the outlook of the average Belarusian political-culture in its own foundation." 101 Thus, the phenomenon of Lukashenko's power and popularity did not come about in a vacuum, but were directly conditioned by the historic political-cultural environment of Belarusian society.

Therefore, throughout Lukashenko's rule there was a certain limit to reforms and changes that could happen. This was due to the finiteness of the ideas and habits that elites and society could draw upon for policy inspiration, which depended largely on the predominant political-cultural worldviews already preexisting in Belarus, which were highly collectivistic, statist, and pro-Soviet. Indeed, Lukashenko, other elites and society chose what was 'known' to them over what was 'unknown.' Moreover, what was 'known' supported Belarusians preconceived worldviews of what was viewed as the 'best,' 'right,' and 'normal' policy practices. As one 
The Effects of Religious-Cultural Worldviews on the Lack of Political-Economic Liberalization in Belarus over Twenty Years since rise of Lukashenko

interviewee pointed out, "the people, and the government believed that this is the right way...and they never abandoned their views and their beliefs." 102

Lukashenko has also been a talented politician by repeatedly using rhetoric playing on the peoples traditionally collectivistic and pro-Soviet worldviews, and in invoking nostalgic historical memories of the BSSR and its leaders such as Masherov. Indeed, a large majority had great nostalgia and positive historical memories of the stability, development, growth and prosperity fostered under the BSSR. ${ }^{103}$ Thus, a large part of Lukashenko's appeal was that he portrayed himself as a "proper Soviet person" whose leadership style was rooted in his experience as manager of a Soviet collective farm and untainted by corruption. ${ }^{104}$ The fact that Lukashenko has successfully promoted such themes shows that large numbers of Belarusians have positive historical memories of the collectivistic, communal, and authoritarian leadership styles found in the BSSR, and also points to the strength of such worldviews, which normatively view such methods to be the 'best' and 'right' means to manage politicaleconomic relations.

The fact that many Belarusians remained highly pro-Soviet after 1991, is illustrated in polls which ranked positive responses regarding approval of the political system before perestroika (pro-Communist), and highlights that Belarusians were far more pro-Communist than the Baltic States and other new-EU members. To illustrate, Belarusian yes responses (pro-Communist) numbered $60 \%$ in 1992, 64\% in 1993, 77\% in 1995, 60\% in 1998, $78 \%$ in 2001 , and $65 \%$ in $2004 .{ }^{105}$ These results showing high pro-Communist/Soviet sentiments is further highlighted in a poll which asked people whether they favour a return to Communism. Here, Belarusians consistently polled in the double digits, where yes responses numbered $37 \%$ in 1993, $49 \%$ in 1995, 33\% in 1998, $27 \%$ in 2001, and 24\% in 2004. ${ }^{106}$ Such numbers are corroborated by other polls, conducted between 1993 and 2009, which showed high yet declining positive attitudes towards the restoration of the USSR. Here, Belarusians answering yes, numbered $55.1 \%$ in $1993,49.9 \%$ in $1997,38 \%$ in $1999,38.8 \%$ in $2002,39.5 \%$ in $2004,38 \%$ in $2005,26.7 \%$ in 2006, $21.5 \%$ in 2008 and $26.7 \%$ in $2009 .{ }^{107}$ Other polls also illustrate that Belarusians have far greater nostalgia for the Soviet Union. This nostalgia can be seen from polls in 2000, 2004 and 2006, which asked if it was a 'misfortune that the USSR no longer exists.' Here, positive responses numbered $70 \%$ (76\% from Belarusian-speaking Belarusians) in 2000, 54\% in 2004 and 39\% in 2006. ${ }^{108}$

Most Belarusians also favour collectivistic, authoritarian, paternalistic and statist solutions for managing political-economic affairs. As one interviewee pointed out, "Belarusians are overwhelmingly collectivist,....and there is huge support for a 'strong hand,' and a view that the state should take care of all citizens and ensure a reasonable standard of living, like a cradle to grave kind of attitude, with few people believing that the state should do as little as possible and not interfere in the lives and the economic activity of the people." ${ }^{109}$ Overall, something like property restitution lacked popular appeal in Belarus, where ideas of individual private property ownership were culturally alien in the worldviews and historical memories of Belarusians. To illustrate, one interviewee pointed out that "there was no cult of private property," and "many people have this attitude that everything belongs to us, everything belongs to everyone... .because everything is still considered to be public property." 110 As a result, Belarusian collectivistic worldviews continued to favour the common use of land after 1991.

Thus, it was unthinkable for most rural Belarusians to break up state-owned collective farms and divide them amongst local inhabitants for their own individual ownership. Due to Belarusians collectivistic/communal traditions, the notion of acquiring more individual property simply did not register in the worldviews of most Belarusians, since the inhabitants had a lack of traditions, experience, nor historical memory of property ownership. As one interviewee mentioned, "my family is from western Belarus, and it's a family memory that everyone knows that we had nothing before $1939 . .$. we had not this mentality of having some parcel of land,...we didn't have this kind of influence." ${ }^{111}$ Evidence of the lack of private property values amongst Belarusians, is further buttressed by Zaprudnik who noted there was "a lack of psychological preparedness among them to become private owners." 112 As a result, Belarusians had no worldviews of private property being sacred. This is 
because Belarusian political-cultural worldviews were infused historically with collectivistic values of "socialism [which] got so widespread that it was the national mentality and national ideology." "113 Indeed, another interviewee pointed out, "people still don't understand the concept of private property...for people, land is something sacred which belongs to the state, and they don't believe in the concept of private property of land...[which] to them...equals exploitation, class struggle, and injustice." 114

Such collectivistic attitudes favouring the communal land ownership would have been hostile at any proposals advocating a more liberal-individualist regime to manage property relations. As one interviewee pointed out, "the fact that people see the whole country as everyone's property, I don't think that they would eagerly agree to see it the other way,...I don't think this would be very popular, I wouldn't be a fan of it." 115 Not only did such attitudes limit reforms, but these continue to limit prospects for land privatization, as many people continue to view the ownership of land from a clearly collectivistic mindset.

Belarusian collectivistic worldviews can also be seen in polls that gauged attitudes towards money and material possessions, as well as attitudes concerning income equality in society. As these polls illustrate, responses verged towards more collectivistic responses, and favoured the idea of placing less emphasis on money and material possessions, where yes responses saying that it was a 'good thing' or they 'don't mind,' numbered a combined $82.9 \%$ in $1990,56.6 \%$ in 2000, and 56.8\% of Belarusian Orthodox respondents also in $2000 .{ }^{116}$ Moreover, in a poll that measured attitudes towards promoting income equality, $54.4 \%$ of respondents overall and $55.9 \%$ of Orthodox-Belarusians polled in 2000 answered yes in favour. ${ }^{117}$

When examining polls in regards to political-economic policy preferences, significant trends are revealed. In terms of privatization, and preferences favouring state or private ownership of business, in initial polls conducting in the period following independence, Belarusian responses remained consistent in favouring staterun enterprises over private enterprises. ${ }^{118}$ In other polls from 2000, when asked what type of economic system Belarus should have, the overwhelming majority favoured a regime that was lopsided towards heavy state involvement in the economy. To illustrate, 36\% overall and 39\% of Belarusian-speaking Belarusians favoured primarily statist solutions, $45 \%$ and $43 \%$ preferred equal state and private, and only $20 \%$ and $17 \%$ respectively favoured primary emphasis on private solutions. ${ }^{119}$ Overall, Belarusians tend to favour large state involvement in managing political-economic affairs. As one interviewee pointed out, "we go back to our old policies because we believe in the policies of sponsorship, subsidization and state loans." ${ }^{120}$ Additionally, another pointed out, "most of the population believes that the state should do a lot, such as ensuring job creation, investment, everything, which is why when Lukashenko took over, his messages coincided with the expectations of the people." 121

These sentiments are further corroborated by other polls, where respondents were asked whether they preferred liberal-individualist forms of management (owners; owners/employees), or collectivist forms of management (state; employees). As these polls show, high preferences for collectivist forms of management were found amongst respondents, where $66.7 \%$ in 1990, and $47.4 \%$ in 1996, and $48.3 \%$ of Belarusian-Orthodox respondents in 1996, favoured collectivist forms of management. ${ }^{122}$ Similar results were found in other polls, which ranked preferences towards private versus state ownership, and revealed that Belarusian (Orthodox) respondents tended in large parts to favour state ownership, numbering 52.9\% in $1996 .{ }^{123}$ Moreover, in another poll conducted in $2008,48.2 \%$ of respondents answered no when asked whether the large-scale state-owned enterprises should be privatized, while only $39.7 \%$ answered yes. ${ }^{124}$ Such results are important for showing the presence of deeply rooted collectivistic cultural-religious norms infusing Belarusian worldviews, even though at first glance cultural-religious influences might not appear to be teeming to the surface to influence matters that seem secularized.

In regards to questions relating to preferences of having a secure job versus a job that is well paid, in a poll conducted in 1993, only 35\% favoured the well-paid job, with $65 \%$ favouring the secured job. ${ }^{125}$ Such numbers are further supported by polls, from 1997 to 2006, indicating that Belarusians favoured low, but 
guaranteed income, numbering $65.3 \%$ in $1997,57.8 \%$ in $1999,51.8 \%$ in 2000 , and $53.6 \%$ in $2006 .{ }^{126}$ Indeed, such numbers indicate the high levels of support for statist solutions in managing the economy.

Overall, repeated polls from 1994 to 2007, indicate that the largest plurality of Belarusians favour an economy with high amounts of state control, as most respondents either mentioned explicitly their preference for a planned economy or a market economy with substantial state control (see Figure 2). While numbers for those expressing a preference for a market economy with some state control might tempt some to infer the presence of strong segments of liberalist sentiment, such results should be viewed with a degree of skepticism. First, Belarusians did not have good grasp of liberal market principles, which was found in the comments of several interviewees noted above. Moreover, other polls contradict such claims of possible liberalist sentiments, which indicated that the overwhelming majority of respondents, in the 70\% range, answered repeatedly from 1990 to 2007 that they preferred the state to regulate prices for good and services (see Figure 3). This highlights that Belarusians, regardless of what they might answer in regards to hypothetical market scenarios, nevertheless continue to prefer substantial state regulation and control over the most basic everyday aspects of the economy, such as price controls. 


\section{Figure 2}

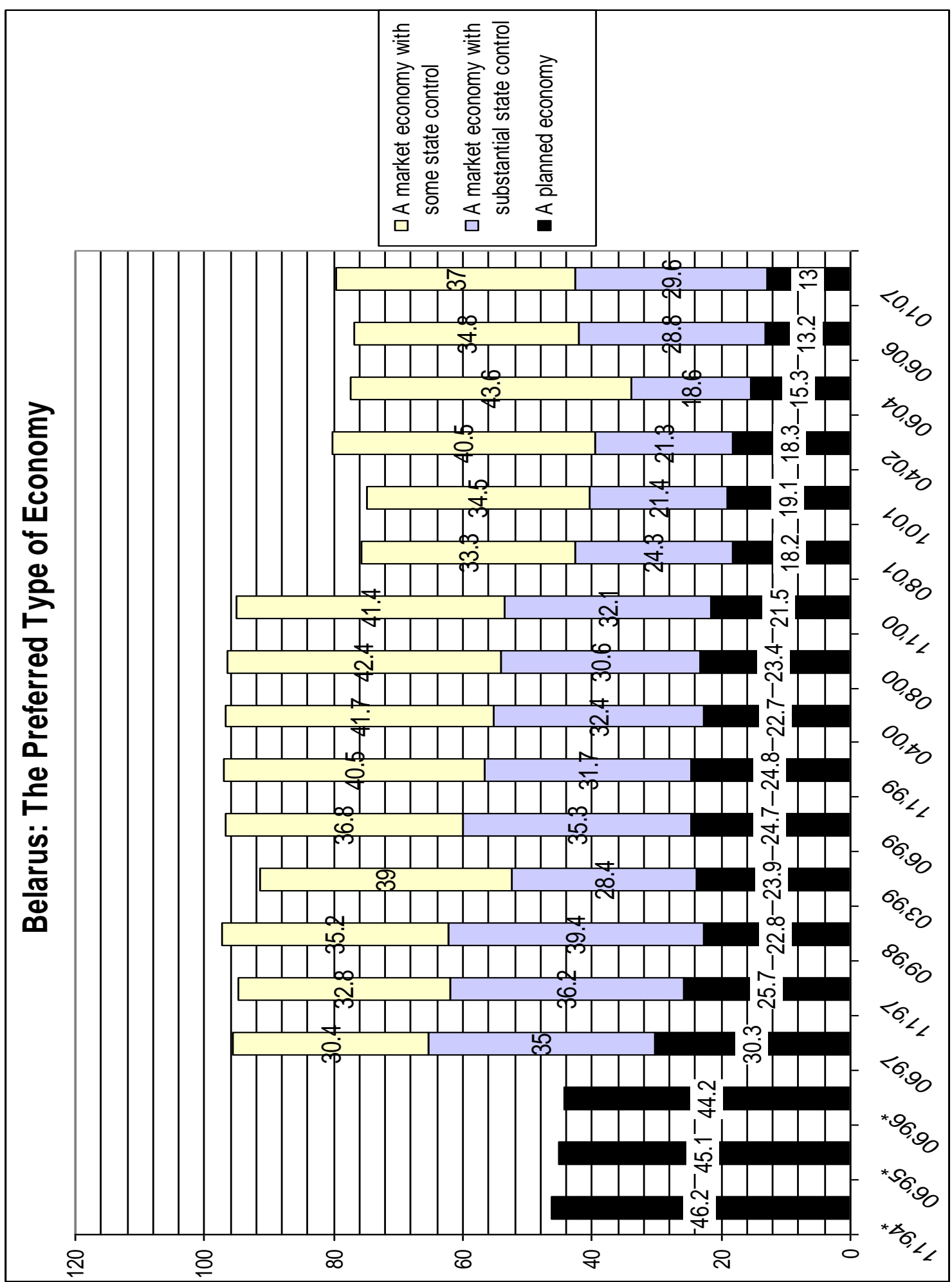

Source(s): (IISEPS 2000d; IISEPS 2001c; IISEPS 2001d; IISEPS 2002b; IISEPS 2006c; IISEPS 2007a). 
Figure 3

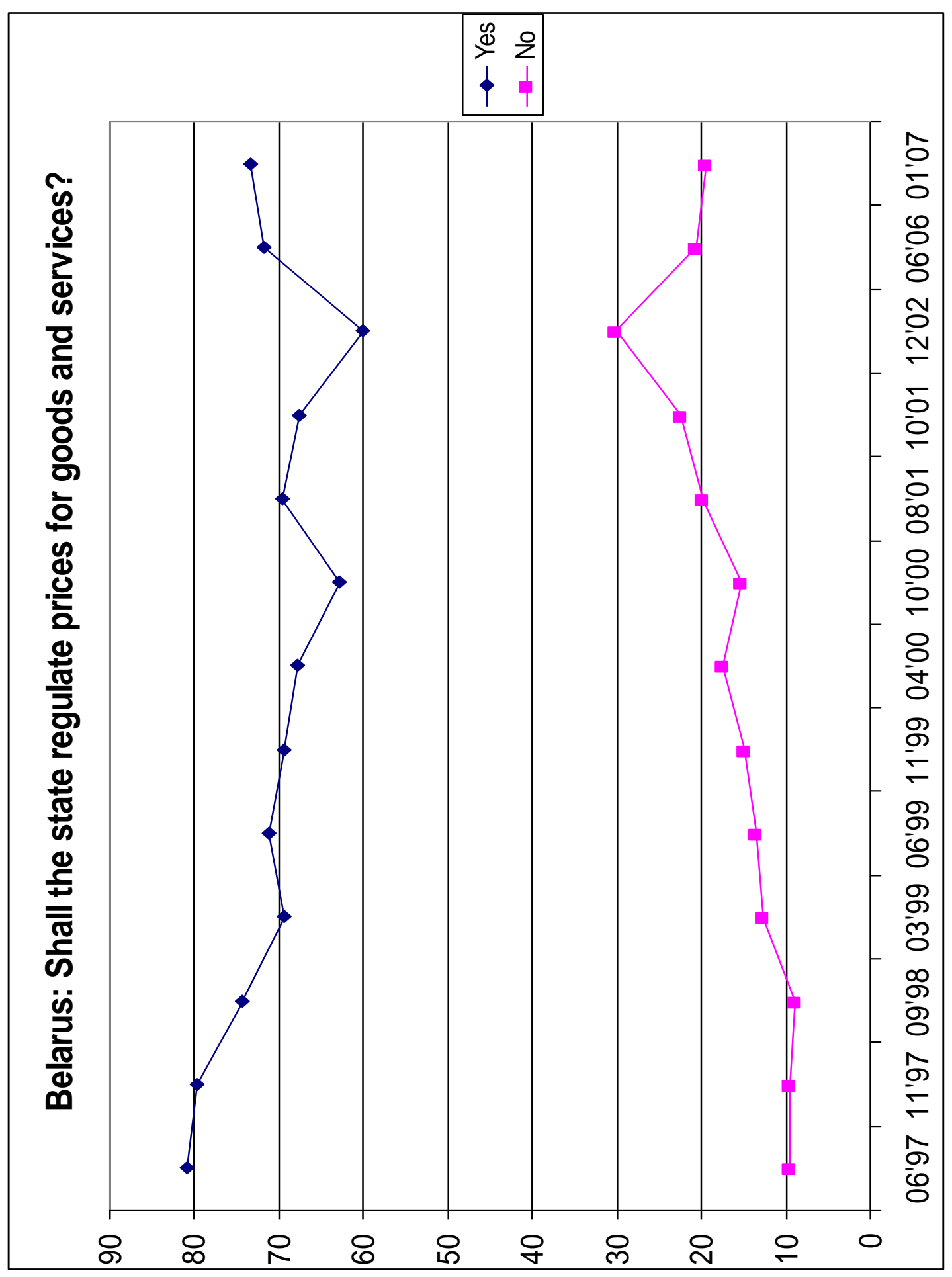

Source(s): (IISEPS 2001c; IISEPS 2001d; IISEPS 2002d; IISEPS 2006c; IISEPS 2007a). 
In regards to Lukashenko's absolutist, authoritarian, and paternalistic style of leadership, such patterns correspond to leadership traditions experienced historically by Belarusians. Indeed, Lukashenko's authoritarian style, where decisions are often made by decrees, are reminiscent of previous similar patterns of leadership under both Soviet rule and under Russian Tsars. In fact, Lukashenko's leadership could be described as embodying a mini-Tsar, where he acts as father figure, similar to historically authoritarian leadership patterns found under Tsars, village commune heads, and the tradition of rule by decree preferred by Soviet leaders. As one interviewee observed, "we just had this kind of Tsarist concept of the state, we had Batka who was kind of like father of the nation, and so we let him run the country and we followed." 127 Similarly, another argued that "the politicaleconomy is very much patriarchal with its big father figure." 128 Such authoritarian, absolutist and paternalistic patterns adhere to many ideals of strong leadership preferred by Belarusian political-cultural worldviews that have their roots in the strong influence of the Russian Orthodox faith historically predominant amongst Belarusians. To illustrate, one interviewee mentioned that...

here a lot depends on the mentality of the people, and of the religion...Belarus is a very patriarchal country...you can see it everywhere in the family, and in the political system where we have one man that is very much like a Tsar. Even though conditions are different and the system has changed, if you look deeply, you can see those roles are still in place. And...I don't think that it just comes from the Soviet times, but it comes from earlier on...from the Byzantine religious idea of the Orthodox Church being part of the state." 129

Certainly, these worldviews that exhibit predominant attitudes that are collectivistic, statist, patriarchal and show a penchant for authoritarian leadership would work against the promotion of market liberalization and liberal democracy. As one interviewee mentioned, “in Belarus there is huge support for a 'strong hand,' and view that the state should take care of all citizens." 130 Such conclusions can also be made from observations that the "citizens of Belarus... have yet to adhere to democratic values, and...the mentality of the former Soviet period still prevails." 131 These attitudes are further corroborated by reports that "his [Lukashenko's] tough-guy approach to politics had strong appeal for a society craving authority and a firm hand - the same society that had been overwhelmingly rural and patriarchal only a half-century ago." ${ }^{132}$ Indeed, another commentator offered the pointed observation that a favouritism towards "authoritarian power is embedded in the political-culture of the population." 133 Such attitudes are revealed in repeated polls from 1996 to 2008, which highlight that the most attractive and "ideal" historical and contemporary politicians that respondents prefer, adhered to strongauthoritarian types such as Masherov, Lukashenko, and Russian President Vladimir Putin. ${ }^{134}$

Such observations are further conferred from polls that measured positive attitudes towards the prospect of having dictatorship rule. For example, a majority were consistent in giving positive attitudes towards dictator rule in four separate polls from 1992 to 2004, where 76\% (1992), 57\% (1993), 56\% (1995), and 63\% (2004) of respondents answered yes to favouring dictatorship. ${ }^{135}$ In another poll asking whether there were no alternatives to democracy, only a minority of respondents said yes, which numbered $27 \%$ in $1993,26 \%$ in $1995,39 \%$ in 1998 , and $25 \%$ in $2004 .{ }^{136}$

Furthermore, one can infer positive attitudes towards authoritarian rule from polls rating positive attitudes towards the future political regime. Specifically, polls from the New Democracies Barometer indicate that satisfaction went up just as all of the small amounts of reform were eradicated and Belarus moved towards an increasingly authoritarian political-economic regime under Lukashenko. ${ }^{137}$ Such numbers are further supported by other polls that indicate for much of Lukashenko's rule during the past ten years, the majority of respondents, for the most part, answered that Belarus was going in the right direction (see Figure 4). Overall, the strong 
collectivistic, communal, paternalistic, and statist ethos characterizing Belarusian political-culture played a big influence on such preferences for the continuance of collectivistic, statist, and authoritarian solutions.

Figure 4

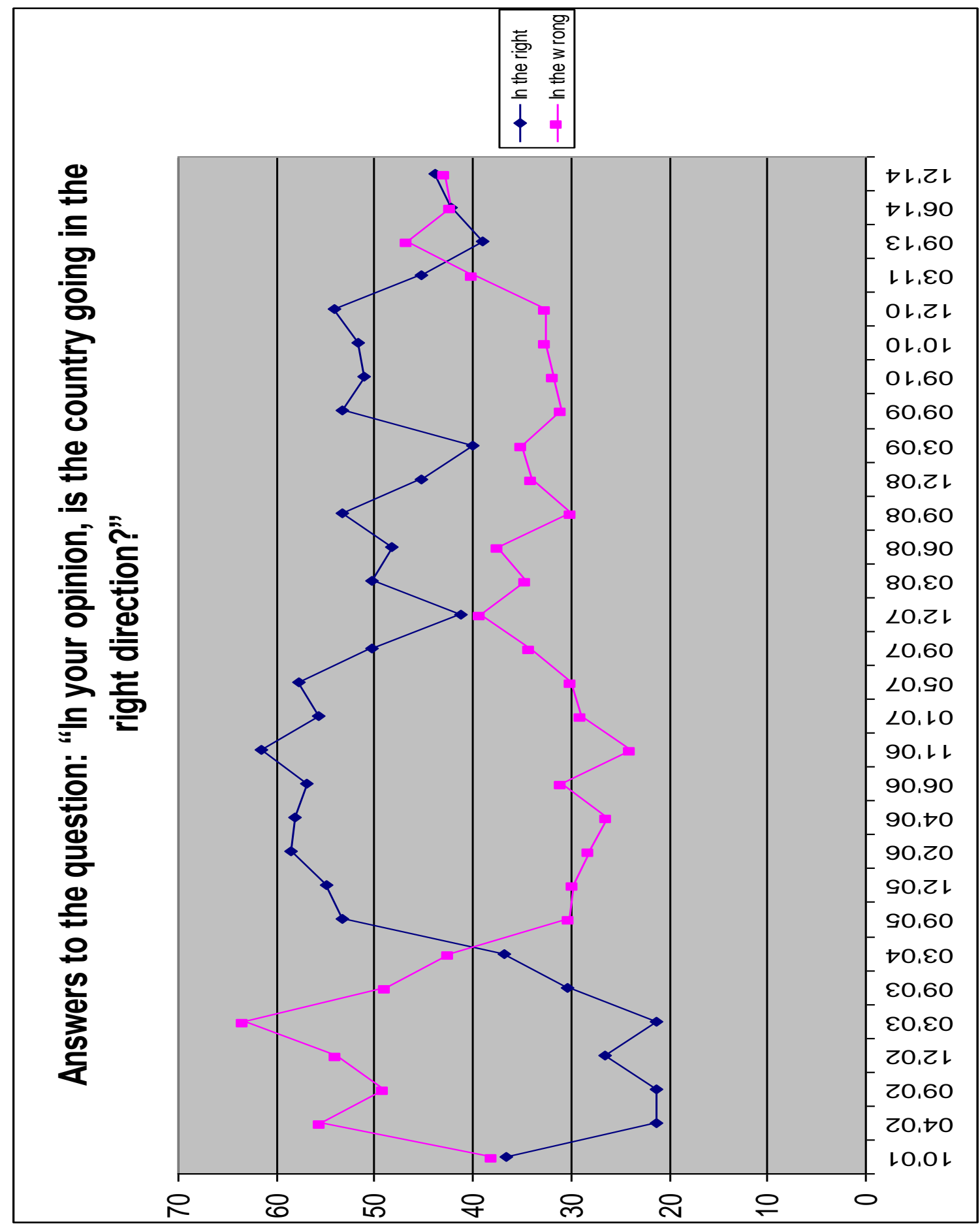

Source(s): (IISEPS 2004a; IISEPS 2006a; IISEPS 2006c; IISEPS 2008b; IISEPS 2009a; IISEPS 2011a). 
Overall, Lukashenko has been highly successful at retaining power, and in maintaining a strong plurality of support amongst large segments of Belarusian society. Not only is there high levels of support for collectivist solutions in managing political-economic relations, there has also been high levels of trust and support voiced in favour of Lukashenko, which shows support not only for his neo-Soviet policy practices but also for his authoritarian leadership style. Here, one can find political-cultural worldviews at play, in that Lukashenko is a skillful politician and was able build strong connections with society through his understanding the peoples mindset, seen with his ability to speak the language of average people. First, he literally speaks the peoples language, in that Lukashenko does not speak excellent Russian or Belarusian, but instead uses a mixture of the two languages speaking the Transyanka dialect that incorporates aspects of Belarusian and Russian, which is the everyday language for many Belarusians. Secondly, Lukashenko speaks the peoples language in regards to consistently promoting themes in his rhetoric that plays on the peoples predominant collectivist, statist and proSoviet worldviews and historical memories. As one opposition elite mentioned, "Lukashenko was the first to essentially understand the people in a way that he talked the language that the people were used too....his messages coincide with the expectations of the people, and he is quite smart in using his rhetoric exactly to match the expectations of the people." 138 Such sentiments are corroborated by Andrei Okara, who pointed out that "the popularity of President Lukashenko is largely due to his rhetoric, behavior, and policies matching the Belarusian peasant archetype." 139 Similarly, Jan Maksymiuk observed that Lukashenko has "a deep understanding of the national psyche." 140

Evidence suggests that Lukashenko does have greater support than many would argue. For example, if one looks at electoral indicators, Belarusian voting preferences show that the populace remains solidly illiberal, collectivist and anti-reform in its voting habits. This was illustrated in 1994, when Lukashenko was first elected president in free and fair elections on a pro-Soviet, illiberal, and authoritarian election platform, receiving over $80 \%$ of the vote against his main opponent Kebich, who was also illiberal and anti-reform in his policy positions. ${ }^{141}$ Even though Belarusian elections have ceased to be free and fair, there is evidence that President Lukashenko still remains popular, and would have been elected with a majority in 2001 under democratic procedures. For example, a poll in 2001 indicated that $53 \%$ of respondents overall, and $64 \%$ of Belarusianspeakers answered that they would have voted for Lukashenko, while all other candidates listed only in the single digits below 5\%. ${ }^{142}$ Moreover, as Figure 5 reveals, polls show that upwards of $45 \%$ of respondents in August and October 2001, listed Lukashenko as the candidate they would have voted for. What is also important to note is that when Belarusians were polled in regards to their perceptions whether voting and administering the ballot was fair, $63 \%$ overall and 67\% identifying themselves as Belarusian-speakers in 2000, and 62\% in 2004 responded the election processes were fair. ${ }^{143}$ These numbers are further supported by polls from December 2001, where Belarusians were asked if they trusted the results by the Central Elections Commission, and 55.3\% answered yes, while only $30.5 \%$ answered no. ${ }^{144}$

Figure 5 also reveals that by the next elections in March 2006, polls showed that on four separate occasions in February, April, August, and November 2006 that respectively 57.6\%, 60.3\%, 54.9\%, and 49.7\% of respondents answered they would vote for Lukashenko. While not giving Lukashenko the inflated results listed by the Central Commission on Elections, Lukashenko nevertheless was polling the highest, and either would have been elected with a slim majority on the first round, or eventually won on a second ballot. In another poll, which asked in April 2006, "for whom did you vote at the past presidential election in March," 54.2\% listed Lukashenko, while his next highest opponent, Milinkevich, received only 15.8\%. ${ }^{145}$ Moreover, when Belarusians were polled in October 2008, in regards to perceptions of whether voting and administering the ballot was free and just, 56.3\% said yes, while only $24.2 \%$ answered no. ${ }^{146}$ Indeed, others noted that if a free and fair vote were held, Lukashenko would still have won in 2006, and would likely have won in $2010 .{ }^{147}$ 
Figure 5

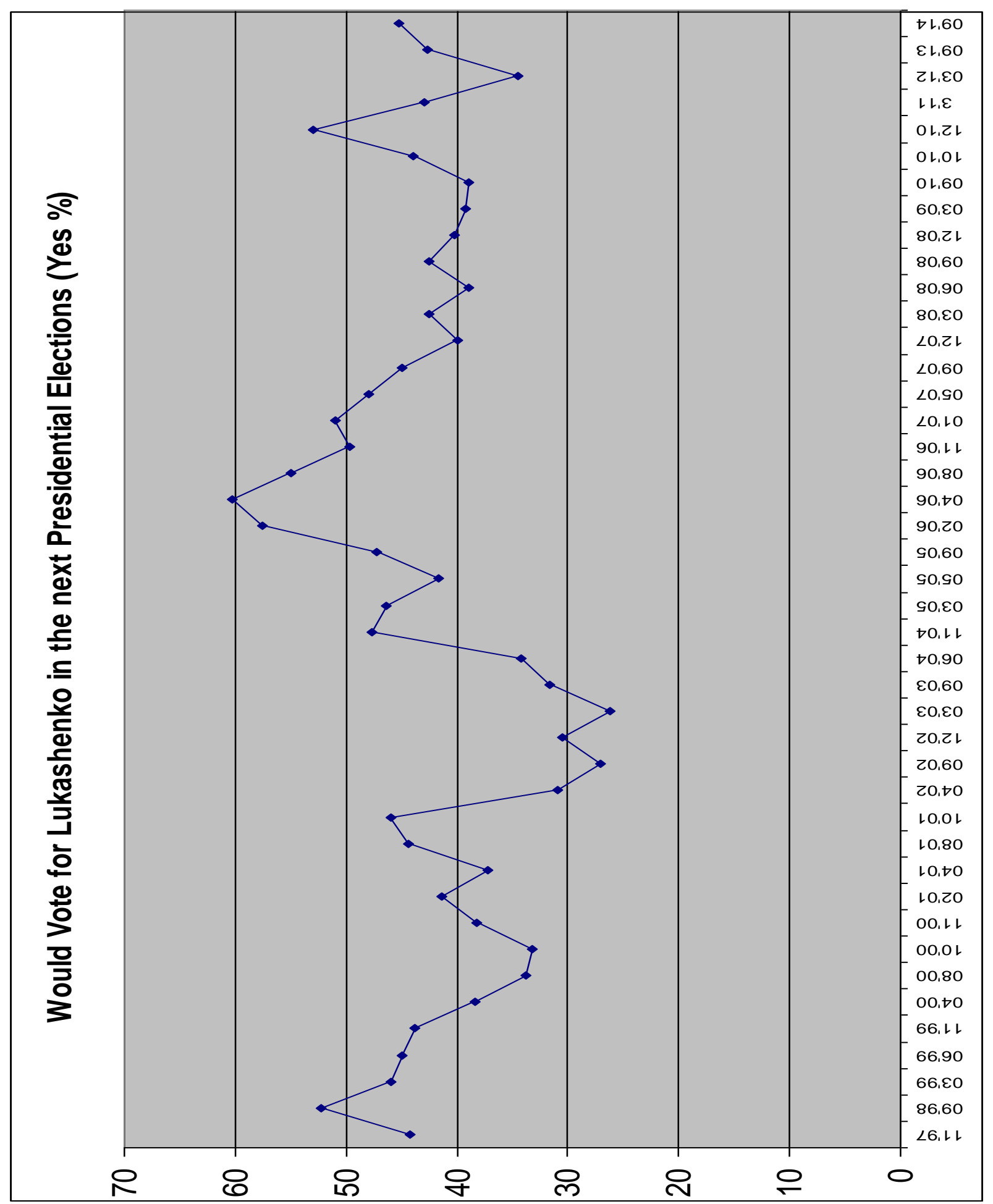

Source(s): (IISEPS 2000d; IISEPS 2001c; IISEPS 2003a; IISEPS 2004d; IISEPS 2005c; IISEPS 2006b; IISEPS 2007a; IISEPS 2008b; IISEPS 2008d; IISEPS 2009a; IISEPS 2011b; IISEPS 2015). 
Evidence suggests Lukashenko does have a strong rapport with large segments of society, as several polls measuring support and trust for Lukashenko attest. As Figures 5 and 6 indicate, polls numbers have shown that support and trust for Lukashenko has remained consistently high throughout his tenure. Such numbers are corroborated by other polls that reveal that Belarusians have retained high amounts of trust in Lukashenko, since he was elected in 1994, where 58\% in 1998, 57\% in 2000, and 62\% in 2004 responded that they trust the President, while only $28 \%, 28 \%$ and $23 \%$, respectively responded they did not. ${ }^{148}$ From viewing such numbers, it is easy to agree with several interviewees that concluded that if a free and fair vote were to be held in December 2010, Lukashenko would still have won. ${ }^{149}$

Lukashenko's initial success and continuing longevity can be linked to his close ties to rural Belarus, where a strong base of support exists for the President. Certainly, the fact that Belarus remained largely rural prior to 1945, and the fact that many people in Belarus, even urban dwellers, still retain many of political-cultural worldviews historically rooted in the Belarusian countryside, helps to understand the popular appeal of Lukashenko's style of governance. This can be inferred from findings that found that the "village remained a comparatively solid carrier of the traditional culture in its folkloric and ethnographic form." ${ }^{150}$ Additionally, Lukashenko has not only played on pro-Orthodox religious themes, but also received praise and endorsement from high ranking officials in the Belarusian Orthodox Church. ${ }^{151}$ Overall, Lukashenko has tended to speak the language of Belarusian society, in terms of speaking to the predominant collectivist policy preferences of the people for statist solutions, collective management of political-economic relations, and in having a strong leader. 


\section{Figure 6}

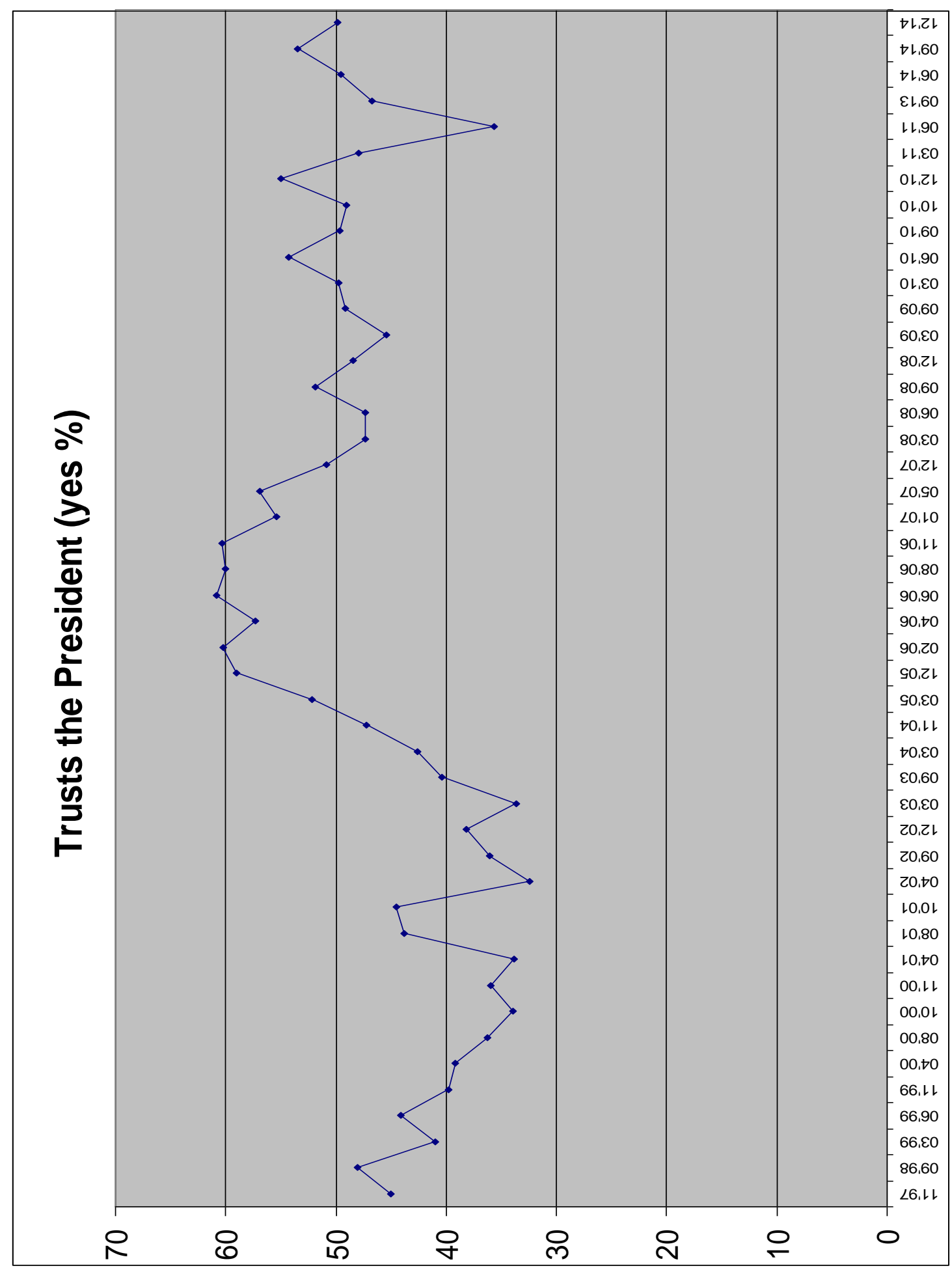

Source(s): (IISEPS 2000d; IISEPS 2001c; IISEPS 2003a; IISEPS 2004d; IISEPS 2005c; IISEPS 2006b; IISEPS 2007a; IISEPS 2008b; IISEPS 2008d; IISEPS 2009a; IISEPS 2011b: IISEPS 2015). 


\section{Inadequacy of Theories of National Identity}

While National Identity theories opened promising avenues of research, the evidence from Belarus poses significant problems for these explanations. For example, National Identity frameworks explained the divergent policies amongst post-Soviet countries by pointing to variations in the strength of national identity between these states. Specifically, National Identity explanations argued that Belarus's inability to reform and illiberal policy practices, as well as high-levels of pro-Soviet nostalgia, and close orientation towards Russia, resulted from a lack of a cohesive national identity amongst Belarusians, with the view that Belarus is a "denationalized nation." 152

However, National Identity arguments are inadequate to explain the illiberal political-economic behavior and lack of reforms in Belarus. Methodologically, issues arise because the primacy of nationalist ideas was brought into question by the alleged instrumental actions of political actors. For example, Abdelal's arguments take on Rationalist formulations, in that Belarusian policies lacked "purpose," and were driven by the self-interest and materialistic ends of political leaders, as "economic relations with Russia were interpreted as mutually beneficial exchange." 153 In other words, by following their short term material interests, such accounts assume that Belarus was acting against its long-term national interests, and as a result lacked a coherent sense of national identity.

National identity explanations often characterized Belarusian policies, such as the lack of politicaleconomic reforms, and continuing cooperation with Russia, in the form of receiving cheap oil and gas, and potential customs union, as primary examples of a lack of national identity resulting often in rent-seeking. ${ }^{154}$ In doing so, such arguments imply that this structurally worked against reform, since Belarus's heavily industrialized economy was dependent on Russian oil and gas. Additionally, several commentators even made doom and gloom predictions about the prospects for Belarus's long-term sovereignty as a result of Minsk's close relations with Moscow. ${ }^{155}$

However, such friendliness with Russia should not be confused with Belarus lacking a national identity or simply being driven by rational economic motives. This is because Belarusians favour close relations with Russia, as a result of shared historic religious-cultural links, and positive historical memories towards Russia. Such cultural affinity can be inferred from a statement of former Prime Minister Kebich, where he stated that " it is not just a question of economic circumstances. We are linked by the closest spiritual bonds; we have a common history and similar cultures." "156 Similarly echoing such close cultural affinity, Lukashenko was quoted, saying that "Belarusian people from the depths of its soul longs for union with Russia." "157 Indeed, due to common cultural histories, the tendency to want to be friends and cooperative with Russia is only normal and natural for Belarusians.

Such positive attitudes are seen with Belarusians continuing to favour close relations with Russia, where few see Russia as a threat. To illustrate, numerous polls show that Belarusian perceptions of Russia as a security threat is low, where those answering yes only numbered $13 \%$ in $1992,8 \%$ in $1993,14 \%$ in $1995,13 \%$ each in 1998, 2000, and 2004. ${ }^{158}$ In other polls, Belarusian responses placed greatest importance on future close relations with Russia and the CIS, with positive responses numbering $69.7 \%$ in 2004, 58.6\% in 2007, and 64.7\% in $2008 .{ }^{159}$

Additionally, four other polls, conducted in 1998, 2000, 2004, and 2006, showed large numbers of Belarusians held more negative worldviews to questions of NATO membership. ${ }^{160}$ Indeed, Lukashenko's rhetoric has consistently and effectively played on these underlying popular sentiments that had an historically antiWestern bent, by portraying NATO as an enemy to Belarusian interests. ${ }^{161}$ Additionally, it is evident that many Belarusians tend to think of themselves as culturally different from the West, which is illustrated in polls from 2009, which asked Belarusians their opinions about the West, where the highest number of respondents, 37.2\% listed the West as "a different civilization, an alien world with its laws, [and a] different people." 162 
It is also important to emphasize that Lukashenko sought to cooperate with Russia on equal terms, as two independent states, and as a result has been instrumental in maintaining and strengthening Belarusian sovereignty. Cooperation with Russia has also been moving at an exceedingly slow pace since the mid-1990s, and more often then not, Lukashenko has extracted significant gains from Moscow, without conceding much in return. Therefore, in spite of the many doom and gloom predictions there is increasing consensus that Lukashenko can be seen as a strong defender of Belarusian national interests and sovereignty. For example, when Belarusians were polled on their views regarding successful activity by Lukashenko in 2007 and 2008, 61.3\% and 64.5\% respectively, answered yes to "the construction of an independent state." 163 This view of Lukashenko acting as a protector of national independence was echoed by several interviewees. ${ }^{164}$

Another substantial counterpoint can be raised by the fact that that countries that were categorized as having strong national identities, such as the Baltic States, which 'returned to Europe,' nevertheless remained dependent on imports of Russian oil and gas. ${ }^{165}$ Not only does this make problematic National Identity explanations, since the Baltic States remain dependent on Russian oil and gas, but it also casts serious doubt on many of the other connected premises, such as that Russian energy dependence is a serious inhibitor of reforms.

Most importantly, while favouring close relations and orientation towards Russia, the vast majority of people do not wish to see close relations resulting in the loss of Belarusian sovereignty. Specifically, if one examines polls regarding the types of Belarusian-Russian integration favoured by Belarusians, the vast majority favour the options of two independent sovereign states, with only a minority supporting the full integration of Belarus into Russia. This is seen in Figures 7 and 8 below, which show that in repeated polls, from 1997 to 2008, Belarusians consistently answered that they were in favour of close cooperation with Russia, with Belarus remaining independent. ${ }^{166}$

In examining such responses, it appears that there is a significant normative bias placed by National Identity explanations against Belarusian support for more friendly relations with Russia. Specifically, Abdelal's arguments normatively imply that "nationalism" should only be associated with a policy behavior that is "purposive" in the form of being "liberal," oriented towards Europe, and away from Russia. These normative assertions when combined with the Rationalist undertones of the explanations are problematic. As Hopf notes, this is because "individuals always operate according to their interests - but those interests do not always correspond to the ones assigned by the omniscient observer." 167 Thus, while not wrong to assume that Belarusians did not interpret closer relations with Russia as a problem, it is unfair to normatively argue that Belarus lacks a national identity because Belarusians prefer to gravitate towards the cultural pole, which they have the strongest links. Indeed, Belarusians could not imagine being outside or de-linking from their traditional cultural realm and being closely oriented towards Russia

Significant problems also exist with explanations arguing that Belarusian national identity is "contested" and "ambiguous." This is because Belarusian policies actually failed to meet the assumed outcome of National Identity explanations, namely that instead of the assumption of policy being incoherent and inconsistent, ${ }^{168}$ Belarusian political-economic practices have shown high levels of consistency. Secondly, and more problematic, the claim that Belarusian identity is "contested" and "ambiguous" is not conclusive, and creates the impression that Belarus lacks an identity and has no coherent worldviews. ${ }^{169}$ 
Figure 7

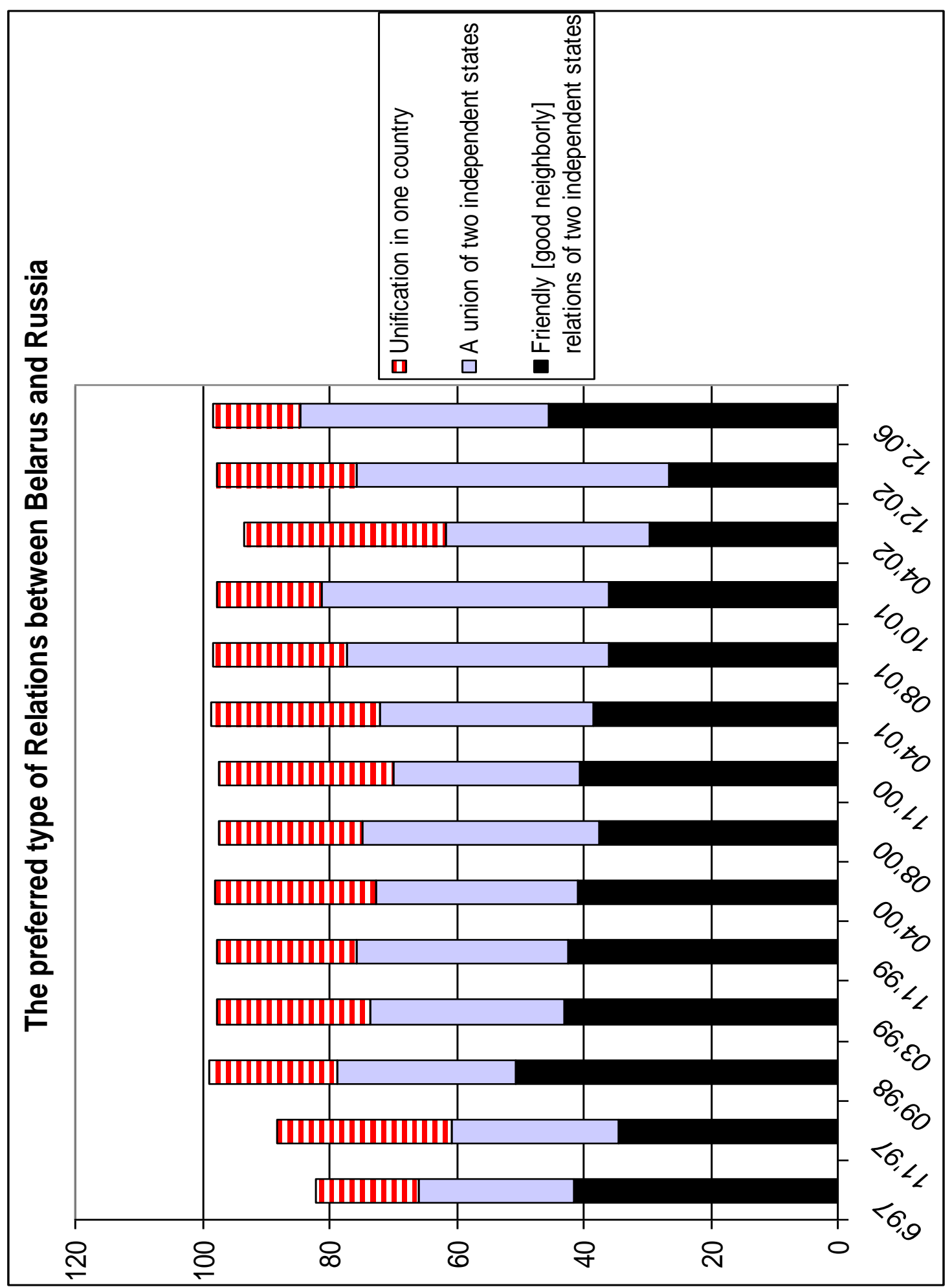

Source(s): (IISEPS 2000d; IISEPS 2001b; IISEPS 2001c; IISEPS 2002b; IISEPS 2006a). 
Figure 8

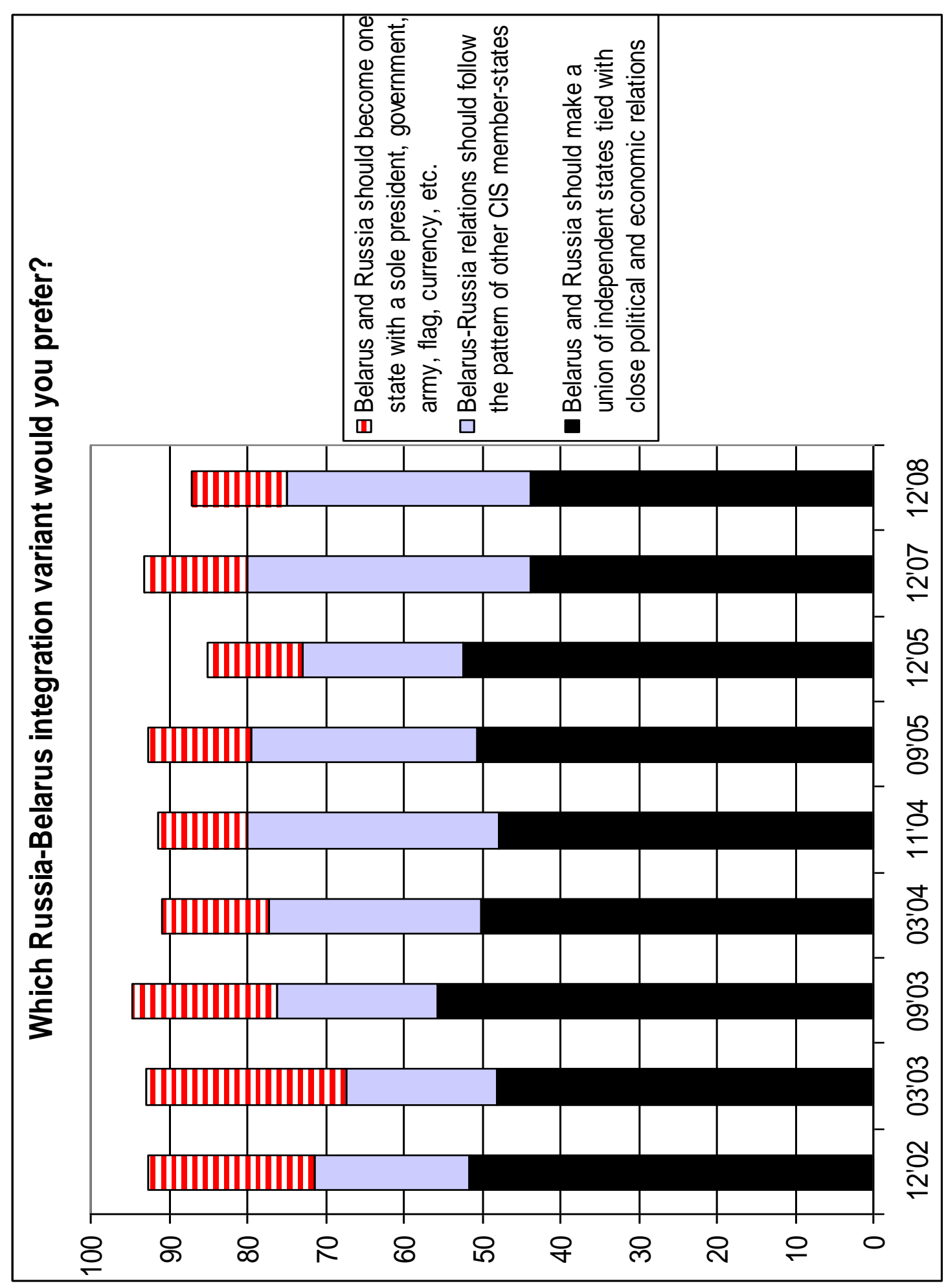

Sources: (IISEPS 2004a; IISEPS 2004b; IISEPS 2005c; IISEPS 2007d; IISEPS 2008d). 
Of critical importance is the fact that most Belarusians have never offered much support for the political groups designated by National Identity commentators as being 'nationalists.' This is even noted by many utilizing National Identity explanations, whom acknowledge that such "nationalist groups were largely rejected by most other societal actors." 170 Obviously, there is a huge divide between these 'nationalist' elites and the majority of Belarusian society. Overall, the BPF's 'nationalist' versions of history and ideologies were out of touch with the attitudes of most Belarusians, and were viewed to be elitist and of a radical, hard-core and extremist nature. ${ }^{171}$ Indeed, the policy goals and vision espoused by the BPF did not resonate with the Belarusian public.

A large reason for this was that a great deal of ideational support and inspiration for the BPF (founded in Vilnius, Lithuania in June 1989), came from the Popular Fronts in the Baltic States. At the ideological level, many of the anti-Russian/Soviet narratives of the BPF were inspired and borrowed from the negative historical interpretations of Soviet/Russian rule predominant in the Baltic States, which exhibited a noticeable cultural clash between the local cultures and Russia. However, such worldviews and historical memories were absent from the Belarusian political-cultural environment, where Belarusians had vastly different historical memories than did the Latvians, Estonians, and Lithuanians about life under Soviet rule. This was problematic as one interviewee observed, because the "nationalist" BPF "lived physically in Belarus, but mentality in the Baltic and in Poland....They hated the Soviet era, yet they didn't have a strong Belarusian tradition to support them in their anti-Soviet struggle, so they turned to our neighbouring countries to give this ideology,...and they didn't deliberate on the differences between here and there." 172

Also important in explaining the BPF's failure was that the pro-Western and anti-Russian narrative promoted by the BPF did not resonate with the predominant historical memories informing Belarusian worldviews. First, most Belarusians did not share the historical memories of Belarusian statehood being rooted and linked to the Grand Duchy of Lithuanian and Poland, nor the negative portrayals of the BSSR, which were themes regularly promoted by the BPF and its leaders, such as Pazniak. As one interviewee observed, "the people simply do not identify with the Polish-Lithuanian Grand Duchy that existed over nearly 400 years ago...and if there are any memories about the Poles, it is also that they did not treat Belarusians well either." 173

Thus, most Belarusians did not identify with historical narratives about the Grand Duchy, because Belarusians had not lived under it for generations. Moreover, if there were historical memories, these would have been negative due to the fact that Polish domination was characteristic of Grand Duchy rule. Such negative worldviews would have been further exacerbated by more recent historical memories of Belarusians suffering under Polish domination during the interwar. Additionally, BPF 'nationalists' were out of tune with Belarusian political-culture, in their borrowing of rhetoric from the historical memories of the Baltic States and Poland, which had negative historical memories of the Molotov-Ribbentrop Pact. As one interviewee noted, "one of the idiotic examples is when the Belarusian opposition even now criticize the events of 1939," because even though "it was tragic, it was the only chance where we could gain national unity." 174

In regards to the rejection of the BPF's anti-Soviet narrative, most Belarusians identified with the BSSR because in their historical memory it represented real progress. Moreover, the BSSR was for most people the only tangible memory of real Belarusian statehood and state-building which served as a positive historical reference point in their political-cultural worldviews. The fact that "the importance of Belarusians only experience of modern statehood was with the BSSR...was the point which was missed by the leadership of BPF." 175 This positive assessment of the BSSR, was often overlooked by many National Identity commentators or taken as an example of a lack of national identity. From such a vantage point, one can understand how 'nationalist' politicians, when they repeatedly spoke negatively of all things Soviet, ended up running into a wall because such negative narratives about the BSSR did not resonate with the worldviews and historical memories of average Belarusians.

One can see how this Westernized and anti-Russian historical narrative of Belarus portrayed by the BPF was rejected, since even Western scholars promoting this version of Belarus's cultural and national identity, also admit that under such narratives, "the nation is being redefined both in terms of its history and its place in the 
The Effects of Religious-Cultural Worldviews on the Lack of Political-Economic Liberalization in Belarus over Twenty Years since rise of Lukashenko

world." 176 The problem is that this 'nationalist' redefinition of Belarusian history was elite driven by those who made up only a small minority of Belarus's political, economic, and cultural elite, and who were generally out of touch with most of society. Indeed, such narratives about Belarusian 'nationalism,' promoted by the BPF, were only followed by a minority of the population. ${ }^{177}$ Thus, the fact that very little contestation took place, and these groups only received minute support and were "largely rejected," contradicts claims that Belarusian Identity is "contested" and "ambiguous." Instead, when one unloaded this normative baggage, evidence illustrates there was not only a cohesive Belarusian identity, but also strongly coherent political-worldviews evident in the attitudinal preferences of Belarusians, which were consistently collectivistic, communal, paternalistic, statist, and proRussian in orientation.

Some of the most specific problems found with National Identity explanations was that most of these accounts failed to incorporate relevant polls. This included numerous polls conducted during the 1990s and 2000s, which showed that National Identity explanations are far from conclusive. The results of these polls illustrated that while countries that were labeled as having strong national identities, such as the Baltic States, regularly polled slightly higher than Belarus on identity questions, the results were far from polar opposites, and Belarus polled a great deal closer than one would expect, if one were to conclusively accept National Identity explanations.

In one group of polls, Belarusians identifying primarily with their nation, numbered $56 \%$ in $1995,60 \%$ in $1998,74 \%$ in 2004, and 85\% in 2006. ${ }^{178}$ Additionally, in results on identity from other polls conducted from 1990 to 2000 , Belarusians polled $30.3 \%$ in $1990,71.3 \%$ in 1996 , and $57.4 \%$ in $2000 .{ }^{179}$ The only anomaly is from the poll in 1990 where respondents identified predominantly with their locality/region as opposed to their nation. Here, the nation could be viewed to signify the Soviet Union at the time, while the locality/region would have meant the BSSR for Belarusians.

In terms of national pride, evidence suggest that Belarusians do have a strong identity and are quite secure in terms of knowing who they are as Belarusians. As one interviewee mentioned, "the very idea that Belarus is an independent country and that this is valuable, is already here." ${ }^{180}$ It should also be noted that many advocates of National Identity explanations have acknowledged that Belarusian identity, "Russified or not, remains distinctively Belarusian." ${ }^{181}$ Strong sentiments of national identity can be found in polls showing high levels of national pride amongst Belarusians. For example, $79.7 \%$ in 1990, 76.3\% of Orthodox Belarusians in 1996, and $73.9 \%$ in 2000 responded that they were proud of their nationality. ${ }^{182}$ Such numbers are corroborated by other polls gauging national pride, where $63 \%$ in 1998, and $87 \%$ in 2004 answered that they were proud of their citizenship, while only $20 \%$ and $13 \%$ responded that they were not proud in both years. ${ }^{183}$ Additionally, the presence of a robust national identity and national pride can be seen in other polls where $74 \%$ overall, and $75 \%$ of Belarusian-speakers in 2000 listed 'patriotism and preference for interests of one's nation,' as ideological qualities desirable for politicians to have. ${ }^{184}$

Some National Identity accounts also point to the high percentage of Russian-speakers in Belarus, and that over $80 \%$ of the population voted in 1995 to make Russian one of Belarus's official languages, as an example of the lack of national identity. As polls indicate, a large number of the population prefers to speak Russian, with only a small numbers, around $10 \%$ of the population, actually using the Belarusian language entirely. In fact, the predominant majority of the population, 69\%, including President Lukashenko prefer to speak the Transyanka dialect that incorporates aspect of Belarusian and Russian into the everyday language of speaking. ${ }^{185}$ However, Transyanka, is often looked down upon by Russian-speakers as being unsophisticated, and also negatively putdown as being not sufficiently 'Belarusian' by the 'nationalist' BPF, and many commentators utilizing National Identity explanations. ${ }^{186}$

However, National Identity claims regarding Russian language use are seriously compromised by evidence, which show that Russian-speaking Belarusians actually have strong Belarusian identities, and that just because they speak Russian, does not mean that they identify themselves as Russian. Overall, one should not 
associate a person's language choice with lack of national identity. As one interviewee pointed out, "Belarusians are not defined primarily by the language...We have a different mentality compared to Russians...we're not Russians, that's completely true, that's 100\% true...I speak Russian in my family, but I don't feel Russian."187 Moreover, one only needs to examine polls measuring national pride, which shows that most Russian-speakers identify first and foremost as Belarusians. For example, in a poll from 2000, 92\% of Belarusian-speakers identified Belarusian as their nationality, while $72 \%$ of Russian-speakers identified as Belarusian, for a combined overall total of $78 \%$ identifying their nationality as Belarusian. ${ }^{188}$

Overall, Belarusians did not see the widespread use of the Russian language as a cultural threat nor as culturally alien. Indeed, evidence suggests that the adoption of the Russian language or a mixture of Belarusian/Russian was largely voluntary and natural for most Belarusians. As one interviewee argued, "in the Soviet Union for people just to interact on the Union level, they needed to know Russian...and most of the time this was voluntary, and not assimilation....It was more an appropriation of language skills which shouldn't put it into the bin with real Russification." 189 Here, close cultural affinities were at play in influencing the voluntary adoption of Russian by Belarusians as their primary language, due to the similarities between the Belarusian and Russian languages. This resulted from strong historic cultural links shared by Belarusians with Russians, where most Belarusians continued to view Russia and any seeming aspects of Russification with little hostility.

A central problem lies in the black and white terms of how National Identity definitions are constructed, as being either strong or ambivalent. In reality, what these arguments miss is that Belarus has its own robust national identity. That there was a lack of national discord and high amounts of cultural cohesion in Belarus can be seen in the identity polls above, and other polls showing Belarusians tend not to view ethnic-minorities living in Belarus as a threat. ${ }^{190}$ Moreover, as one former prominent Belarusian journalist during the 1990s, Anatol Maisenya reported, "Belarus stood out against the background of the former USSR republics for the fact that there were no signs of national discord." 191 Thus, what National Identity arguments miss is that Belarus has its own coherent and unique national identity, which contains different ideas, contrary to normative definitions constructed by many observers that seek to wrongly pit Belarusians against Russians.

One contributing factor why National Identity arguments get it wrong, results from much of historical analysis of these explanations being cursory, and not looking in depth enough at the historical roots of identity, which leaves many questions unanswered and/or ignores important contradictory evidence. ${ }^{192}$ Most problematic, however, was that these explanations dismissed that these identities are primarily informed by the historic religious-cultural roots that are predominant in Belarus, ${ }^{193}$ which the findings here have shown to be the primary influencers of attitudinal preferences shaping Belarusian behavior.

Overall, a major problem is that most National Identity arguments have faced serious problems, due not only to the repeated tunnel vision on 'national identity,' without adequately acknowledging the preeminent role of political-culture, but also as result of a normative blindness caused by their completely understandable aversion to Lukashenko's illiberal, and authoritarian leadership style. However, as noted above, the values and behavior of Lukashenko have largely been in tune with the political-cultural worldviews of much of Belarusian society. Indeed, Belarusian worldviews favouring collectivism, a pro-Soviet/Russian orientation, and strong leadership have all been cultivated by Lukashenko, which helps explain his longevity, popular appeal and staying power.

\section{Conclusions}

The main findings of this paper have shown that political-culture has had a central influence on the patterns of political-economic development chosen by Belarus since 1991. Specifically, it was illustrated that the illiberal political-economic orientations found in Belarus were driven by its political-cultural worldviews, ways of life and historical memories, which were conditioned by its unique historical legacies relating to the Orthodox religiouscultural environment in which Belarus is historically situated. Moreover, such worldviews were crucial in shaping 
The Effects of Religious-Cultural Worldviews on the Lack of Political-Economic Liberalization in Belarus over Twenty Years since rise of Lukashenko

preferences favouring collectivist, communal, paternalistic, statist and authoritarian solutions to solve problems of political-economic development, even long after much of these religious-cultural worldviews had become seemingly secularized.

In doing so, this paper has revealed the serious issue of how out of step conventional wisdom was with what is actually happening on ground in Belarus, which is especially the case in regards to analysis about President Lukashenko, where analysts have since 1994 repeatedly made incorrect and premature assessments about what was viewed as the impending demise of Lukashenko. However, such predictions are premature, and it is likely that Lukashenko will retain his hold over Belarusian politics for the foreseeable future.

In response to the critiques regarding the protests after the December 2010 Presidential elections, it is important to point out that these were small protests, both in size and duration, compared to ones that had occurred in Ukraine during the Orange Revolution and Maidan Protests. Moreover, these protests were short-lived and not much has been heard since. While Lukashenko's voter support of $80 \%$ is accepted as being over inflated, it is also true that Lukashenko still would have succeeded had elections been totally free and fair, as he remained the most popular politician in country, with support in the 53\% range, as indicated in polls from December 2010 (see Figure 5). It should also be of no surprise that these protests were concentrated in Minsk, which is predominantly where most opposition to Lukashenko is located. Additionally, it is important to note that there was virtually no corresponding protests in centers outside of Minsk nor in rural areas of Belarus, where there is little grass-roots opposition, and which tend to be the hotbed of support for Lukashenko. ${ }^{194}$

While many commentators also expect huge change should Lukashenko's demise come, such assessments are problematic because these do not adequately examine the past history and traditions of Belarus that might point to the situation not radically changing in a liberal direction. Indeed, even by 2008 , it was reported "that there are no indications of a general public uprising or that the electorate is hungry for change." ${ }^{195}$ Thus, even when Lukashenko leaves office, or is forced from power, which seems unlikely in the near future, the end result of such a change will not necessarily result in Belarus experiencing comprehensive liberal reform.

First, most opposition forces remain extremely divided in outlook and orientation, especially in regards to specific concrete policy matters. Indeed, the Belarusian opposition is far from united in terms of visions of future economic policy and possibilities for reform. Moreover, only a small minority of the opposition actually advocates for extensive liberal reforms. Thus, the general absence of liberal values in the broader society tends to be mimicked at the elite opposition level, where opposition parties rarely make any concrete explanations of their economic policy proposals. Instead, many opposition factions, while favouring a return to democracy, are quite outspoken in their criticisms of groups advocating for liberal-shock therapy. Overall, most opposition parties favour a retention of many of the collectivistic and statist features, which have come to characterize Belarusian political-economic relations. As one interviewee mentioned, "the opposition is normally quite near to the government in their notions, and you cannot find much difference between them, with all taking an etatist approach, where the economy is, if not government controlled, then at least heavily government oriented."196

Furthermore, most opposition elites remain largely disconnected from the rest of society. From the comments of interviewees, one got the general sense that not only is the opposition out of touch with the worldviews and sentiments of the people, but also that many of the key opposition figures sound to be somewhat elitist. Certainly, this divide is further exacerbated by the fact that many opposition groups most often work with outside [Western] agencies, which does not always sit well with the anti-liberal attitudes of locals, particularly when it comes to some of the political-economic reforms being advocated. ${ }^{197}$

Such observations about the elitism of the opposition and its disconnect from society can be corroborated by news reports, which blamed the opposition's marginal status on their "questionable strategy that favoured political change from the top over a grassroots approach," which was problematic "when two-thirds of Belarusians believe the current political situation is safe and stable." 198 Because of the divisions characterizing Belarusian 
opposition, and the oppositions elitist attitudes towards society, there is a high probability that Lukashenko could be replaced by another strong authoritarian-type president, especially so since there is a tradition for paternalistic and authoritarian modes of political rule.

Alternatively, if democracy does develop, it is far from certain that a democratic regime would implement rapid liberal transformation, due to the absence of neo-liberal values amongst large segments of Belarusian society and elites. Indeed, several interviewees voiced there opinion that such prospects were unlikely, with some openly stating that they would be opposed to comprehensive liberal reforms that occurred in the Baltic States and countries such as Poland and Czech Republic. ${ }^{199}$ Additionally, most Belarusian tend to view the reforms in Russia and Ukraine, which were not even halfway at best, as being too much reform in the wrong direction. Indeed, both young and old Belarusians look on the instability and the corruption of oligarchs that was witnessed in Russian and Ukraine, with disfavour. ${ }^{200}$ Thus, even if the people would like more democracy opened up, it does not mean they favour unfettered liberalism in politics or the economy per se. Moreover, such factors as the historic lack of private property, a preference for collectivistic solutions, and favouritism for having a strong leader, which characterize Belarusian political-culture, all limit future prospects for comprehensive liberal reform. 
The Effects of Religious-Cultural Worldviews on the Lack of Political-Economic Liberalization in Belarus over Twenty Years since rise of Lukashenko

\section{Sources from Figures}

Independent Institute of Socio-Economic and Political Studies (IISEPS). (2000d). IISEPS News, Issue 4, 18 (December). http://www.iiseps.org/ebullet00-4.html.

IISEPS. (2001b). IISEPS News, Issue 2, 20 (June). http://www.iiseps.org/ebullet01-2.html.

IISEPS. (2001c). IISEPS News, Issue 3, 21 (September).http://www.iiseps.org/ebullet01-3.html.

IISEPS. (2001d). IISEPS News, Issue 4, 22 (December). http://www.iiseps.org/ebullet01-4.html.

IISEPS. (2002b). IISEPS News, Issue 2, 24 (June). http://www.iiseps.org/ebullet02-2.html.

IISEPS. (2002d). IISEPS News, Issue 4, 26 (December). http://www.iiseps.org/ebullet02-4.html.

IISEPS. (2003a). IISEPS News, Issue 1, 27 (March). http://www.iiseps.org/ebullet03-1.html.

IISEPS. (2004a). IISEPS News, Issue 1, 31 (March). http://www.iiseps.org/ebullet04-1.html.

IISEPS. (2004b). IISEPS News, Issue 2, 32 (June). http://www.iiseps.org/ebullet04-2.html.

IISEPS. (2004d). IISEPS News, Issue 4, 34 (December). http://www.iiseps.org/ebullet04-4.html.

IISEPS. (2005c). IISEPS News, Issue 3, 37 (September). http://www.iiseps.org/ebullet05-3.html.

IISEPS. (2006a). IISEPS News, Issue 1, 39 (March). http://www.iiseps.org/ebullet06-1.html.

IISEPS. (2006b). IISEPS News, Issue 2, 40 (June).http://www.iiseps.org/ebullet06-2.html.

IISEPS. (2006c). IISEPS News, Issue 3, 41 (September). http://www.iiseps.org/ebullet06-3.html.

IISEPS. (2007a). IISEPS News, Issue 1, 43 (January). http://www.iiseps.org/ebullet07-1.html.

IISEPS. (2007d). IISEPS News, Issue 4, 46 (December).http://www.iiseps.org/ebullet07-4.html.

IISEPS. (2008b). IISEPS News, Issue 2, 48 (June). http://www.iiseps.org/ebullet08-2.html.

IISEPS. (2008d). IISEPS News, Issue 4, 50 (December). http://www.iiseps.org/ebullet08-4.html.

IISEPS. (2009a). IISEPS News, Issue 1, 51 (March). http://www.iiseps.org/ebullet09-1.html.

IISEPS. (2011a). “Trends of Change in Belarusian Public Opinion.” April 31.

http://www.iiseps.org/etrend.html. 
IISEPS. (2011b). “Trends of Change in Belarusian Public Opinion.” June 30. http://www.iiseps.org/etrend.html.

IISEPS. (2015). “Trends of Change in Belarusian Public Opinion.” March 30. http://iiseps.org/old/etrend.html.

\section{Interviews}

Belarusian Governmental Official. Interview. Minsk, Belarus (March 23, 2010).

Belarusian Opposition Activist. Interview. Minsk, Belarus (April 1, 2010).

Belarusian Senior Journalist. Interview. Minsk, Belarus (April 5, 2010).

Belarusian Senior Academic. Interview. Minsk, Belarus (April 6a, 2010).

Belarusian Academic. Interview. Minsk, Belarus (April 6b, 2010).

Belarusian Opposition Leader/Former Presidential Candidate. Interview. Minsk, Belarus (April 7a, 2010).

Belarusian Senior Academic. Interview. Minsk, Belarus (April 7b, 2010)

Belarusian Journalist. Interview. Minsk, Belarus (April 8, 2010).

Latvian Government Official. Interview. Riga, Latvia (February 26b, 2010).

\footnotetext{
${ }^{1}$ Fukuyama, Francis. (1992). The End of History and the Last Man. New York: Simon and Schuster; Bierstecker, Thomas J. (1992). "The 'Triumph of Neoclassical Economics in the Developing World: Policy Convergence and Bases of Governance in the International Economic Order.” Ch. 4. In Governance Without Government: Order and Change in World Politics, ed. James N. Rosenau and Ernst-Otto Czempiel. Cambridge: Cambridge University Press. p. 102-131. Widespread assumptions about liberalcapitalist convergence fostered the impression and misunderstanding that comprehensive reforms were widespread and being conducted in most post-Soviet states. This criticism can be leveled at Stiglitz, Joseph E. (2002). Globalization and its Discontents. New York: W. W. Norton, for his primary focus on Russia, which lagged continually behind rapid reformers. Further widespread assumption of transformation was evident in the debate between "shock-therapists" and "gradualists" in the early 1990s. For "shocktherapists," see Lipton, David and Jeffrey D. Sachs. (1990). "Creating a Market in Eastern Europe: The Case of Poland." Brookings Papers on Economic Activity 20, 1: 75-147; Balcerowicz, Leszek. (1994). "Understanding Postcommunist Transitions.” Journal of Democracy 5, 4: 75-89; Winiecki, J. (1990). Resistance to Change in the Soviet Economic System. New York: Routledge. For "gradualists," see Przeworski, Adam. (1993). "Economic Reforms, Public Opinion, and Political Institutions: Poland and Eastern Europe in Comparative Perspective." In Economic Reforms in New Democracies: A Social Democratic Approach, ed. L. C. Bresser Pereira, J. M. Maravall, and A. Przeworski. Cambridge: Cambridge; Poznanski, Kazimierz Z. (2002). "The Crisis of Transition as a State Crisis." ch. 3. In Postcommunist Transformation and the Social Sciences, ed. F. Bönker, K. Müller, and A. Pickel. Oxford: Rowman and Littlefield.
}

${ }^{2}$ See Weber, Max. (1975). “The Social Psychology of the World Religions.” Ch. 11. In From Max Weber: Essays in Sociology, Translated, edited and with an introduction by H. H. Gerth and C. Wright Mills. New York: Oxford University Press; Weber, Max. (1978a). Economy and Society: An Outline of Interpretive Sociology, Volume 1, ed. Guenther Roth and Claus Wittich. Berkeley: University of California Press; Weber, Max. (1992). The Protestant Ethic and the Spirit of Capitalism. Translated by Talcott Parsons, with introduction by Anthony Giddens. New York: Routledge. 
The Effects of Religious-Cultural Worldviews on the Lack of Political-Economic Liberalization in Belarus over Twenty Years since rise of Lukashenko

\footnotetext{
${ }^{3}$ Berger, Peter L., and Thomas Luckmann. (1966). The Social Construction of Reality: A Treatise in the Sociology of Knowledge. New York: Doubleday \& Company., pp. 40-41, 92; Geertz, Clifford. (1973). The Interpretation of Cultures: Selected Essays. New York: Basic Books; Bourdieu, Pierre. (1990). The Logic of Practice. Translated by R. Nice. Stanford: Stanford University Press., pp. 52-65; Wittgenstein, Ludwig. (1958). Philosophical Investigations. Translated by G. E. M. Anscombe, $2^{\text {nd }}$ ed. New York: Macmillan; Putnam, Robert D. (1993). Making Democracy Work: Civic traditions in Modern Italy. Princeton: Princeton University Press; Hopf, Ted. (2009)." Identity Relations in the Sino-Soviet Split." Ch. 10. In Measuring Identity: A Guide for Social Scientists, eds. R. Abdelal, Y. M. Herrera, A. I. Johnston, and R. McDermott. Cambridge: Cambridge University Press., p. 280.
}

${ }^{4}$ Ross, Marc Howard. (1997). "Culture and Identity in Comparative Political Analysis." Ch. 3. In Comparative Politics: Rationality, Culture, and Structure, ed. M. I. Lichbach and A. S. Zucherman. Cambridge: Cambridge., p. 72. On culture as a way of life, see also Geertz. 1973, p. 89; Berger and Luckmann 1966, ch. 1; Braudel, Fernand. (1992). Civilization and Capitalism, $15^{\text {th }}-18^{\text {th }}$ Century, Volume III: The Perspective of the World. Berkeley: University of California Press., pp. 65-67; White, Stephen. (1979a). Political Culture and Soviet Politics. New York: St. Martin's Press., p. 164.

${ }^{5}$ Others sharing a 'strong' view of culture include, Elkins, David J., and Richard E. B. Simeon. (1979). "A Cause in Search of Its Effect, or What Does Political Culture Explain?" Comparative Politics, 11, 2: 127-45., p. 130; Pye, Lucien W. (1985). Asian Power and Politics: The Cultural Dimensions of Authority. Cambridge: Belknap Press; Eckstein, Harry. (1988). "A Culturalist Theory of Political Change." American Political Science Review, 82, 3: 789-804., p. 792; Almond, Gabriel A. (1991). A Discipline Divided: Schools and Sects in Political Science. London: Sage., p. 150; Braudel, Fernand. (1993). A History Of Civilizations. New York: Penguin; Hopf, Ted. (2002). Social Construction of International Politics: Identities and Foreign Policies, Moscow, 1955 and 1999. Ithaca: Cornell University Press.

${ }^{6}$ Thomson, Michael, Richard Ellis and Aaron Wildavsky. (1990). Cultural Theory. Boulder: Westview., pp. 22-23). See also, Hopf 2009, p. 296.

${ }^{7}$ For other's that agree that culture is not an outgrowth of existing material structure of power, see Hopf 2002, pp. 2, 3; Thelen, Kathleen. (2003). How Institutions Evolve: Insights from Comparative Historical Analysis." Ch. 6. In Comparative Historical Analysis and the Social Sciences, eds., J. Mahoney and D. Rueschemeyer. Cambridge: Cambridge University Press., p. 217.

${ }^{8}$ Parsons, Craig. (2007). How to Map Arguments in Political Science. Oxford: Oxford University Press., p. 100. See also, DiMaggio, Paul J. and Walter W. Powell. (1991). "Introduction.” In The New Institutionalism in Organizational Analysis, ed. Walter W. Powell and Paul J. DiMaggio. Chicago: The University of Chicago Press; Dobbin, Frank. (1994). Forging Industrial Policy: The United States, Britain, and France in the Railway Age. Cambridge: Cambridge; Geertz 1973.

${ }^{9}$ Parsons 2007, p. 75. See also, DiMaggio and Powell 1991, pp. 12-15; Hopf. 2002.

${ }^{10}$ Bourdieu, Pierre. (1977). Outline of a Theory of Practice. Translated by Richard Nice. Cambridge: Cambridge University Press., pp. 18, 21, 77, 177. See also, Weber 1978a, p. 320; Hopf 2002, p. 14; Berger and Luckmann 1966, p. 109; Powell, Walter W. (1991). "Expanding the Scope of Institutional Analysis." Ch. 8. In The New Institutionalism in Organizational Analysis, eds., Walter W. Powell and Paul J. DiMaggio. Chicago: University of Chicago Press., p. 192.

${ }^{11}$ Berger and Luckmann 1966, p. 109; Powell 1991, p. 192.

${ }^{12}$ Hopf 2002, p. 3. For other key works emphasizing the importance of everyday habits and practice in shaping behavior, see Bourdieu 1990, pp. 52-65; Bourdieu 1977; Adler, Emanuel. (2005). Communitarian International Relations: The Epistemic Foundations of International Relations. New York: Routledge; Wenger, Etienne. (1998). Communities of Practice: Learning, Meaning, and Identity. Cambridge: Cambridge University Press; Pouliot, Vincent. (2008). "The Logic of Practicality: A Theory of Practice of Security Communities." International Organization 62 (Spring): 257-288.

\footnotetext{
${ }^{13}$ Hopf 2002, p. 10.

${ }^{14}$ Berger and Luckmann 1966, pp. 50, 110.
} 
${ }^{15}$ This builds on Kirshner's argument that "ideas...can be self-confirming." Kirshner, Jonathan. (2003a). "The Inescapable Politics of Money." Ch. 1. In Monetary Orders: Ambiguous Economics, Ubiquitous Politics, ed. J. Kirshner. Ithaca: Cornell University Press., p. 15.

${ }^{16}$ As Smith points out, "the subjective perception and understanding of the communal past by each generation...is a defining element in the concept of [political]-cultural identity." Smith, Anthony D. (1992). "National Identity and the Idea of European Unity."

International Affairs, 68, 1: 55-76., p. 58.

${ }^{17}$ Kirshner 2003a, p. 14.

${ }^{18}$ Braudel 1993, p. 22-23. For others pointing to the importance of religion in shaping culture and politics, see Braudel 1992, pp. 6567; Weber 1975; Weber 1978a; Weber, Max. (1978b). Economy and Society: An Outline of Interpretive Sociology, Volume 2, ed. G. Roth and C. Wittich. Berkeley: University of California Press; Weber, Max. (1993). The Sociology of Religion. Introduction by Talcott Parsons. Foreword by Ann Swidler. Boston. Beacon Press; Huntington, Samuel P. (1996). The Clash of Civilizations and the Remaking of World Order. New York: Simon and Schuster., p. 70; Tocqueville, Alexis De. (2000). Democracy in America. Translated by H. Reeve. Toronto: Bantam Books., pp. 351-354, 530; Nettl, J. P. and R. Robertson. (1968). International Systems and the Modernization of Societies: The Formation of National Goals and Attitudes. London: Faber and Faber., pp. 152-155; Smith, Anthony D. (1991). National Identity. Reno: University of Nevada Press., pp. 6-7, 27-28, 62; Robertson, Roland. (1992). Globalization: Social Theory and Global Culture. London: Sage., pp. 42-43, 85-96; Wuthnow, R. (1993). Christianity in the Twenty-First Century: Reflections on the Challenges Ahead. Oxford: Oxford., p. 104; Clark, Peter D. (1999). How Religious, Political and Emotional Predispositions Affect the Prospects for Civil Society in Post-Soviet Belarus. Doctoral Dissertation. Cornell University; Seul, Jeffrey R. (1999). “'Ours Is the Way of God': Religion, Identity and Intergroup Conflict.” Journal of Peace Research, 36, 5: 553-569. However, this paper is important because religion has remained understudied by theorists of International Relations, International Political Economy, and Comparative Politics. Fox, Jonathan and Shmuel Sandler. (2004). Bringing Religion into International Relations. New York: Palgrave. This dismissal of religion is problematic as Casanova points out, because "theories...which systematically ignore this public dimension of modern religion are necessarily incomplete theories." Casanova, J. (1994). Public Religions in the Modern World. Chicago: Chicago University Press, p. 66.

${ }^{19}$ For discussion of importance of natural law and natural rights, see Weber 1978b, p. 867.

${ }^{20}$ Here it is important to refer to cultural maps, which place Belarus largely in the realm of Orthodox Christianity. See Huntington 1996, p. 159; Eberhardt, Piotr. (2004). "The Concept of Boundary between Latin and Byzantine Civilization in Europe.” Przeglad Geograficzny, 76, 2: 169-188., p. 184. For historical consensus that Belarus firmly belongs in the cultural realm of Russian Orthodox Christianity, see Plokhy, Serhii. (2006). The Origins of the Slavic Nations: Premodern Identities in Russia, Ukraine, and Belarus. Cambridge: Cambridge University Press., p. 93; Graham, Malbone W., Jr. (1927). New Governments of Eastern Europe. New York: Henry Holt \& Co., p. 6; Berdyaev, Nicholas. (1960). The Origin of Russian Communism. Ann Arbor: University of Michigan Press., pp. 8-9, 21-28; Lubachko, Ivan S. (1972). Belorussia under Soviet Rule, 1917-1957. Lexington: University Press of Kentucky., p. 4. See also, Kohn, Hans, ed. (1962). The Mind of Modern Russia: Historical and political thought of Russia's Great Age. New York: Harper Torch., p. 201; Pipes, Richard. (1979). Russia Under the Old Regime. New York: Peregrine., p. 266; Gray, Jack. (1979). "Conclusions." Ch. 9. In Political Culture and Political Change in Communist States, eds., Archie Brown and Jack Gray. New York: Holmes \& Meier., p. 258; Gerner, Kristian, and Stefan Hedlund. (1993). The Baltic States and the end of the Soviet Empire. London: Routledge., p. 179; Ioffe, Grigory. (2008). Understanding Belarus and How Western Foreign Policy Misses the Mark. Lanham: Rowman and Littlefield., p. 68.

${ }^{21}$ Hopf 2009, pp. 282-283, 285-286, 291, 299; Hopf 2002, p. 3. To avoid selection bias, it was necessary to consult from a diverse set of sources and historiographic schools to ensure a sample that is representative. Lustick, Ian S. (1996). "History Historiography, and Political Science: Multiple Historical Records and the Problem of Selection Bias." American Political Science Review 90, 3: 605-618, p. 605; Mahoney, James, and Dietrich Rueschemeyer. (2003). "Comparative Historical Analysis: Achievements and Agendas." Ch. 1. In Comparative Historical Analysis in the Social Sciences, eds., J. Mahoney and D. Rueschemeyer. Cambridge: Cambridge., p. 18, no. 40. See also, George, Alexander L., and Andrew Bennett. (2005). Case Studies and Theory Development in the Social Sciences.

Cambridge: MIT Press., pp. 91, 95.

${ }^{22}$ Hopf 2009, p. 299. 
The Effects of Religious-Cultural Worldviews on the Lack of Political-Economic Liberalization in Belarus over Twenty Years since rise of Lukashenko

\begin{abstract}
${ }^{23}$ Braudel 1993.
${ }^{24}$ Hopf 2002.

${ }^{25}$ Sylvan, Donald A. and Amanda K. Metskas. (2009). "Tradeoffs in Measuring Identities: A Comparison of Five Approaches." Ch. 3. In Measuring Identity: A Guide for Social Scientists, eds., R. Abdelal, Y. M. Herrera, A. I. Johnston, and R. McDermott. Cambridge: Cambridge University Press., p. 83). Interviewees names were kept anonymous, in adherence with the guidelines approved by the Research Ethics Board at Dalhousie University.
\end{abstract}

${ }^{26}$ For examples of societal preferences shaping elite perceptions and behavior even in authoritarian contexts see, Hopf 2002, pp. 3233; Hopf 2009, p. 284; Sylvan and Metskas 2009, p. 83.

${ }^{27}$ Keep, John L. H. (1976). The Russian Revolution: A Study in Mass Mobilization. New York: W. W. Norton., p. 6. Weber also argued that in the village commune, "firmly rooted concepts of natural law [were] at work." Weber, Max. (1995). The Russian Revolutions, Translated and Edited by Gordon C. Wells and Peter Baehr. Cambridge: Polity Press., pp. 89, 64-63; Weber, Max. (1964). The Sociology of Religion. Boston: Beacon Press., pp. 136, 176.

${ }^{28}$ Berdyaev 1960, p. 17. For consensus, see Vakar, Nicholas. (1961). The Taproot of Soviet Society. New York: Harper and Brothers., pp. 38, 46; Keep 1976, p. 7; Pipes, Richard. (1999). Property and Freedom. New York: Vintage Books., pp. xi, 158-162, 198; Pipes, Richard. (2005). Russian Conservatism and Its Critics: A Study in Political Culture. New Haven: Yale., p. 10.

${ }^{29}$ For consensus on traditions and values of private property being culturally alien, see Pipes 1979, pp. 266-267; Dovnar-Zapolsky, M. (1988). "The Basis of White Russia's State Individuality." In Byelorussian Statehood: Reader and Bibliography, eds. Vitaut Kipel and Zora Kipel. New York: Byelorussian Institute of Arts and Sciences., p. 46; Pipes 1999, p. xi, 158-162. That there are no widespread traditions of private land ownership was mentioned by several during interviews. Belarusian Opposition Activist. Interview. Minsk, Belarus (April 1, 2010); Belarusian Journalist. Interview. Minsk, Belarus (April 8, 2010).

${ }^{30}$ Vakar 1961, pp. 34, 38. On authoritarianism and absolutism of head of peasant families being rooted in natural law, which promoted the collective and habits of passivity, see Vakar, Nicholas. (1956). Belorussia: The Making of a Nation. Cambridge: Harvard., pp. 2021, 23; Pipes 1999, p. 204; White 1979a, pp. 58-59; Gsovski, Vladimir. (1959). "The Soviet Union." Ch. 58, in Government, Law and courts in the Soviet Union and Eastern Europe: Volume 2, eds., V. Gsovski and K. Grzybowski. London: Stevens \& Sons., pp. 16071608. Observations on historic patterns of passivity, and that the family was key in socializing such habits was mentioned by several interviewees. Belarusian Opposition Activist. Interview. Minsk, Belarus (April 1, 2010); Belarusian Academic. Interview. Minsk, Belarus (April 6b, 2010); Belarusian Opposition Leader/Former Presidential Candidate. Interview. Minsk, Belarus (April 7a, 2010); Belarusian Senior Academic. Interview. Minsk, Belarus (April 7b, 2010).

${ }^{31}$ Vakar 1961, pp. 32, 47. For consensus on lack of individual rights, see Vakar 1956, pp. 17, 19-21; Male, D. J.. (1971). Russian Peasant Organization Before Collectivization. Cambridge: Cambridge; Robinson, Geroid T. (1972). Rural Russia under the Old Regime: A History of the Landlord-Peasant World and a Prologue to the Peasant Revolution of 1917. $3^{\text {rd }}$ Printing. Berkeley: University of California., pp. 34-35, 125; Keep 1976, p. 9; Weber 1995, pp. 77, 91; Pipes 1999, pp. 184-186.

${ }^{32}$ For consensus on rule of law traditions being alien, see Vakar 1961, p. 48; Vakar 1956, pp. 24-25; Robinson 1972, pp. 41-42; Pipes 1979, pp. 154-158, 267; Pipes 1999, p. 205.

${ }^{33}$ Pipes 2005, p. 10. See also footnotes no. 28 above.

${ }^{34}$ Vakar 1961, p. 40. Pipes also pointed out the "contributing factor to the rise of an extreme form of autocracy was the Orthodox religion." Pipes 2005, p. 12. See also Pipes 1979, pp. 161, 221-222, 232-233. For others that agree that Orthodox religious doctrines were key in promoting habits of passivity and legitimizing authoritarianism, see Berdyaev 1960, pp. 8-9; Kohn 1962, p. 266; White, Stephen. (1979b). "The USSR: Patterns of Autocracy and Industrialism." Ch. 2. In Political Culture and Political Change in Communist States, eds., A. Brown and J. Gray. New York: Holmes \& Meier., pp. 29-30; White 1979a, pp. 27, 38; Graham 1927, p. 15; Weber 1993, p. 179. Several interviewees mentioned passivity and preferences for authoritarianism being rooted in Orthodoxy. Belarusian Academic. Interview. Minsk, Belarus (April 6b, 2010); Belarusian Senior Academic. Interview. Minsk, Belarus (April 7b, 2010). 
${ }^{35}$ On the Grand Duchy's elites being largely Poles or Polonized, see Vakar 1956, pp. 45, 64; Lubachko 1972, p. 3; Mihalisko, Kathleen J. (1997). "Belarus: Retreat to Authoritarianism." In Democratic Changes and Authoritarian Reactions in Russia, Ukraine, Belarus, and Moldova, ed. K. Dawisha and B. Parrott. Cambridge: Cambridge., p. 227; Novina, Anton. (1988). "Building the State." In Byelorussian Statehood, eds. V. Kipel and Z. Kipel. New York: Byelorussian Institute of Arts and Sciences. [Originally published. (1918). in Varta, Miensk, 1, 1 (October): 30-32]., p. 67; Zaprudnik, Jan, and Michael Urban. (1997). "Belarus: From Statehood to Empire.” Ch. 7. In New States, New Politics, eds. I. Bremmer and R. Taras. Cambridge: Cambridge., p. 277.

${ }^{36}$ For example, $70 \%$ of Belarusians had been brought under the dominion of the Uniate Church from 1569 to 1839 Ioffe 2008 , p. 38.

${ }^{37}$ For consensus on forced Polonization via conversion to Uniate Church, and that the Uniate Church can be viewed more as a Polish cultural institution in Belarusian areas, see Zaprudnik, Jan. (1993). Belarus: At a Crossroads in History. Boulder: Westview., pp. 34, 38; Lubachko 1972, p. 3; Anonymous. (1988). "A Summary Glance into the History and the Situation of White Russia." In

Byelorussian Statehood, eds. V. Kipel and Z. Kipel. New York: Byelorussian Institute of Arts and Sciences. [Printed in 1919, in Eastern Europe, Paris, 2 (September 2): 45-49]., p. 126; Mihalisko 1997, p. 229; Marples, David R. (1999a). Belarus: A Denationalized Nation. Amsterdam: Harwood.,

p. 1; Snyder, Timothy. (2003). The Reconstruction of Nations: Poland, Ukraine, Belarus, 1569-1999. New Haven: Yale University Press., p. 45.

${ }^{38}$ Zaprudnik 1993, pp. 19, 24.

${ }^{39}$ Dovnar-Zapolsky 1988, pp. 42-43, 50.

${ }^{40}$ Vakar 1956, pp. 60-61, 45, 64. Lubachko also points out that "The Lithuanian, Belorussian peasantry retained their languages and national customs, thus becoming a barrier to the solid establishment of Polish nationality." Lubachko 1972, p. 4. See also Anonymous 1988, p. 125.

${ }^{41}$ Several noted that Belarusians looked towards Russia for protection Vakar 1956, p. 62; Dovnar-Zapolsky 1988, p. 43; Zaprudnik, Jan. (1994). "Development of Belarusian National Identity and its Influence on Belarusian Foreign Policy." In National Identity and Ethnicity in Russia and the New States of Eurasia, ed. R. Szporluk. London: M.E. Sharpe., p. 141.

${ }^{42}$ By the $16^{\text {th }}$ century, the percentage of land owned by Polish landlords had increased to $65 \%$, with also an additional $5 \%$ belong to the church Zaprudnik 1993, p. 24.

${ }^{43}$ By the 1890 s, $34 \%$ to $40 \%$ of land was held communally, around 5\% held by the state and church, while much of the rest around $60 \%$ was held in private holdings. See Vakar 1956, p. 32; Zaprudnik 1993, p. 46, 55; Gershenkron, Alexander. (1968). Continuity in History and other Essays. Cambridge: Harvard., p. 185; Watters, F. M. (1968). "The Peasant and the Village Commune." Ch. 5. In The Peasant in Nineteenth-Century Russia, ed. W. S. Vucinich. Stanford: Stanford University., p. 146.

${ }^{44}$ For examples of Belarusians viewing Polish landlords as oppressors, see Zaprudnik, Jan. (1988). "The National Consciousness of the Byelorussians and the Road to Nationhood.” In Byelorussian Statehood, eds. V. Kipel and Z. Kipel. New York: Byelorussian Institute of Arts and Sciences., p. 11; Vakar 1956, pp. 30-31, 66; Lubachko 1972, pp. 31, 6-7,10; Palisander, Heb. (1988). "The WhiteRussians: A Nation driven back into the Middle Ages Under Muscovite Rule.” In Byelorussian Statehood, eds. V. Kipel and Z. Kipel. New York: Byelorussian Institute of Arts and Sciences., p. 34; Varonka, Jazep. (1988). "The Byelorussian Movement from 1917 to 1920: A Short Review.” In Byelorussian Statehood, eds. V. Kipel and Z. Kipel. New York: Byelorussian Institute., p. 121; Zaprudnik and Urban 1997, p. 277; Urban, Michael E. (1989). An Algebra if Soviet Power: Elite Circulation in the Belorussian Republic, $1966-$ 86. Cambridge: Cambridge., p. 10.

${ }^{45}$ As Vakar points out, before 1917, 87\% of Belarusian farms were "closely tied to the village." Vakar 1956, pp. 17, 19. For consensus on Emancipation of 1861 reinforcing traditional collectivist political-cultural bodies such as the village commune for the majority of Belarusians, see Zaprudnik and Urban 1997, p. 280; Vakar 1961, p. 51; Robinson 1972, pp. 71, 118-119; Gershenkron 1968, p. 209; Keep 1976, p. 9; Dovnar-Zapolsky 1988, p. 46; Pipes 1979, p. 164-165; Pipes 1999, p. 203; Ioffe, Grigory, Tatyana Nefedova, and Illya Zaslavsky. (2006). The End of Peasantry? The Disintegration of Rural Russia. Pittsburgh: Pittsburgh University Press., pp. 1011; Marples 1999a, p. 2. 
The Effects of Religious-Cultural Worldviews on the Lack of Political-Economic Liberalization in Belarus over Twenty Years since rise of Lukashenko

\begin{abstract}
${ }^{46}$ For examples of Bolshevik inspired rural revolt, and examples of collectivistic land seizures, see Pipes, Richard. (1968). The Formation of the Soviet Union: Communism and Nationalism, 1917-1923. Revised Edition. New York: Atheneum., p. 152; Lubachko 1972, pp. 11, 15, 23; Gill, Graeme J. (1979). Peasants and Government in the Russian Revolution. New York: Harper and Row., p. 190-191. For evidence of Bolsheviks popular appeal, see Mienski, J. (1988). "The Establishment of the Belorussian SSR." In Byelorussian Statehood, eds. V. Kipel and Z. Kipel. New York: Byelorussian Institute. [Originally published (1955). Belarusian Review, Munich, 1: 5-33]., pp. 143, 156; Varonka 1988, p. 105. Zaprudnik (1993), who disputes the strength of Bolsheviks (pp. 1819), also notes that "the rural areas were dominated by the Socialist Revolutionaries" (p. 79).
\end{abstract}

${ }^{47}$ Berdyaev 1960, pp. 140-141, 135-136, 165. For Bolshevik support amongst Belarusians, and evidence of appeal of Communist ideas to their collectivistic political-culture, see Vakar 1961, pp. 37, 56; Vołacič, M. (1956). "The Curzon Line and Territorial Changes in Eastern Europe.” Belorussian Review, 3: 37-72., p. 44; Lubachko 1972, pp. 7-8; Robinson 1972, p. 143; Kohn 1962, pp. 233, 252-255; Nedasek, N. (1988a). "Bolshevism in the Revolutionary Movement in Byelorussia." In Byelorussian Statehood, eds. V. Kipel and Z. Kipel. New York: Byelorussian Institute. [Originally published (1956), in Research Materials of the Institute for the Study of the USSR, Munich. 1, 25: 143-145]., p. 57; Pipes 1999, p. 205; Weber 1995, p. 100. Ioffe praises Berdyaev and Vakar on roots of Communism and notes that such assessments are applicable to Belarus Ioffe et al 2006, p. 17; Ioffe 2008, pp. xiii, 136-138.

${ }^{48}$ For evidence of Bolsheviks popular growth to the detriment of more nationalist groups, and the strong appeal of the socialistrevolutionary message emanating from Russian revolutionary groups, which appealed to Belarusians of the younger generations, and that both the Belarusian and Russian political groups promoted similar goals, see Vakar 1956, pp. 85, 97; Pipes 1968, pp. 73-75; Lubachko 1972, pp. 9, 18; Zacharka, Vasil. (1988). "The Major Events in the Byelorussian Movement.” In Byelorussian Statehood, eds. V. Kipel and Z. Kipel. New York: Byelorussian Institute. [Key figure in Belarusian Democratic Republic (BDR) and BDR in Exile. Originally published in the 1920s]., pp. 78-79, 95-96; Urban 1989, p. 12; Zaprudnik 1993, p. 67.

${ }^{49}$ For evidence of such nationalist goals being promoted by both political factions noted above, see Vakar 1956, pp. 97-98, 138-139; Pipes 1968, pp. 11-12, 73-74; Mienski 1988, p. 141; Zacharka 1988, pp. 78-79.

${ }^{50}$ For more on above points, see Zacharka 1988, p. 97; Council (Rada) of the Byelorussian Democratic Republic. (1988). "Constituent Charters [1918]." Translated by T. E. Bird and J. Zaprudnik, in Byelorussian Statehood, eds. V. Kipel and Z. Kipel. New York: Byelorussian Institute., p. 133; Marples 1999a, pp. 3-4; Pipes 1968, pp. 151-152. Vakar notes that the BDR, regardless of its lack of popularity, has for some self-proclaimed 'nationalists,' "grown into a heroic legend," even though such historical memories "may sometimes be at odds with historical truth." Vakar 1956, pp. 105-106.

${ }^{51}$ As one interviewee noted, "if we see how much was done in the BSSR, even for ethnic majority development, we see that it was really even affirmative action.” Belarusian Journalist. Interview. Minsk, Belarus (April 8, 2010). For numbers pointing to advancements of ethnic-Belarusians control of decision-making, and arguments that policies acted as 'affirmative action,' see Martin, Terry. (2001). The Affirmative Action Empire: Nations and Nationalism in the Soviet Union, 1923-1939. Ithaca: Cornell., p. 261). For additional numbers, and consensus on cultural advancements of Belarusification, see Vakar 1956, pp. 140-141; Lubachko 1972, pp. 70, 85-88, 91; Zaprudnik 1993, pp. 76-77, 80; Snyder 2003, p. 65.

${ }^{52}$ Male 1971, pp. 24-25. Others have put the amount of land being farmed by Belarusian farmsteads at 40\%. Lubachko 1972, p. 73. However, claims of private holdings should be taken with a degree of skepticism, and should not be equated with Western traditions of private farming. Belarusian peasants did not also directly own the land in the area designated as private landholdings, since the state having nationalized the land, had merely granted small tenure rights to peasants, but retained ultimate collective ownership over its long-term use.

${ }^{53}$ See Lubachko 1972, pp. 97, 103; Vakar 1956, p. 151. One should note that collectivization moved fastest in the eastern provinces of Mogilev and Mazyr, where up to $80 \%$ had been collectivized by 1930, owing to the fact that this region historically was a stronghold of the communal village. Marples 1999a, p. 10.

${ }^{54}$ Vakar 1961, pp. 37, 56. Vakar also observed that "the [collectivist] principle,... had been known in Belorussia long before the Soviets." Vakar 1956, p. 22. For consensus on appeal of collectivization, and active involvement of peasants, see Berdyaev 1960, pp, 135-136, 140-141, 165; Robinson 1972, p. 143; Male 1971, p. 1; Shragin, Boris. (1978). The Challenge of the Spirit. Translated by P. S. Falla. New York: Alfred A. Knopf., pp. 115-116; Ioffe et al 2006, p. 13; Weber 1995, p. 89. 


\begin{abstract}
${ }^{55}$ Compared to Latvia and the Baltic States, where there is widespread condemnation of collectivization and descriptions of popular resistance, little is mentioned about resistance to collectivization across Belarusian historical literature. For brief mentions of resistance and deportations of Kulaks, see Lubachko 1972, pp. 97, 100, 103; Vakar 1956, p. 148. Still these authors only give a brief mention of resistance. The fact that most only mention the resistance in one sentence and do not give extensive detail, such as that found in Baltic histories, suggests that such resistance might have been just sporadic, and neither as popular, nor widespread. Further contradictory evidence is provided by Savchenko, who noted "although Byelorussia was subjected to collectivization in the thirties, the policy was conducted less brutally than in many other parts of the USSR." Savchenko, Andrew. (2000). Rationality, Nationalism and Post-Communist Market Transformations: A Comparative Analysis of Belarus, Poland and the Baltic States. Aldershot: Ashgate., p. 95.
\end{abstract}

${ }^{56}$ Some have categorized Stalin's crimes against Belarusians as 'genocide,' where an estimated 250,000-300,000 perished executionstyle, such as in Kurapaty outside Minsk, or as a result of being deported to Soviet prison camps. See Zaprudnik 1993, pp. 86-88, 132; Mihalisko, Kathleen. (1991). “The Popular Movement in Belorussia and Baltic Influences.” Ch. 10. In Toward Independence, ed. J. A. Trapans. Boulder: Westview Press., pp. 126-127. Others put the number of Belarusians who perished at 2 million Mihalisko 1997, p. 232. See also, Kabysh, Symon. (1988). "Genocide of the Belorussians." In Byelorussian Statehood, eds. V. Kipel and Z. Kipel. New York: Byelorussian Institute of Arts and Sciences., pp. 231-234. While not labeling these as 'genocide,' Vakar gives a well-detailed description of the extent of Stalin's purges, where few remained except those like Janka Kupala and Jakub Kolas. Vakar 1956, pp. 146-150.

${ }^{57}$ Marples, David R. (2004). “The Prospects for Democracy in Belarus.” Problems of Post-Communism 51, 1: 31-42., p. 32. Even Zaprudnik noted that during the Stalinist period, "the development of this consciousness remained busy." Zaprudnik and Urban 1997, p. 283. Widespread claims of 'genocide' from diverse historiographic schools, such as those consistently found in Latvian literature, are not similarly found in Belarusian historical literature.

${ }^{58}$ Guthier, Steven L. (1977a). "The Belorussians: National Identification and Assimilation, 1897-1970: Part 1, 1897-1939.” Soviet Studies, 29, 1: 37-61., p. 59. For numbers illustrating continued Belarusification in the BSSR, regardless of purges between 19261939, see Martin 2001, pp. 380, 382, 384. Also, it should be noted that the overall population of Belarusians in the BSSR increased by $30 \%$ in the period from 1926-1939. Medvedev, Roy A. (1979). On Stalin and Stalinism. Translated by Ellen de Kadt. Oxford: Oxford University Press., p. 75.

${ }^{59}$ Vakar 1956, pp. 147, 150, 153.

${ }^{60}$ For religious persecution of Belarusians, see Vakar 1956, pp. 121-122, 130-131; Lubachko 1972, p. 135; Marples 1999 a, p. 7.

${ }^{61}$ For examples of coerced Polish assimilation in culture, language and education, and imprisonment of Belarusian elites, see speech of B. Taraškevič in the Polish Sejm (June 6, 1924), in Vakar 1956, pp. 123-124, 125, 130-131. For consensus, see Lubachko 1972, pp. 134-137; Zaprudnik 1993, p. 83; Jaremicz, F. (1988). "White Russia: Its Present Political Situation and Its Aim.” In Byelorussian Statehood, eds. V. Kipel and Z. Kipel. New York: Byelorussian Institute of Arts and Sciences. [Speech by White Russian Deputy in the Polish Parliament (1927). Originally in The Whiteruthenian Tribune, Chicago, 2 (1928)]., p. 222; Zaprudnik and Urban 1997, pp. 282-283; Snyder 2003, p. 65.

${ }^{62}$ Urban 1989, pp. 12-13. See also quote from Josef Lewandowski, in Zaprudnik 1993, pp. 75, 82. Some have described the cultural discrimination and attempts at Polonization, as worse than all attempts at cultural Russification under the USSR. Lubachko 1972, pp. 127, 135; Guthier, Steven L. (1977b). "The Belorussians: National Identification and Assimilation, 1897-1970: Part 2, 1939-1970." Soviet Studies, 29, 2: 270-283., p. 282. See also Vakar 1956, pp. 121-124, 130-131; Vołacič 1956, p. 68; Guthier 1977a, p. 60; Iwanow, Mikołaj. (1991). "The Byelorussians of Eastern Poland under Soviet Occupation, 1939-1941." Ch. 14. In The Soviet Takeover of the Polish Eastern Provinces, 1939-41, ed. K. Sword. New York: St. Martin's., p. 258; Zaprudnik and Urban 1997, p. 282; Magdziak-Miszewska, Agnieszka. (2002). "Belarus: Polands Strange Neighbor." Ch. 14, in Independent Belarus, eds. M. M. Balmaceda, J. I. Clem and L. L. Tarlow. Cambridge: Harvard., p. 346.

${ }^{63}$ Zaprudnik 1993, pp. 83-84, 85-86. For consensus on economic discrimination, and serf-like conditions, see Vakar 1956, pp. 123, 132-133; Lubachko 1972, pp. 132-133, 136; Jaremicz 1988, pp. 222-223. 
The Effects of Religious-Cultural Worldviews on the Lack of Political-Economic Liberalization in Belarus over Twenty Years since rise of Lukashenko

${ }^{64}$ For consensus on strong pro-socialist, pro-Communist and pro-Soviet orientation, see Vakar 1956, pp. 125-128; Iwanow 1991, p. 258; Urban 1989, p. 13; Zaprudnik 1993, p. 84; Zaprudnik and Urban 1997, pp. 282-283; Lubachko 1972, p. 137. Such historical memories were mentioned also by one Belarusian Journalist. Interview. Minsk, Belarus (April 8, 2010).

${ }^{65}$ Negative historical memories of Polish rule were mentioned by several interviewees. Belarusian Senior Academic. Interview. Minsk, Belarus (April 7b, 2010); Belarusian Journalist. Interview. Minsk, Belarus (April 8, 2010). See also, Lubachko 1972, p. 133.

${ }^{66}$ Vakar 1956, p. 156. See also Lubachko 1972, p. 140; Magdziak-Miszewska 2002, p. 346.

${ }^{67}$ Vakar 1956, p. 185. On lack of retribution towards remaining Soviet officials, see Ibid., p. 174; Vakar 1961, p. 43. On feelings of positive indifference to the initial German invasion, see Vakar 1956, pp. 172, 175; Lubachko 1972, pp. 146; Zaprudnik 1993, p. 95; Marples 1999a, p. 15. For eyewitness accounts, see Guderian, Heinz. (1952). Panzer Leader. Translated by C. Fitzgibbon. New York., pp. 193-194.

${ }^{68}$ Vakar 1956, pp. 173-174, also 180-181, 183. For consensus on revival of communal patterns, see Urban 1989, p. 13.

${ }^{69}$ For consensus on grass-roots, mass popularity, and local autonomy, see Vakar 1956, pp. 192, 203; Mihalisko 1997, p. 233; Zaprudnik and Urban 1997, p. 284; Savchenko 2000, p. 97.

${ }^{70}$ Reppert, John C. (2002). "The Security Dimension in the Future of Belarus." Ch. 10, in Independent Belarust, eds. M. M. Balmaceda, J. I. Clem and L. L. Tarlow. Cambridge: Harvard., p. 266. On above themes motivating guerrillas, such as religion, Soviet patriotism, and cultural kinship with Russia, see Vakar 1956, pp. 197-198; Lubachko 1972, pp. 156-157; Marples 2004, p. 33.

${ }^{71}$ Such positive views of Belarusians guerillas and Soviet nostalgia were mentioned by several interviewees. One referred to Belarus as being "a partisan republic.” Belarusian Academic. Interview. Minsk, Belarus (April 6b, 2010); Belarusian Opposition Leader/Former Presidential Candidate. Interview. Minsk, Belarus (April 7a, 2010). Evidence of partisan struggle and historical memories of victory in WWII helping to reinforce pro-Soviet attitudes and BSSR patriotism, are found in Mihalisko 1997, p. 233; Urban 1989, pp. 14-15; Sahm, Astrid. (1999). "Political Culture and National Symbols; Their Impact on the Belarusian NationBuilding Process.” Nationalities Papers, 27, 4: 649-660., p. 653; Zaprudnik and Urban 1997, pp. 283-284. Marples 1999a, pp. 17-18.

${ }^{72}$ For consensus on such leadership attributes, and rural roots of BSSR leaders, see Urban 1989, pp. 13-14. On paternalistic style, see Silitski, Vitali. (2006a). "Still Soviet? Why Dictatorship Persists in Belarus." Harvard International Review (Spring): 46-54., p. 48; Savchenko 2000, p. 97.

${ }^{73}$ Kuzio, Taras, and Marc Nordberg. (1999). "Nation and State Building, Historical Legacies and National Identities in Belarus and Ukraine: A Comparative Analysis." Canadian Review of Studies in Nationalism 26: 69-90., pp. 72, 78. Moscow had a large amount of trust in the Belarusian leadership of the BSSR, signaling a significant degree of cultural kinship between ethnic-Belarusians in Minsk, and ethnic-Russians in Moscow, since the national-communist of Belarus were allowed to stay in power, whereas in many other republics, as seen with Latvia, national communist figures were thoroughly purged. Here, it should be noted that the promotion of Belarusian nationalism and national identity by BSSR authorities was not frowned upon by Moscow. See Vakar 1956, p. 214. Zaprudnik also acknowledges the promotion of national pride by Soviet authorities, pointing to Belarusian cosmonaut Piotr Klimuk reading the poetry of Belarusian poet Jakub Kolas during a 1975 space flight. Zaprudnik 1993, p. 110.

${ }^{74}$ Urban 1989, pp. 160-161, no. 56. Even explicit national identity theorists, who argue that contemporary Belarus lacks a strong national identity, also make contradictory arguments that actually point to the presence of a robust national identity amongst these leaders. This is seen where Savchenko points to the key importance of the "commitment of the Belarusian leaders to the welfare of their republic, their sense of responsibility to the local population... together with the ability to attain their goals." Savchenko 2000, p. 97. Additionally, Marples' notes that while figures such as Mazurov and Masherov were loyal Soviet leaders, they were also strong in "pursu[ing] republican interests," and [working...to secure advancement for their native republic," doing so at times where they were not always popular with Moscow. Marples 1999a, pp. 19-20, 22, 65. Others point out that these leaders "were able to promote a...version of Belarusian national identity," which "fram[ed] national identity in terms not antagonistic to Moscow," and which "was no small achievement." Zaprudnik and Urban 1997, p. 284. See also footnote no. 75 below on these leaders popularity. 
${ }^{75}$ Independent Institute of Socio-Economic and Political Studies (IISEPS). (2008b). IISEPS News, Issue 2, 48 (June).

http://www.iiseps.org/ebullet08-2.html. Only Peter the Great, Alexander Lukashenko, and Vladimir Putin came close to these numbers in these polls. For further consensus that these leaders were popular, see Mihalisko 1997, p. 237; Marples 1999a, p. 22; Marples, David R. (2003). "History and Politics in post-Soviet Belarus." Ch. 2. In Contemporary Belarus: Between Democracy and Dictatorship, ed. E. A. Korosteleva, C. W. Lawson and R. J. Marsh. New York: Routledge., pp. 22-25; Eke, Steven M., and Taras Kuzio. (2000). "Sultanism in Eastern Europe: The Socio-Political Roots of Authoritarian Populism in Belarus." Europe-Asia Studies, 52, 3: 523-547., p. 539; Economist. (1992). "Bewildered." The Economist, January 25, 46-48.

${ }^{76}$ Vakar 1961, p. 57.

${ }^{77}$ Ibid., p. 58. See also, Eke and Kuzio 2000, p. 540. Most Soviet elite also came from rural backgrounds where patriarchal and collectivistic worldviews were strongly rooted. As a result, the Soviet "ruling class...instinctively modeled itself on the village strong man.” Pipes 1979, p. 141.

${ }^{78}$ High levels of pro-Soviet nostalgia, was mentioned by several interviewees. Belarusian Opposition Leader/Former Presidential Candidate. Interview. Minsk, Belarus (April 7a, 2010); Belarusian Senior Academic. Interview. Minsk, Belarus (April 7b, 2010); Belarusian Journalist. Interview. Minsk, Belarus (April 8, 2010). For further consensus, see Maisenya, Anatol. (1997). The Land of Unrealised Hopes: A Portrait of Time and a Portrait of Man. Minsk: National Centre for Strategic Initiatives., p. 163; Mihalisko 1997, p. 259; Kuzio and Nordberg 1999, p. 72; Marples 1999a, p. 23; Eke and Kuzio 2000, pp. 537-538; Gricius, Algirdas. (2002). "Lithuania and Belarus: Different Paths on the Way Back to the Future." Ch. 13, in Independent Belarus, eds. M. M. Balmaceda, J. I. Clem and L. L. Tarlow. Cambridge: Harvard., p. 323; Ioffe 2008, p. xviii.

${ }^{79}$ Zaprudnik and Urban 1997, p. 285. See also, Urban 1989, pp. 50-57, 60, 140. Similar observations were mentioned by one Belarusian Journalist. Interview. Minsk, Belarus (April 8, 2010). For consensus on self-governing characteristics of BSSR, see Hill, Ronald J. (2005). "Post-Soviet Belarus: In Search of Direction." Ch. 1. In Postcommunist Belarus, eds. S. White, E. Korosteleva, and J. Löwenhardt. Lanham: Rowman \& Littlefield., p. 2.

${ }^{80}$ Zaprudnik 1993, pp. 103, 110. On reinforcing pride and national identification, see Taagepera, Rein. (1973). "Dissimilarities Between the Northwestern Soviet Republics." in Problems of Mininations: Baltic Perspectives, eds. Arvids Ziedonis, Jr., Rein Taagepera and Mardi Valgemäe. San Jose: Association for the Advancement of Baltic Studies., pp. 78-79). On foreign affairs, see also footnote no. 79 above.

${ }^{81}$ Rural membership in the BCP far outpaced urban members, which amounted to $11.6 \%$ of the party in 1945, climbing to only $57.1 \%$ by 1978. Urban 1989, p. 15. For 1989 numbers, see Zaprudnik 1993, p. 137.

${ }^{82}$ See polls in Rose, Richard and Christian Haerpfer. (1994). New Democracies Barometer III: Learning from what is Happening, Number 230. Glasgow: Centre for the Study of Public Policy., appendix, table 77; Rose, Richard. (1995). New Baltic Barometer II: A Survey Study. Studies in Public Policy, Number 251. Glasgow: Centre for the Study of Public Policy., p. 60; Rose, Richard and Christian Haerpfer. (1996). New Democracies Barometer IV: A 10-Nation Survey, Number 262. Glasgow: Centre for the Study of Public Policy., p. 88; Rose, Richard and Christian Haerpfer. (1998). New Democracies Barometer V: A 12-Nation Survey. Studies in Public Policy, Number 306. Glasgow: Centre for the Study of Public Policy., pp. 67-68; Rose, Richard. (2000). New Baltic Barometer IV: A Survey Study. Studies in Public Policy, Number 338. Glasgow: Centre for the Study of Public Policy., p. 62; White, Stephen, and Richard Rose. (2001). Nationality and Public Opinions in Belarus and Ukraine. Studies in Public Policy, Number 346. Glasgow: Centre for the Study of Public Policy., p. 56.

${ }^{83}$ High levels of pro-Soviet nostalgia about development under the BSSR, was mentioned by several interviewees. Belarusian Opposition Leader/Former Presidential Candidate. Interview. Minsk, Belarus (April 7a, 2010); Belarusian Journalist. Interview. Minsk, Belarus (April 8, 2010). Nostalgia for the Soviet era was also mentioned by a Latvian elite knowledgeable about Belarus. Latvian Government Official. Interview. Riga, Latvia (February 26b, 2010).

${ }^{84}$ For examples showing presence of robust Belarusian national identity, seen with pride and patriotism in the BSSR, see footnotes no. 73-74. Vakar also notes that "the existence of formal attributes of statehood, have strengthened the feeling of a separate Belarusian identity." Vakar 1956, p. 219. For consensus, see Guthier 1977b, p. 282; Taagepera 1973, pp. 76-79; Maisenya 1997, p. 163. Even those advocating the idea of a lack of national identity also point to a high "sense of national pride" existent in the BSSR. Zaprudnik 1993, p. 
The Effects of Religious-Cultural Worldviews on the Lack of Political-Economic Liberalization in Belarus over Twenty Years since rise of Lukashenko

110. Silitski also argues that there was a strong sense of “'Soviet Belarusian' patriotism." Nevertheless like many other commentators that privilege only the Westernized, anti-Russian narrative of Belarusian 'national identity,' Silitski only calls this a second-class "surrogate national identity." Silitski 2006a, pp. 47-48.

${ }^{85}$ For such arguments, see Zaprudnik 1993, pp. 124, 137, 145.

${ }^{86}$ Marples 2004, p. 33. Sahm also notes that “'stab-in-the-back' myth" developed as the a result of the perceived correlation of Gorbachev's reforms and the downturn. Sahm 1999, p. 651. See also, Mihalisko 1997, pp. 239-240; Zaprudnik and Urban 1997, pp. 285-286; Urban 1989, pp. 70-73, 98-135; Zaprudnik 1993, pp. 116, 179. A general lack of support for perestroika, glasnost and reform is evident from the far fewer cases of reaction and protest, seen with the lack of documents and chronological references to such activities, relative to high levels in the Baltic States. See Furtado, Charles F., Jr., and Andrea Chandler, eds. (1992). Perestroika in the Soviet Republics: Documents on the National Question. Boulder: Westview Press., pp. 247-268.

${ }^{87}$ IISEPS. (2007a). IISEPS News, Issue 1, 43 (January). http://www.iiseps.org/ebullet07-1.html. Additionally, most Belarusians do not rank Gorbachev as strong leader relative to leaders like Masherov and Lukashenko. See IISEPS 2008b.

${ }^{88}$ For documentary evidence, see Furtado and Chandler 1992, pp. 215, 247-250, 252-253, 593. On such issues being important in growth of the BPF, and generally more autonomist sentiment, see Mihalisko 1991, p. 132; Zaprudnik and Urban 1997, p. 288.

${ }^{89}$ For documentary evidence of elite's desire for more autonomy, with simultaneous lack of support for perestroika, glasnost and reform, see "Report by First Secretary of the Communist Party of Byelorussia, Yefrim Ye. Sokulov [25 March 1987]," in Furtado and Chandler 1992, pp. 250-251. See also, "Declaration on State Sovereignty of the BSSR Supreme Soviet - 27 July 1990," which while making calls for increased autonomy, continued with traditional Soviet platitudes containing a noticeable aura of collectivism. Ibid., p. 265-286, 633.

${ }^{90}$ Belarusian Journalist. Interview. Minsk, Belarus (April 8, 2010). Kebich's pro-Soviet and anti-reform mindset was mentioned by others. Belarusian Opposition Leader/Former Presidential Candidate. Interview. Minsk, Belarus (April 7a, 2010). Savchenko also gives a telling quote from Kebich, where he stated that "we managed to stem the tide of reform...thanks to this, our people are not hungry, had their homes heated in winter, produced goods and tilled the soil.” Kebich, 1994 'Interview', Belaya Rus' May 20, quoted in Savchenko 2000, p. 115. For similar evidence of Kebich's and other elites collectivistic, authoritarian, anti-reform, statist, proSoviet, and pro-Russian preferences, see Zaprudnik 1993, p. 144; Zaprudnik and Urban 1997, pp. 299-300; Mihalisko 1997, pp. 250251; Maisenya 1997, p. 155; Eke and Kuzio 2000, p. 541; Marples 1999a, pp. 61-62; Lukashuk, Alexander. (2001).

"Constitutionalism in Belarus: A False Start." In Democratic Consolidation in Eastern Europe, Volume 1: Institutional Engineering, ed. J. Zielonka. Oxford: Oxford., pp. 301, 306-307; Kuzio, Taras. (2001). "Belarus and Ukraine: Democracy Building in the Gray Zone." In Democratic Consolidation in Eastern Europe, Volume 2: International and Transnational Factors, ed. J. Zielonka and A. Pravda. Oxford: Oxford., p. 482; de Weydenthal, Jan. (1998). "Belarus: Government Lauds Economic Growth, But Future Uncertain." Radio Free Europe/Radio Liberty. March 9. HUhttp://www.rferl.org/content/article/1088196.htmlU.; Markus, Ustina. (1996).

"Imperial Understrech: Belarus’s Union with Russia." Current History 95, October: 335-339.

${ }^{91}$ Belarusian Senior Journalist. Interview. Minsk, Belarus (April 5, 2010). Evidence of such distrust of liberal reforms and anti-market attitudes was also found in Zlotnikov, Leonid. (2002). "Possibilities for the Development of a Private Economic Sector and a Middle Class as a Source of Political Change in Belarus." Ch. 5, in Independent Belarus: Domestic Determinants, Regional Dynamic, and Implications for the West, eds. M. M. Balmaceda, J. I. Clem and L. L. Tarlow. Cambridge: Harvard., p. 124; Zaprudnik 1993, pp. 195, 200; Mihalisko 1997, p. 224; Marples, David R. and Uladzimir Padhol. (2002). "The Opposition in Belarus: History, Potential, and Perspectives." Ch. 2 in , in Independent Belarus, eds. M. M. Balmaceda, J. I. Clem and L. L. Tarlow. Cambridge: Harvard., p. 65; Wilde, Caryn. (2002). "The Challenges of Using NGOs as a Strategy for Engagement." Ch. 18, in Independent Belarus, eds. M. M. Balmaceda, J. I. Clem and L. L. Tarlow. Cambridge: Harvard., p. 435.

${ }^{92}$ Belarusian Academic. Interview. Minsk, Belarus (April 6b, 2010). Sahm also noted that "conscious of the people's mentality, the nomenklatura... avoided any serious reform program" Sahm 1999, p. 651. See also footnotes no. 101 to 102 below for consensus that both society and elites believe in these policies, and that serious ideas of liberal reform would have been absent and unthinkable. Such observations are further corroborated by Tsygankov, who while sticking to a national identity explanation, nevertheless noted that "the policy networks in Belarus can be described as a society-dominated one.” Tsygankov, Andrei P. (2000). "Defining State Interests after 
Empire: National Identity, Domestic Structures and foreign Trade Policies of Latvia and Belarus." Review of International Political Economy, 7, 1: 101-137., p. 114.

${ }^{93}$ Belarusian Journalist. Interview. Minsk, Belarus (April 8, 2010). Several others pointed to the absence of liberal values, and the predominance of collectivist, statist, pro-Soviet and anti-reform attitudes of the elite and society. Belarusian Governmental Official. Interview. Minsk, Belarus (March 23, 2010); Belarusian Opposition Activist. Interview. Minsk, Belarus (April 1, 2010); Belarusian Senior Journalist. Interview. Minsk, Belarus (April 5, 2010); Belarusian Senior Academic. Interview. Minsk, Belarus (April 6a, 2010); Belarusian Opposition Leader/Former Presidential Candidate. Interview. Minsk, Belarus (April 7a, 2010); Belarusian Senior Academic. Interview. Minsk, Belarus (April 7b, 2010). For similar evidence that elite and society have similar preferences as noted above, see Zaprudnik 1993, pp. 192-193; Marples 1999a, p. 60; Eke and Kuzio 2000, p. 541; Savchenko 2000, p. 115; Zlotnikov 2002, pp. 125, 142.

${ }^{94}$ Zlotnikov 2002, pp. 152, 138.

${ }^{95}$ Nuti, Mario D. (2005). “The Belarusian Economy: Suspended Animation between State and Markets.” In Postcommunist Belarus, eds. Stephen White, Elena Korosteleva, and John Löwenhardt. Lanham: Rowman \& Littlefield., p. 98. See also, International Monetary Fund (IMF). (2010a). Republic of Belarus: Selected Issues. IMF Country Report No. 10/16. January. Washington: IMF., p. 14. Similar sentiments were mentioned by, Belarusian Academic. Interview. Minsk, Belarus (April 6b, 2010).

${ }^{96}$ Belarusian Academic. Interview. Minsk, Belarus (April 6b, 2010). Several others also mentioned they believe that Lukashenko truly believes and views these policies as the best and right methods. Belarusian Governmental Official. Interview. Minsk, Belarus (March 23, 2010); Belarusian Opposition Activist. Interview. Minsk, Belarus (April 1, 2010); Belarusian Senior Journalist. Interview. Minsk, Belarus (April 5, 2010); Belarusian Senior Academic. Interview. Minsk, Belarus (April 6a, 2010); Belarusian Opposition Leader/Former Presidential Candidate. Interview. Minsk, Belarus (April 7a, 2010); Belarusian Senior Academic. Interview. Minsk, Belarus (April 7b, 2010); Belarusian Journalist. Interview. Minsk, Belarus (April 8, 2010). This was also mentioned by one Latvian Government Official. Interview. Riga, Latvia (February 26b, 2010).

${ }^{97}$ Belarusian Opposition Leader/Former Presidential Candidate. Interview. Minsk, Belarus (April 7a, 2010); Belarusian Academic. Interview. Minsk, Belarus (April 6b, 2010). Similar sentiments were also mentioned by another Belarusian Senior Journalist. Interview. Minsk, Belarus (April 5, 2010). Also mentioned by one Latvian Government Official. Interview. Riga, Latvia (February 26b, 2010). See also, Furman, Dmitrii. (1999). “'Centers' and 'Peripheries': The Political Systems of the Three East Slavic Republics.” Russian Social Science Review, 40, 6: 28-47., p. 39.

${ }^{98}$ Belarusian Senior Journalist. Interview. Minsk, Belarus (April 5, 2010). Neo-Soviet ideologies were mentioned by others. Belarusian Academic. Interview. Minsk, Belarus (April 6b, 2010); Belarusian Opposition Leader/Former Presidential Candidate. Interview. Minsk, Belarus (April 7a, 2010); Belarusian Journalist. Interview. Minsk, Belarus (April 8, 2010).

${ }^{99}$ Zlotnikov 2002, pp. 132, 133. For additional evidence of ideologies favouring collectivistic and statist solutions, see Maisenya 1997, pp. 207, 224, 265, 281, 318-319, 323, 337; Korosteleva, Elena A., Colin W. Lawson and Rosalind J. Marsh. (2003a). "Introduction: Paradoxes of Democratisation in Post-Communist Belarus." In Contemporary Belarus: Between Democracy and Dictatorship, ed. E. A. Korosteleva, C. W. Lawson and R. J. Marsh. New York: Routledge., pp. 15-16.

${ }^{100}$ Lukashenko quoted in Silitski, Vitali. (2005). "Internal Developments in Belarus.” In Changing Belarus, eds. Dov. Lyn et al. Chaillot Paper No. 85. November. EU Institute for Security Studies., p. 33. For similar assessments of Lukashenko’s strong commitment to such ideologies, see footnotes no. 96-99, and Maksymiuk, Jan. (2007). "Belarus: Father of the Nation, or Fatherless Son?." Radio Free Europe/Radio Liberty, February 8. www.rferl.org/featuresarticle/2007/02/d22a8d8e-95a3-48f5-a3fdcf11f7536421.html.; Marples 1999a, p. 118; Wilde 2002, p. 429. Lukashenko's own website also has the main slogan prominent displayed that "We will build a strong and prosperous Belarus - the state for the people." Lukashenko, Aleksander. (2010). "The Official Internet Portal of the President of the Republic of Belarus." http://president.gove.by/en/.

101 Silitski, Vitali. (2006b). “Памятаць, што дыктатуры руйнуюцца.”Arche, 7, 8. http://arche.bymedia.net/2006-7/silicki706.htm. Moreover, Vladimir Karyagan was quoted in the Economist as saying that "'Lukashenko reflects the interests of the great majority of the population...the working class like him because he is no different from themselves." Economist. (1995). "In the Slav Shadowlands." The Economist, May 20, 47-49. That Lukashenko was in tune with the values of society, was mentioned by several 
The Effects of Religious-Cultural Worldviews on the Lack of Political-Economic Liberalization in Belarus over Twenty Years since rise of Lukashenko

interviewees. Belarusian Governmental Official. Interview. Minsk, Belarus (March 23, 2010); Belarusian Opposition Activist. Interview. Minsk, Belarus (April 1, 2010); Belarusian Senior Journalist. Interview. Minsk, Belarus (April 5, 2010); Belarusian Academic. Interview. Minsk, Belarus (April 6b, 2010); Belarusian Opposition Leader/Former Presidential Candidate. Interview. Minsk, Belarus (April 7a, 2010); Belarusian Senior Academic. Interview. Minsk, Belarus (April 7b, 2010); Belarusian Journalist. Interview. Minsk, Belarus (April 8, 2010). For consensus, see Furman 1999, p. 45; Zlotnikov 2002, p. 133; Colton, Timothy J. (2002). "Belarusian Public Opinion and the Union with Russia." Ch. 1, in Independent Belarus, eds. M. M. Balmaceda, J. I. Clem and L. L. Tarlow. Cambridge: Harvard., pp. 21-22; Ioffe 2008, pp. 153, 234; Hill 2005, p. 9. On popular appeal see footnotes no. 133, 138-140.

102 Belarusian Academic. Interview. Minsk, Belarus (April 6b, 2010). That both society and elites believe in the rightness of these policies was mentioned by others. Belarusian Governmental Official. Interview. Minsk, Belarus (March 23, 2010); Belarusian Opposition Activist. Interview. Minsk, Belarus (April 1, 2010); Belarusian Senior Journalist. Interview. Minsk, Belarus (April 5, 2010); Belarusian Senior Academic. Interview. Minsk, Belarus (April 6a, 2010); Belarusian Opposition Leader/Former Presidential Candidate. Interview. Minsk, Belarus (April 7a, 2010); Belarusian Senior Academic. Interview. Minsk, Belarus (April 7b, 2010); Belarusian Journalist. Interview. Minsk, Belarus (April 8, 2010).

103 That Lukashenko was able to tap into pro-Soviet or neo-Soviet worldviews and historical memories about the BSSR was mentioned by several interviewees. Belarusian Opposition Leader/Former Presidential Candidate. Interview. Minsk, Belarus (April 7a, 2010). Belarusian Opposition Activist. Interview. Minsk, Belarus (April 1, 2010); Belarusian Senior Journalist. Interview. Minsk, Belarus (April 5, 2010); Belarusian Academic. Interview. Minsk, Belarus (April 6b, 2010); Belarusian Senior Academic. Interview. Minsk, Belarus (April 7b, 2010); Belarusian Journalist. Interview. Minsk, Belarus (April 8, 2010). This was also mentioned by one Latvian Government Official. Interview. Riga, Latvia (February 26b, 2010). For consensus, see Zlotnikov 2002, p. 126; Korosteleva et al 2003a, pp. 7, 12; Silitski 2006a, p. 48; Eke and Kuzio 2000, p. 535.

${ }^{104}$ This was mentioned by one Latvian elite with knowledge of Belarusian affairs. Latvian Government Official. Interview. Riga, Latvia (February 26b, 2010). Several Belarusian interviewees noted that Lukashenko was not just portraying such an image, but actually has "the mentality of a Soviet person." Belarusian Opposition Leader/Former Presidential Candidate. Interview. Minsk, Belarus (April 7a, 2010). See remarks by Lukashenko’s former press attaché, Alexander Feduta. Feduta, Alexander. (2005). Lukashenko: Politischeskaya Biografiya. Moscow: Referendum., p. 127, and also Maisenya 1997, pp. 167-169, 234, 325-326, 330; Marples 2003, pp. 25, 28; Mihalisko 1997, p. 254; Lindner, Rainer. (2002). "The Lukashenka Phenomenon.” Ch. 2 in , in Independent Belarus, eds. M. M. Balmaceda, J. I. Clem and L. L. Tarlow. Cambridge: Harvard., pp. 84-85; White, Stephen and Elena Korosteleva. (2005). "Lukashenko and the Postcommunist Presidency." Ch. 4. In Postcommunist Belarus, eds. S. White, E. Korosteleva, and J. Löwenhardt. Lanham: Rowman \& Littlefield., p. 59.

${ }^{105}$ See polls in Rose, Richard and Christian Haerpfer. (1993). New Democracies Barometer II: Adapting to Transformation in Eastern Europe, Number 212. Glasgow: Centre for the Study of Public Policy., appendix, Table 23; Rose and Haerpfer 1994, appendix, Table 32; Rose and Haerpfer 1996, p. 72; Rose and Haerpfer 1998, pp. 48-49; White and Rose 2001, pp. 20-21; Rose, Richard. (2005b). Insiders and Outsiders: New Europe Barometer 2004. Studies in Public Policy Number 404. Aberdeen: Centre for the Study of Public Policy., p. 47; Rose, Richard. (2006). Diverging Paths of Post-Communist Countries: New Europe Barometer Trends since 1991. Studies in Public Policy Number 418. Aberdeen: Centre for the Study of Public Policy., p. 57. For Baltic States numbers, see Rose, Richard \& William Maley. (1994). Nationalities in the Baltic States: A Survey Study. Studies in Public Policy, Number 222. Glasgow: Centre for the Study of Public Policy., p. 34; Rose 1995, p. 25; Rose, Richard. (1997). New Baltic Barometer III: A Survey Study. Studies in Public Policy, Number 284. Glasgow: Centre for the Study of Public Policy., pp. 18-19; Rose 2000, pp. 51-52; Rose, Richard. (2002). New Baltic Barometer V: A Pre-Enlargement Survey. Studies in Public Policy, Number 368. Glasgow: Centre for the Study of Public Policy., pp. 7-8; Rose, Richard. (2005a). New Baltic Barometer VI: A Post-Enlargement Survey. Studies in Public Policy, Number 401. Glasgow: Centre for the Study of Public Policy., pp. 13-14.

106 See polls in Rose and Haerpfer 1994, appendix, Table 43; Rose and Haerpfer 1996, p. 77; Rose and Haerpfer 1998, p. 53; White and Rose 2001, p. 25; Rose 2005b, pp. 13-14; Rose 2006, p. 57. For contrastingly low numbers in the Baltic States of Latvia and Estonia, which were well below and never reaching above 5\% to similar questions, see Rose 1995, p. 35; Rose 1997, p. 28; Rose 2002, pp. 12-13; Rose 2005a, p. 18.

${ }^{107}$ For polls, see IISEPS. (2002b). IISEPS News, Issue 2, 24 (June). http://www.iiseps.org/ebullet02-2.html.; 
IISEPS. (2006b). IISEPS News, Issue 2, 40 (June).http://www.iiseps.org/ebullet06-2.html.; IISEPS 2007a; IISEPS 2008b; IISEPS. (2008d). IISEPS News, Issue 4, 50 (December). http://www.iiseps.org/ebullet08-4.html.; IISEPS. (2010). "Trends of Change in Belarusian Public Opinion.” December 4. http://www.iiseps.org/etrend.html.

${ }^{108}$ See polls in White and Rose 2001, p. 44; White, Stephen and Ian McAllister. (2008). Belarus, Ukraine and Russia: East or West? Studies in Public Policy, Number 437. Aberdeen: Centre for the Study of Public Policy., p. 19.

${ }^{109}$ Belarusian Opposition Leader/Former Presidential Candidate. Interview. Minsk, Belarus (April 7a, 2010). Similar sentiments were mentioned by others. Belarusian Opposition Activist. Interview. Minsk, Belarus (April 1, 2010); Belarusian Senior Journalist. Interview. Minsk, Belarus (April 5, 2010); Belarusian Senior Academic. Interview. Minsk, Belarus (April 6a, 2010); Belarusian Academic. Interview. Minsk, Belarus (April 6b, 2010); Belarusian Journalist. Interview. Minsk, Belarus (April 8, 2010). See also, Zlotnikov 2002, p. 124.

${ }^{110}$ Belarusian Senior Journalist. Interview. Minsk, Belarus (April 5, 2010). Examples of private property accumulation being unthinkable was mentioned by others. Belarusian Opposition Activist. Interview. Minsk, Belarus (April 1, 2010); Belarusian Senior Academic. Interview. Minsk, Belarus (April 6a, 2010); Belarusian Academic. Interview. Minsk, Belarus (April 6b, 2010); Belarusian Opposition Leader/Former Presidential Candidate. Interview. Minsk, Belarus (April 7a, 2010); Belarusian Senior Academic. Interview. Minsk, Belarus (April 7b, 2010); Belarusian Journalist. Interview. Minsk, Belarus (April 8, 2010).

${ }^{111}$ Belarusian Journalist. Interview. Minsk, Belarus (April 8, 2010). See footnote no. 110 above. Similar sentiments of Belarus having historically collectivistic traditions was mentioned by one Latvian Government Official. Interview. Riga, Latvia (February 26b, 2010).

112 Zaprudnik 1993, p. 193. For similar observations inferring lack of private property attitudes and support for maintaining collective farms, see also Ioffe 2008, p. 120. Ioffe portrays somewhat more rationalistic motives, but still that there was strong support for collective farms.

${ }^{113}$ Belarusian Journalist. Interview. Minsk, Belarus (April 8, 2010).

${ }^{114}$ Belarusian Opposition Leader/Former Presidential Candidate. Interview. Minsk, Belarus (April 7a, 2010). On private property accumulation being unthinkable, see also footnote no. 110 above.

${ }^{115}$ Belarusian Senior Journalist. Interview. Minsk, Belarus (April 5, 2010).

${ }^{116}$ For polls, see "Politics and Society" section of the World Values Survey. (1990-2000). http://www.worldvaluessurvey.org/.

${ }^{117}$ For polls, see "Attitudes Concerning Society: Income Equality," in the "Politics and Society" section of the World Values Survey 2000.

${ }^{118}$ For example, respondents saying yes to preferring state enterprises over private, numbered $66 \%$ in $1995,58 \%$ in 1998 , and $50 \%$ in 2000, where 62\% of Belarusian-speaking Belarusians also responded yes in 2000. See polls in Rose and Haerpfer 1996, p. 71; Rose and Haerpfer 1998, p. 70; White and Rose 2001, pp. 14-15. For contrasting numbers in Baltic States and Central and Eastern European averages, which show preferences in favour of private enterprises, see Rose and Maley 1994, pp. 2-3; Rose 2005a, p. 29; Rose 2005b, p. 69.

${ }^{119}$ White and Rose 2001, p. 15.

${ }^{120}$ Belarusian Academic. Interview. Minsk, Belarus (April 6b, 2010).

${ }^{121}$ Belarusian Opposition Leader/Former Presidential Candidate. Interview. Minsk, Belarus (April 7a, 2010). Similar sentiments pointing to preference for such a system was also mentioned by others. Belarusian Governmental Official. Interview. Minsk, Belarus (March 23, 2010); Belarusian Opposition Activist. Interview. Minsk, Belarus (April 1, 2010); Belarusian Senior Journalist. Interview. Minsk, Belarus (April 5, 2010); Belarusian Journalist. Interview. Minsk, Belarus (April 8, 2010). 
122 This compared to lower numbers in favour of private enterprise management for the same years, and also contrasted with numbers in favour of private enterprise in the Baltic States. See "Rule of Government" and "Attitudes Concerning Society" in the "Politics and Society" section of the World Values Survey 1990-1996.

${ }^{123}$ See "Politics and Society" section of the World Values Survey 1990-1996.

${ }^{124}$ IISEPS 2008b.

${ }^{125}$ See Rose and Haerpfer 1993, appendix, table 22.

${ }^{126}$ Those answering no and preferring more market based high income, numbered only $32.8 \%$ in $1997,40.2 \%$ in $1999,46.8 \%$ in 2000 , and 30.8\% in 2006. See IISEPS. (2001c). IISEPS News, Issue 3, 21 (September).http://www.iiseps.org/ebullet01-3.html.; IISEPS $2006 \mathrm{~b}$.

${ }^{127}$ Belarusian Opposition Leader/Former Presidential Candidate. Interview. Minsk, Belarus (April 7a, 2010). Similar sentiments were mentioned by others. Belarusian Senior Journalist. Interview. Minsk, Belarus (April 5, 2010). To see historical similarities between autocratic rule during Tsarist times with those of today, where Lukashenko could be described as acting like a 'mini-Tsar,' Vakar pointed out that "like the modern dictator, a father was held to act as trustee and embodiment of the will of all... the totalitarian leader, like the peasant father, does not just take care of his subjects; he knows and exercises their true will by doing for them what they want done even when they do not themselves know their own minds." Vakar 1961, p. 34. Similarly, one can find continuity in Lukashenko's authoritarian rule with that of Tsarist times, from White's description that "the Tsar remained the ultimate source of legislative authority, an 'autocratic and unlimited monarch' whose commands... could endorse or reject legislative proposals, determine when the Duma should sit and when it should be dissolved... [where] his own authority had the force of law." White 1979a, p. 27.

${ }^{128}$ Belarusian Senior Academic. Interview. Minsk, Belarus (April 6a, 2010). Belarusian Academic. Interview. Minsk, Belarus (April $6 \mathrm{~b}, 2010)$. Additionally, in a BBC news report, Anatoly Gulyaev, who knew Lukashenko from when he was a manager of a collective farm, was quoted as saying, "Lukashenko is known to Belarusians as 'Batka,' or 'Daddy." BBC News. (2008). "Farming Roots of Belarussian leader." BBC News. September 27. http://news.bbc.co.uk/2/hi/7639562.stm. On being described as 'father of the nation,' see Maisenya 1997, pp. 216, 223, 325-326; Furman 1999, p. 45; Maksymiuk 2007.

${ }^{129}$ Belarusian Academic. Interview. Minsk, Belarus (April 6b, 2010). Similar insight on the importance of values promoted by the religious teachings of the Orthodox Church in influencing such tendencies were given in the observations of another interviewee. Belarusian Senior Academic. Interview. Minsk, Belarus (April 7b, 2010). This importance of passivity was mentioned by others. Belarusian Opposition Activist. Interview. Minsk, Belarus (April 1, 2010); Belarusian Opposition Leader/Former Presidential Candidate. Interview. Minsk, Belarus (April 7a, 2010); Belarusian Journalist. Interview. Minsk, Belarus (April 8, 2010).

${ }^{130}$ Belarusian Opposition Leader/Former Presidential Candidate. Interview. Minsk, Belarus (April 7a, 2010). Similar sentiments were mentioned by others. Belarusian Opposition Activist. Interview. Minsk, Belarus (April 1, 2010); Belarusian Senior Journalist. Interview. Minsk, Belarus (April 5, 2010); Belarusian Senior Academic. Interview. Minsk, Belarus (April 6a, 2010); Belarusian Academic. Interview. Minsk, Belarus (April 6b, 2010); Belarusian Journalist. Interview. Minsk, Belarus (April 8, 2010). See also Zlotnikov 2002, p. 124.

${ }^{131}$ Marples and Padhol 2002, p. 65. For consensus, see Lindner 2002, p. 96; Zlotnikov 2002, p. 131; Gricius 2002, p. 323; Ioffe 2008, p. 141; Eke and Kuzio 2000, pp. 537, 542.

${ }^{132}$ Maksymiuk 2007.

${ }^{133}$ Silitski 2006a, p. 47. That there is still strong authoritarian tendencies permeating the leadership preferences of average Belarusians and that this helps explains significant political support for Lukashenko, and that his values are in tune with large segments of the population, see footnotes no. 101-102 and 138-140. For consensus, see Lukashuk 2001, p. 301; Ioffe 2008, pp. 138, 151; Eke and Kuzio 2000, p. 536; Korosteleva, Elena A. (2005). “The Emergence of a Party System.” Ch. 3. In Postcommunist Belarus, eds. Stephen White, Elena Korosteleva, and John Löwenhardt. Lanham: Rowman \& Littlefield., p. 55; Mihalisko 1997, p. 259. 
${ }^{134}$ In one set of polls conducted in 1996, 2004, and 2008, Masherov's popularity averaged 33.8\%, while Lukashenko and Putin averaged 23.3\% and 35.3\% respectively. IISEPS 2008b. In other polls running from 1997 to 2008, Putin and Lukashenko ranked as the top choices for the most "ideal" politicians, averaging 53.8\% and 38.0\% respectively IISEPS. (2001b). IISEPS News, Issue 2, 20 (June). http://www.iiseps.org/ebullet01-2.html.; IISEPS 2001c; IISEPS 2002b; IISEPS. (2002d). IISEPS News, Issue 4, 26 (December). http://www.iiseps.org/ebullet02-4.html.; IISEPS. (2003c). IISEPS News, Issue 3, 29 (September). http://www.iiseps.org/ebullet033.html.; IISEPS. (2004d). IISEPS News, Issue 4, 34 (December). http://www.iiseps.org/ebullet04-4.html.; IISEPS $2008 \mathrm{~b}$.

${ }^{135}$ For numbers see Rose and Haerpfer 1993, appendix, table 31; Rose and Haerpfer 1994, appendix, table 45; Rose and Haerpfer 1996, p. 78; Rose 2005b, p. 53.

${ }^{136}$ For numbers see Rose 2006: 57.

${ }^{137}$ To illustrate numbers indicating increased regime satisfaction, Belarusians respondents to the pro-future regime numbered $46 \%$ in $1992,56 \%$ in $1993,66 \%$ in $1995,66 \%$ in $1998,71 \%$ in 2001 , and $82 \%$ in 2004. Rose and Haerpfer 1993, appendix, table 25; Rose and Haerpfer 1994, appendix, table 34; Rose and Haerpfer 1996, p. 75; Rose and Haerpfer 1998, pp. 51-52; White and Rose 2001, pp. 22-23; Rose 2005b: pp. 50-51.

${ }^{138}$ Belarusian Opposition Leader/Former Presidential Candidate. Interview. Minsk, Belarus (April 7a, 2010).

${ }^{139}$ Okara, N. Andrei. (2001). "Belarus in the Absence of the Third Alternative [Беларусь в отсутствие третьей альтернативы]." Russian Journal [Русский Журнал]. November 14. http://old.russ.ru/politics/20011114-oka.html.

${ }^{140}$ Maksymiuk 2007. Similar sentiments on Lukashenko speaking the language of the people was mentioned by others. Belarusian Senior Journalist. Interview. Minsk, Belarus (April 5, 2010); Belarusian Journalist. Interview. Minsk, Belarus (April 8, 2010). This was also mentioned by one Latvian Government Official. Interview. Riga, Latvia (February 26b, 2010). Also, Ioffe notes that "Lukashenko appears to be in sync with most of his fellow countrymen." Ioffe 2008, pp. 183-184, 168, 188-189. For consensus, see footnote no. 101-102, and Maisenya 1997, pp. 167-169, 330; Marples 1999a, p. 75; Marples 2003, p. 28; Mihalisko 1997, pp. 253, 259; Lindner 2002, p. 81; Ioffe, Grigory. (2003). “Understanding Belarus: Questions of Language.” Europe-Asia Studies 55, 7: 10091047., p. 1016; White and Korosteleva 2005, pp. 70-71.

${ }^{141}$ Only one year later in 1995, Lukashenko was given a huge mandate of approximately $77.7 \%$ in favour of the President dissolving parliament. In another referendum held in 1996, with $84 \%$ of the eligible electorate taking part, $70.5 \%$ of voters gave their support for a new draft constitution, which gave Lukashenko increased powers over parliament, and the power to appoint the prime minister, deputy ministers, members of the Constitutional court, and also the head of the National Bank. For numbers, see Central Commission of the Republic of Belarus on Elections and Holding Republican Referenda. (1995). "The Report of the Central Commission on Voting Results at the National Referendum.” Minsk, Belarus. http://www.rec.gov.by/sites/default/files/pdf/Archive-Referenda-1995Soob.pdf.; Central Commission of the Republic of Belarus on Elections and Holding Republican Referenda. (1996). "The Report of the Central Commission on Voting Results at the National Referendum.” Minsk, Belarus.

http://www.rec.gov.by/sites/default/files/pdf/Archive-Referenda-1996-Soob.pdf.

${ }^{142}$ White and Rose 2001, pp. 39-40. In another poll from IISEPS, which asked on October 10, 2001, "for whom did you vote at the past presidential election," 48.2\% listed Lukashenko, while his next highest opponent Goncharik received 21.0\%. IISEPS. (2001d). IISEPS News, Issue 4, 22 (December). http://www.iiseps.org/ebullet01-4.html. For consensus that Lukashenko would have won, see Economist. (2001). “The Nostalgic Opposition." The Economist, September 15, 46-47; Korosteleva, Elena A., Colin W. Lawson and Rosalind J. Marsh. (2003b). "Afterword: The Presidential Election of September 2001.” In Contemporary Belarus, ed. E. A.

Korosteleva, C. W. Lawson and R. J. Marsh. New York: Routledge Curzon., p. 194; White and Korosteleva 2005, p. 60; Lynch, Dov. (2005b). "Catalysing Change.” In Changing Belarus, eds. Dov. Lyn et al. Chaillot Paper No. 85. November. EU Institute for Security Studies., pp. 103, 109.

${ }^{143}$ In contrast, only $24 \%$ overall, and $21 \%$ of Belarusian-speaking Belarusians in 2000, and $30 \%$ in 2004 responded that elections were not fair. White and Rose 2001, p. 32; Rose 2005b, p. 57. In another poll from 2000, it is interesting to note that $62 \%$ overall, and 69\% of Belarusian-speaking Belarusians responded that they, for the most part, viewed Belarus as being fair in giving people with different views a voice in parliament. White and Rose 2001, p. 33. 
The Effects of Religious-Cultural Worldviews on the Lack of Political-Economic Liberalization in Belarus over Twenty Years since rise of Lukashenko

${ }^{144}$ IISEPS 2001d. One should note that elections were more free but unfair, and that there were only small irregularities, which made Lukashenko the clear winner. Marples and Padhol 2002, p. 91. Others agreed that the Lukashenko regime was more like an 'elected dictatorship.' Korosteleva et al 2003a, p. 15; Ioffe 2008, pp. 147, 150; Marples, David R. (2005). 'Europe's Last Dictatorship: The Roots and Perspectives of Authoritarianism in 'White Russia."' Europe-Asia Studies, 57, 6: 895-908., p. 905.

\section{${ }^{145}$ IISEPS 2008b.}

${ }^{146}$ IISEPS 2008d. Such numbers are further corroborated in another poll from October 2008, where 53.3\% of respondents answered yes that elections were free and democratic, while only $26.2 \%$ answered no. Ibid.

${ }^{147}$ Belarusian Academic. Interview. Minsk, Belarus (April 6b, 2010); Belarusian Senior Academic. Interview. Minsk, Belarus (April 7b, 2010); Belarusian Opposition Leader/Former Presidential Candidate. Interview. Minsk, Belarus (April 7a, 2010); Belarusian Journalist. Interview. Minsk, Belarus (April 8, 2010). See also IISEPS polling numbers from 2000 to 2010, which illustrate that support for Lukashenko's opponents never regularly surpassed 10\%. See IISEPS 2001b; IISEPS 2001c; IISEPS 2007a; IISEPS 2010.

${ }^{148}$ Rose and Haerpfer 1998, pp. 62; White and Rose 2001, p. 30; Rose 2005b, p. 65.

${ }^{149}$ Belarusian Academic. Interview. Minsk, Belarus (April 6b, 2010); Belarusian Senior Academic. Interview. Minsk, Belarus (April 7b, 2010). See also Figures 5 and 6, and footnote no. 147.

${ }^{150}$ Citing Belarusian scholar G. Kasperovich, in Marples 1999a, pp. 52, 125. On strength of traditional rural cultural attributes influencing support for Lukashenko, see footnotes no. 138-140, and Maksymiuk 2007.

151 This is important considering that in "Belarus...the Orthodox Church is strong despite decades of persecution" Bourdeaux, Michael, ed. (1995). The Politics of Religion in Russia and the New States of Eurasia. Armonk: M. E. Sharpe., p. 11. See also, Kuzio and Nordberg 1999, p. 77; Marples 1999a, p. 113; Eke and Kuzio 2000, p. 535; Snyder 2003, p. 280; Dunlop, John B. (1995). "The Russian Orthodox Church as an 'Empire-Saving' Institution." Ch. 2. In The Politics of Religion in Russian and the New States of Eurasia, ed., M. Bourdeaux. Armonk: M. E. Sharpe., p. 28.

${ }^{152}$ See for example, (Marples 1999a; Savchenko 2000, p. 39; Abdelal, Rawi. (2001). National Purpose in the World Economy: PostSoviet States in Comparative Perspective. Ithaca: Cornel University Press., pp. 127-128; Burant, Stephen R. (1995). "Foreign Policy and National Identity: A Comparison of Ukraine and Belarus." Europe-Asia Studies, 47, 7: 1125-1144; Mihalisko 1997, p. 224; Kuzio and Nordberg 1999; Eke and Kuzio 2000; Kuzio 2001, p. 462; Silitiski 2006a, p. 47; Ioffe 2008, p. 235; Zuprudnik 1993. One of the better examples in the literature, is done by Ioffe, who incorporates other variables such as history, geography, culture, ethnicity, language, authoritarianism, and geopolitics into his framework to trace the roots of national identity. In his earlier work, Ioffe et al suggest the strong influence of rural socio-cultural influences on politics in Russia, as being structurally rooted in the geographic nature of Russia with its vast open spaces, which necessitated peasants to band together into collectives for personal survival, which historically also helped lead to support for Communism from the majority rural populace. Ioffe et al 2006, p. 18. Ioffe builds on his work on Russia, arguing that this geographic explanation is directly applicable to Belarusian politics, particularly why democracy failed. Ioffe 2008, pp. 137, 235. In the final analysis, however, ideas remain a secondary variable to that of historic geographic circumstances. However, problems exist with this geographic explanation, in that prominent authors have shown that geographic determinism is not a strong enough variable to explain cross-cultural differences and cultural uniqueness. Deutsch, Karl W. (1981). "On Nationalism, World Regions and the Nature of the West." In Mobilization, Center-Periphery Structures and Nation-Building: A Volume in Commemoration of Stein Rokkan, ed. Per Torsvik. Oslo: Universitetsforlaget., pp. 89-90). Finally, important cultural variables such as religious worldviews are only passed over briefly by Ioffe and discounted.

${ }^{153}$ Abdelal 2001, p. 128. Another example that blurs the explanatory variables between national identity and rationalist explanations, as well as exogenous structural variables is Eke and Kuzio 2000, pp. 528, 530-531; Savchenko 2000, p. 102; Marples 1999a, pp. 3132. Such arguments sound similar to the Rationalist formulations of Åslund and others, who argued that Belarus's divergent policy behavior could be explained by the near dearth of ideology in Belarus, which resulted not only in a lack of reform, but also in a lack of purpose, and rent-seeking by elites. See Åslund, Anders. (2002). Building Capitalism: The Transformation of the Former Soviet Bloc. Cambridge: Cambridge., p. 393, and Eke and Kuzio 2000, p. 538. Such explanations are inadequate to explain Belarus's behavior, because while there was an absence of liberal ideology in Belarus, it was shown that there was a strong presence of ideologies, 
amongst elites and society, favouring collectivist, communal, statist, paternalistic, and authoritarian methods for managing politicaleconomic relations.

${ }^{154}$ See Savchenko 2000, p. 102; Marples 1999a, pp. 31-32; Eke and Kuzio 2000, pp. 530-531.

${ }^{155}$ See Mihalisko 1997, pp. 274-275; Kuzio and Nordberg 1999, pp. 75, 84; Tsygankov 2000, pp. 116, 118; Eke and Kuzio 2000; Marples 1999a, p. 110.

${ }^{156}$ Kebich quoted in Burant 1995, p. 1136.

${ }^{157}$ Lukashenko quoted in Burant 1995, p. 1136. Evidence of close historical religious-cultural-linguistic bonds, and how such links would produce natural feelings for close relations with Russia, can be found in Maisenya 1997, pp. 172, 270, 282-283, 335; Drakokhrust, Yuri and Dmitri Furman. (2002). "Belarus and Russia: The Game of Virtual Integration." Ch. 9, in Independent Belarus, eds. M. M. Balmaceda, J. I. Clem and L. L. Tarlow. Cambridge: Harvard., pp. 232, 250. Even those who argue that Belarus lacked a coherent national identity also noted that "there was undeniably a cultural impulse involved." Zaprudnik 1993, p. 130.

${ }^{158}$ Rose and Haerpfer 1993, appendix, Table 28; Rose and Haerpfer 1994; Rose and Haerpfer 1996, pp. 83-85; Rose and Haerpfer 1998, pp. 63-64; White and Rose 2001, pp. 51-52; Rose 2005, pp. 61-62. One should contrast these low numbers in Belarus compared to the high numbers in the Baltic States and Latvia, which averaged $62.2 \%$ for those that responded that they view Russia as a security threat. See Rose and Maley 1994, pp. 43-44; Rose 1995, p. 37; Rose 1997, pp. 34-35; Rose 2000, p. 37; Rose 2005, p. 24.

${ }^{159}$ See IISEPS. (2004b). IISEPS News, Issue 2, 32 (June). http://www.iiseps.org/ebullet04-2.html.; IISEPS 2008d. Such numbers are supported by another poll from 2000, where over $70 \%$ of Belarusians argued that it was most important to have good relations with Russia, while only a minority responded in favour of a more Western orientation. White and Rose 2001, pp. 43-44. That there has always been a strong cultural identification with Russia, and that Russia is not seen as a threat, was pointed out by several interviewees. Belarusian Senior Journalist. Interview. Minsk, Belarus (April 5, 2010); Belarusian Academic. Interview. Minsk, Belarus (April 6b, 2010); Belarusian Senior Academic. Interview. Minsk, Belarus (April 7b, 2010); Belarusian Journalist. Interview. Minsk, Belarus (April 8, 2010). Similar sentiments were mentioned by a Latvian Government Official. Interview. Riga, Latvia (February 26b, 2010).

${ }^{160}$ See Rose and Haerpfer 1998, pp. 77-78; White and Rose 2001, p. 53; White and McAllister 2008, p. 16.

${ }^{161}$ Such observations were mentioned by several elites. Belarusian Opposition Leader/Former Presidential Candidate. Interview. Minsk, Belarus (April 7a, 2010). Belarusian Senior Journalist. Interview. Minsk, Belarus (April 5, 2010); Belarusian Journalist. Interview. Minsk, Belarus (April 8, 2010). Most Belarusians when polled in 1999, in the range of 47.7\% thought that NATO's eastward expansion was a threat, while only 17.6\% answered no. IISEPS. (1999d). IISEPS News, Issue 4, 14 (December). http://www.iiseps.org/ebullet994.html. For consensus, see Maisenya 1997, pp. 196, 330; Marples and Padhol 2002, p. 67; Marples 2004, p. 41; Lindner 2002, pp. 9193; Hill 2005, p. 10.

162 Additionally, $14.0 \%$ listed the West as "a rational and cold world with formal and selfish relations between people," while $10.2 \%$ said "these are states and political forces which will always be hostile to our country." IISEPS. (2009a). IISEPS News, Issue 1, 51 (March). http://www.iiseps.org/ebullet09-1.html. In another poll from 2006, asking Belarusians what they thought of the influence of Belarus, Russia, and the U.S. in the world, $43.5 \%$ said Belarusian influence was positive, $68.3 \%$ gave a positive response to Russian influence, which contrasted with 52.0\% who found U.S. influence negative. IISEPS. (2006c). IISEPS News, Issue 3, 41 (September). http://www.iiseps.org/ebullet06-3.html.

${ }^{163}$ IISEPS. (2008a IISEPS News, Issue 1, 47 (March). http://www.iiseps.org/ebullet08-1.html. In a poll from January 2007, 52.6\% gave Lukashenko high marks for standing up to Russia during the Belarus-Russia oil and gas conflict, saying "he showed himself a strong politician." In contrast, only $25.7 \%$ responded no, answering "he showed himself a weak politician.” IISEPS 2007a.

${ }^{164}$ Belarusian Senior Journalist. Interview. Minsk, Belarus (April 5, 2010); Belarusian Academic. Interview. Minsk, Belarus (April 6b, 2010); Belarusian Opposition Leader/Former Presidential Candidate. Interview. Minsk, Belarus (April 7a, 2010); Belarusian Journalist. Interview. Minsk, Belarus (April 8, 2010). Such a fact has been acknowledged by several National Identity theorists. Sahm 1999, p. 658; Eke and Kuzio 2000, p. 530; Drakokhrust and Furman 2002, pp. 239, 253; Silitski, Vitali. (2003). "Explaining postCommunist Authoritarianism in Belarus.” Ch. 3. In Contemporary Belarus, ed. E. A. Korosteleva, C. W. Lawson and R. J. Marsh. 
The Effects of Religious-Cultural Worldviews on the Lack of Political-Economic Liberalization in Belarus over Twenty Years since rise of Lukashenko

New York: Routledge., p. 43; Silitski 2006a, p. 50; Ioffe 2008, pp. 93, 170; Snyder 2003, p. 284; Marples 1999a, p. 118; Marples 2004, p. 40; Rontoyanni, Clelia. (2005). "Belarus and the East.” Ch. 7. In Postcommunist Belarus, eds. S. White, E. Korosteleva, and J. Löwenhardt. Lanham: Rowman \& Littlefield., p. 132; Maksymiuk, Jan. (2008). "Commentary: Is the Belarusian Opposition Losing the Battle for Young Minds?” Radio Free Europe/Radio Liberty, June 10. http://www.rferl.org/content/article/1144587.html.

${ }^{165}$ See Svedberg, Marcus. (2007). "Energy in Eurasia: The Dependency Game.” Transition Studies Review 14, 1: 195-202; Energy Information Administration (EIA). (2006). "Baltic Sea Regional Factsheet." Country Analysis Briefs.

http://www.eia.doe.gov/emeu/cabs/Baltic/pdf.pdf.

${ }^{166}$ Such numbers were corroborated by other polls where close to $70 \%$ responded in 2000 that they prefer close relations with Russia, with Belarus remaining independent. White and Rose 2001, p. 18. Additionally, in a poll from June 1997, 85.4\% of respondents answered that Belarus should be sovereign, while only $12.8 \%$ said no. IISEPS 1999d. Such views were echoed by several interviewees, especially in regards to that Belarusians highly value that Belarus remains sovereign. Belarusian Senior Journalist. Interview. Minsk, Belarus (April 5, 2010); Belarusian Academic. Interview. Minsk, Belarus (April 6b, 2010); Belarusian Opposition Leader/Former Presidential Candidate. Interview. Minsk, Belarus (April 7a, 2010); Belarusian Senior Academic. Interview. Minsk, Belarus (April 7b, 2010); Belarusian Journalist. Interview. Minsk, Belarus (April 8, 2010).

${ }^{167}$ Hopf 2002, p. 18.

${ }^{168}$ Abdelal, Rawi. (2005). "Nationalism and International Political Economy.” Ch. 1. In Economic Nationalism in a Globalizing World, ed. Eric Helleiner and Andreas Pickel. Ithaca: Cornell University Press., p. 40.

${ }^{169}$ Abdelal 2001, p. 43. It is possible that the normative bias in categorizing national identity has resulted in Abdelal and others incorrectly and prematurely labeling the wrong groups 'nationalist.' In addition to critiquing this normative bias, it is also possible to make a methodological critique that National Identity arguments appear circular at times. For instance, such explanations assert that 'strong nationalism' drives policy away from Russia, but their gauge for judging high rates of 'nationalism' many times appears to ultimately fall back on the dependent variable. Thus, many accounts allude, for example, that Belarus has weak national identity, and in foreign policy has close relations with Russia, which is a detriment to its sovereignty and shows a lack of national identity e.g. Abdelal 2001, pp. 116, 118; Savchenko 2000; Eke and Kuzio 2000, p. 536.

${ }^{170}$ Abdelal, Rawi. (2003) "National Strategy and National Money: Politics and the End of the Ruble Zone, 1991-1994." Ch. 5. In Monetary Orders: Ambiguous Economics, Ubiquitous Politics, ed. J. Kirshner. Ithaca: Cornell., p. 117. See also, Abdelal 2001, pp. 134, 138-139; Abdelal 2005, pp. 40-41; Beissinger, Mark R. (1996). "How Nationalisms Spread: Eastern Europe Adrift the Tides and Cycles of Nationalist Contention." Social Research, 63, 1: 97-146; Marples 2004.

${ }^{171}$ This observation that the BPF was too radical and extreme was echoed by many elites. Belarusian Opposition Activist. Interview. Minsk, Belarus (April 1, 2010); Belarusian Senior Academic. Interview. Minsk, Belarus (April 6a, 2010); Belarusian Academic. Interview. Minsk, Belarus (April 6b, 2010); Belarusian Senior Academic. Interview. Minsk, Belarus (April 7b, 2010); Belarusian Journalist. Interview. Minsk, Belarus (April 8, 2010). For consensus on 'nationalist' opposition being seen as out of touch and extreme by large segments of society, see Maisenya 1997, pp. 26, 37, 42-43, 154, 270, 335; Economist 1995; Mihalisko 1997, pp. , 240, 261 262; Sahm 1999, pp. 655, 657; Tsygankov 2000, p. 114; Marples and Padhol 2002, p. 61; Marples 2004, pp. 33-34; Silitski 2003, pp. 39-40, 42; Snyder 2003, p. 266; Korosteleva 2005, p. 43; Ioffe 2008, p. 95; Prazauskas, Algimantas. (1994). "The Influence of ethnicity on the Foreign Policies of the Western Littoral States." Ch. 7. In National Identity and Ethnicity in Russia and the New States of Eurasia, ed. Roman Szporluk. Armonk: M.E. Sharpe., p. 165; Eke and Kuzio 2000, pp. 534, 540; Ioffe 2003, p. 1041.

172 This elite also argued that "the problem was that they wanted Belarus to be like something they are not." Belarusian Journalist. Interview. Minsk, Belarus (April 8, 2010). Similar sentiments were mentioned by one Belarusian Academic. Interview. Minsk, Belarus (April 6b, 2010). For evidence of BPF's reliance on, and ideational inspiration from Baltic movements, see Mihalisko 1991, pp. 125-126, 130; Zaprudnik 1993, p. 130; Zaprudnik and Urban 1997, p. 287; Neimanis, George J. (1997). The Collapse of the Soviet Empire: A View from Riga. Westport: Praeger., p. 56.

${ }^{173}$ More importantly, this same interviewee pointed out that "the 'nationalist' opposition did not get this memory passed down from their parents or grandparents, but instead from history books." Belarusian Senior Academic. Interview. Minsk, Belarus (April 7b, 2010). Similar points were mentioned by others. Belarusian Academic. Interview. Minsk, Belarus (April 6b, 2010); Belarusian 
Journalist. Interview. Minsk, Belarus (April 8, 2010). For documentary evidence of BPF linking Belarus culturally to West via the Grand Duchy argument, see "Program of the Byelorussian People's Front for Perestroika - Rebirth [June 1989]," in Furtado and Chandler 1992, pp. 253-260.

${ }^{174}$ Belarusian Journalist. Interview. Minsk, Belarus (April 8, 2010).

175 This interviewee argued that "one shouldn't just demonize the BSSR and Soviet Union, because there were also positive points." Belarusian Journalist. Interview. Minsk, Belarus (April 8, 2010). High pro-Soviet nostalgia found in Belarusian historical memories was mentioned by others. Belarusian Academic. Interview. Minsk, Belarus (April 6b, 2010); Belarusian Opposition Leader/Former Presidential Candidate. Interview. Minsk, Belarus (April 7a, 2010); Belarusian Senior Academic. Interview. Minsk, Belarus (April 7b, 2010). Such observations were mentioned by a Latvian elite knowledgeable in Belarusian affairs. Latvian Government Official. Interview. Riga, Latvia (February 26b, 2010).

${ }^{176}$ Zaprudnik 1993, pp. 131-132. Even claims by several Western historians making arguments about Belarus's 'Western' cultural roots (e.g. Zaprudnik 1994, p. 133; Zaprudnik 1993, p. 9; Zaprudnik, Jan. (1973). "Interpretation of the Grand Duchy of Lithuania in Recent Works of Soviet Belorussian Historians." In Baltic History, eds. Arvids Ziedonis, Jr., William L. Winter and Mardi Valgemäe. Columbus: Association for the Advancement of Baltic Studies., pp. 61-67), are contradicted by themselves. This can be seen where Zaprudnik acknowledges that the strong historic cultural links with Russia, including "elements of language, religion, ethnicity," as well as a strong Soviet mentality, "are clearly persistent and even resilient." Zaprudnik 1994, p. 147. Similar acknowledgement of the BPF's Western and anti-Russian narrative not resonating is noted by Silitski 2006a, p. 480.

177 As Ioffe noted, "no more than $20 \%$ (at the very best!) identify with that ideological niche," so "presenting it as the only interpretation of what it means to be a Belarusian, as Zaprudnik does, reflects a narrow, biased, and somewhat self-centered - Belarusis-me - view." Ioffe 2008, p. xiv. For an example of a 'Belarus-is me-view," see Silitski where he describes the BPF and its minority of supporters as "ethnically conscious," while the majority that did not respond positively to the BPF's 'nationalist' message are portrayed as having a "weak sense of national identity." Silitski 2003, p. 42. Recall that Silitski had also downplayed the strong patriotism towards the BSSR as only a second-rate national identity (see footnote no. 84).

${ }^{178}$ Rose and Haerpfer 1996, p. 90; Rose and Haerpfer 1998, p. 68; Rose 2005, pp. 58-59; White and McAllister 2008, p. 13.

${ }^{179}$ See 'National Identity' and 'Geographical Background' sections within the 'Politics and Society' section of the World Values Survey 1990-2000.

${ }^{180}$ Belarusian Senior Journalist. Interview. Minsk, Belarus (April 5, 2010). Another argued, "we have quite a strong sense of identity." Belarusian Academic. Interview. Minsk, Belarus (April 6b, 2010). Similar sentiments attesting to the strength of Belarusian national identity were given by others. Belarusian Opposition Activist. Interview. Minsk, Belarus (April 1, 2010); Belarusian Senior Academic. Interview. Minsk, Belarus (April 6a, 2010); Belarusian Opposition Leader/Former Presidential Candidate. Interview. Minsk, Belarus (April 7a, 2010); Belarusian Senior Academic. Interview. Minsk, Belarus (April 7b, 2010); Belarusian Journalist. Interview. Minsk, Belarus (April 8, 2010).

${ }^{181}$ Marples 1999a, p. 123. Additionally, Mihalisko argued that "many Western observers have fallen prey to the misconception that Belarusians consider themselves Russian. They do not." Mihalisko 1997, p. 236. See also, Snyder 2003, p. 280.

${ }^{182}$ See 'Politics and Society' section of the World Values Survey 1990-2000.

${ }^{183}$ Rose and Haerpfer 1998, pp. 66-67; Rose 2005b, pp. 60-61. Such numbers are relatively similar to results measuring pride in the Baltic States. For numbers, see Rose 2002, p. 36.

${ }^{184}$ White and Rose 2001, pp. 34-37.

${ }^{185}$ For polls see IISEPS 2000d; IISEPS 2001b; IISEPS 2002b; IISEPS. (2004a). IISEPS News, Issue 1, 31 (March). http://www.iiseps.org/ebullet04-1.html.; IISEPS. (2005c). IISEPS News, Issue 3, 37 (September). http://www.iiseps.org/ebullet053.html.; IISEPS. (2006a). IISEPS News, Issue 1, 39 (March). http://www.iiseps.org/ebullet06-1.html. For additional supporting numbers, see Economist 1995; Ioffe 2003, p. 1016. 
The Effects of Religious-Cultural Worldviews on the Lack of Political-Economic Liberalization in Belarus over Twenty Years since rise of Lukashenko

${ }^{186}$ See Zaprudnik 1993, pp. 125-128; Burant 1995, p. 1133; Marples 1999a, pp. 50-52; Marples 2003, p. 27; Goujon, Alexandra. (1999). "Language, Nationalism, and Populism in Belarus." Nationalities Papers, 27, 4: 661-677., p. 668; Eke and Kuzio 2000, p. 525. Ioffe offers a good critique of such arguments, particularly the negative assessments based on the high use of Transyanka, noting that arguing this is "insufficiently Belarusian...does not make sense at all," due to the fact that only a small percentage actually claim to be pure speakers of Belarusian. Ioffe 2003, p. 1017.

${ }^{187}$ Belarusian Academic. Interview. Minsk, Belarus (April 6b, 2010). Others mentioned similar sentiments. Belarusian Senior Academic. Interview. Minsk, Belarus (April 6a, 2010); Belarusian Opposition Leader/Former Presidential Candidate. Interview. Minsk, Belarus (April 7a, 2010); Belarusian Senior Academic. Interview. Minsk, Belarus (April 7b 2010); Belarusian Journalist. Interview. Minsk, Belarus (April 8, 2010).

${ }^{188}$ See White and Rose 2001, p. 56. One should also note that most of the opposition and 'nationalist' forces are predominantly located in Minsk, many of whose members also use Russian as their first language. Moreover, it is in rural Belarus where most native Belarusian speakers reside, and it is from this group where the strongest support for Lukashenko exists. Such conclusions were gained from insights of several interviewees. Belarusian Opposition Activist. Interview. Minsk, Belarus (April 1, 2010); Belarusian Senior Academic. Interview. Minsk, Belarus (April 6a, 2010); Belarusian Senior Academic. Interview. Minsk, Belarus (April 7b, 2010). For similar observations, see Maksymiuk 2007; Furman 1999, p. 38.

${ }^{189}$ Belarusian Journalist. Interview. Minsk, Belarus (April 8, 2010). That the process was voluntary and there was no overt coercion was also noted by Guthier 1977b, p.278; Ioffe 2003, p. 1041; Furman, Dmitrii, and Oleg Bukhovets. (1996). "Belarusian SelfAwareness and Belarusian Politics." Russian Politics and Law, 34, 6 (December)., p. 9. Even some utilizing National Identity explanations, acknowledge that adoption of the Russian language historically was often done willingly, naturally and voluntarily rather than on any overt coercive measures from Soviet authorities. Marples 1999a, p. 51; Eke and Kuzio 2000, p. 535.

${ }^{190}$ In terms of viewing minorities as a threat, only $9 \%$ in 1993, 14\% in 1998, and 9\% in 2004 of Belarusian respondents answered yes. See Rose and Haerpfer 1994, appendix, table 69; Rose and Haerpfer 1998, p. 64; Rose 2005, pp. 61-62. Such numbers stand in contrast to Baltic States where minorities were viewed as a greater threat by large numbers of respondents. See Rose and Maley 1994, pp. 43-44; Rose 1995, p. 37; Rose 1997, pp. 34-35; Rose 2000, p. 37.

${ }^{191}$ Maisenya 1997, p. 254. Similar sentiments on ethnic harmony were mentioned by others. Belarusian Senior Academic. Interview. Minsk, Belarus (April 6a, 2010); Belarusian Senior Academic. Interview. Minsk, Belarus (April 7b 2010). See also, Zaprudnik and Urban 1997, pp. 291, 302; Mihalisko 1997, p. 243.

${ }^{192}$ In doing so, such analysis largely falls back on historical institutional frameworks in pointing to institutional structures from the interwar period or the Soviet era as being key in informing national identities. See for example, Abdelal 2001, p. 126; Tsygankov 2000; Savchenko 2000. However, Belarus's unique historic political-culture was key in influencing the patterns of politics in Belarus during the interwar period. Moreover, Abdelal and others were too quick to play down, negate, and/or ignore the positive feelings that Belarusians held towards the BSSR, instead of acknowledging or seeking to better understand how these positive historical memories of BSSR state-building formed a key component and reinforced the worldviews and historical memories informing the content of Belarusian identity.

${ }^{193}$ Specifically, this was done by Abdelal, who too quickly dismissed explanations formatted along the lines of a Huntingtonian thesis that it was religious-cultural roots at play in informing divergent attitudinal preferences and behavior. While (Huntington 1996), can be criticized for not providing enough empirical evidence to back up his arguments, Abdelal was to quick to brush religious-cultural variables of explanation, and provided little by the way of comparative historical analysis, nor historical consensus for why such variables should be dismissed in favour of his proposition that identity outlooks were driven by historical institutional factors. Abdelal 2001, pp. 123-126. The importance of religion can be inferred from polls conducted between 1992 and 2004 where the vast majority of Belarusian respondents increasingly indicated their faith as Orthodox, while the number of atheist believers was steadily on the decline. See Rose \& Haerpfer 1993: appendix, table 34; Rose \& Haerpfer 1994: appendix, table 73; Rose \& Haerpfer 1996: 86-87; Rose \& Haerpfer 1998: 66-67; Rose 2005b: 83. Evidence of religious values at play, is also tacitly corroborated by Ioffe's observations where he noted that that although Belarusian "people may not attend services, most are keenly aware of their religious backgrounds." Ioffe 2008, p. 39. Ioffe, while adding this important observation about religious identification, nevertheless discounts the importance of religious values, even those that have been secularized in playing an important role in shaping peoples worldviews in regards to political, economic and social matters. 
${ }^{194}$ On oppositions confinement to Minsk and lack of grass-roots organization in outside areas, see Fuller, Liz, and Jan Maksymiuk. (2008). "Opposition in Belarus, Azerbaijan Differ Over Election Boycotts." Radio Free Europe/Radio Liberty. September 27. http://www.rferl.org/content/Opposition_In_Belarus_Azerbaijan_Differ_Over_Election_Boycotts/1292046.html. It should also be noted that one of the key neo-liberal opposition presidential candidates, Yaroslav Romanchuk was opposed to such "plans of radical action," and did not face arrest either. Quote from Romanchuk, in Radio Free Europe/Radio Liberty. (2010). "Lukashenka Claims Victory Amid Mounting Criticism." Radio Free Europe/Radio Liberty. December 20.

http://www.rferl.org/content/belarus_lukashenka_election_vote_crackdown_fraud/2253668.html.

195 Drakakhrust, Yuri. (2008). “Belarus’s Quiet Campaign.” Radio Free Europe/Radio Liberty. September 24. http://www.rferl.org/content/Belaruss_Quiet_Campaign_Election_Lukashenka_Vote/1291139.html.

${ }^{196}$ Belarusian Journalist. Interview. Minsk, Belarus (April 8, 2010). Similar consensus on most of opposition favouring statist approaches, criticisms of opposition advocating rapid liberal reforms, and divide within elite were mentioned by others. Belarusian Senior Journalist. Interview. Minsk, Belarus (April 5, 2010). Belarusian Senior Academic. Interview. Minsk, Belarus (April 7b 2010). Additionally, several during interviews openly criticized the more liberal United Civic Party and Jaroslav Romanchuk, because such groups 'liberal' ideas were out of touch with popular sentiments in Belarus and would not get that much traction amongst the broader society. Belarusian Opposition Activist. Interview. Minsk, Belarus (April 1, 2010); Belarusian Journalist. Interview. Minsk, Belarus (April 8, 2010).

${ }^{197}$ Such observations of opposition forces being elitist and out of touch with the mass public were gained during interviews. Belarusian Senior Academic. Interview. Minsk, Belarus (April 7b, 2010); Belarusian Senior Journalist. Interview. Minsk, Belarus (April 5, 2010); Belarusian Senior Academic. Interview. Minsk, Belarus (April 6a, 2010). Belarusian Academic. Interview. Minsk, Belarus (April 6b, 2010); Belarusian Journalist. Interview. Minsk, Belarus (April 8, 2010). Similar observation were mentioned by one Latvian Government Official. Interview. Riga, Latvia (February 26b, 2010). Additionally, it was noted that the Belarusian opposition, which have been educated in the West, now hold a Westernized mindset that is divergent from the predominant political outlooks shared by most average Belarusians. Belarusian Opposition Activist. Interview. Minsk, Belarus (April 1, 2010). One study also found that obstacles faced by Western NGO's in Belarus were due to the lack of liberal-democratic and market values in society. Wilde 2002, p. 435.

${ }^{198}$ Maksymiuk 2008. For consensus on oppositions elitism and being out of touch with society, see footnote no. 201, and Marples and Padhol 2002, pp. 55-76; Ioffe 2008, p. 184. This divide between the general public and the opposition parties can be inferred from polls in 2003, which asked people which political party is close to your political views, where $64.2 \%$ answered none or that they did not know. IISEPS 2003c.

${ }^{199}$ As one pointed out, “today...I don't think most people really believe that it can be any other way,...they don't want to change much... most people don't really see the way to change it, and don't believe that it will change eventually.... and while they're sometimes critical about our economy, I don't think that they would eagerly trade it for the market economy." Belarusian Senior Journalist. Interview. Minsk, Belarus (April 5, 2010). Another also commented on the unlikely prospects of Belarus following the radical liberal reforms in the Baltic States by noting that "we don't know that much about Latvia or Lithuania, because they have different languages and cultures." Belarusian Academic. Interview. Minsk, Belarus (April 6b, 2010). Others voiced there opinion that such prospects were unlikely, with some openly stating that they would be opposed to comprehensive liberal reforms. Belarusian Opposition Activist. Interview. Minsk, Belarus (April 1, 2010); Belarusian Senior Academic. Interview. Minsk, Belarus (April 6a, 2010); Belarusian Opposition Leader/Former Presidential Candidate. Interview. Minsk, Belarus (April 7a, 2010); Belarusian Senior Academic. Interview. Minsk, Belarus (April 7b, 2010); Belarusian Journalist. Interview. Minsk, Belarus (April 8, 2010).

200 This negative views towards 'reforms' in Ukraine and Russia, was mentioned by several elites. Belarusian Senior Journalist. Interview. Minsk, Belarus (April 5, 2010); Belarusian Senior Academic. Interview. Minsk, Belarus (April 6a, 2010); Belarusian Academic. Interview. Minsk, Belarus (April 6b, 2010); Belarusian Opposition Leader/Former Presidential Candidate. Interview. Minsk, Belarus (April 7a, 2010). For evidence showing the presence of such attitudes, see also Marples 1999a, p. 69; Ioffe 2008, p. 236. For example of Lukashenko portraying dangers in Ukraine, see Bennett, Brian. (2011). The Last Dictatorship in Europe: Belarus Under Lukashenko. London: Hurst \& Company., p. 165, 187. 